\title{
A Genomic Screen of Saccharomyces cerevisiae Reveals a Potential Link Between Nonstop Decay and Autophagy
}

\author{
by
}

Tom Kazmirchuk, B.Sc (Honours)

A thesis submitted to the Faculty of Graduate and Postdoctoral Affairs in partial fulfillment of the requirements for the degree of:

\section{Master of Science}

in

Department of Biology and Institute of Biochemistry,

The Ottawa-Carleton Institute of Biology, and The Ottawa Institute of Systems Biology

Carleton University

Ottawa, Ontario

(C) 2017, Tom Kazmirchuk 


\section{"By Endurance We Conquer" \\ - Cpt. Ernest Shackleton}




\begin{abstract}
Little has been described about the mechanisms of the Nonstop Decay (NSD) pathway. To discover new genes involved in NSD, we performed a genome wide investigation in Saccharomyces cerevisiae which yielded 446 gene candidates that when deleted, allowed production of a nonstop mRNA. Of the gene families found in our screen, we decided to follow up on the autophagy candidates. First, we used the autophagy inhibiting drug verteporfin to confirm that autophagy does not occur in our candidates. The results confirm our prediction that autophagy is inhibited in our two autophagy candidates. Next, we assessed the abundance of nonstop mRNA using qRT-PCR analysis. This resulted in lower than expected nonstop mRNA abundance relative to the WT, which led us to investigate nonstop protein abundance. Interestingly, we see an increase in the abundance of nonstop protein abundance relative to the WT. Together, our results suggest that NSD may occur through autophagy.
\end{abstract}




\section{Acknowledgments}

First, I would like to thank every member from the Department of Biology and Institute of Biochemistry at Carleton. I had the privilege of getting to know all of you over my 6 years at Carleton. Being a $\mathrm{BC}$ boy, coming to Carleton in the first place was a big step in my life. Having such a supportive and caring department made the transition to academic life very easy.

In my first year, I took a class called "Natural Sciences Seminar" where I met the wonderful and very supportive Dr. Alex Wong, my first supervisor. The first thing I said to him was "Give me job, I don't care if it's volunteer or paid, just give me a job". Well, that turned into a 3-year volunteer position in his lab, and eventually a thesis which was co-supervised by Dr. Jeff Manthorpe. Not being a chemist, I had a lot to learn about organic chemistry. Jeff, I remember all the times when I wanted to just talk for 10 minutes because I had to go to the lab, and we chatted about science and everything else for about 2-3 hours each time! You are such a passionate scientist, and a great person. During my time in both the Wong and Manthorpe labs, I met amazing people! MK, you're the best. Sam, you helped me so much with the chemistry. Liam, Trevor, Prabh, Ahlam, Kamya, Nicole, Andrew, Lena, Megan, Jess, and to everyone else, you made my undergrad years in both labs unforgettable.

Of course, there is Dr. Jeff Dawson. He is such an amazing person, and is always there if you just need to talk. You are my friend, and you helped me out so much over my final years at Carleton. When I couldn't bring myself to cut the heads off the locusts, you would do it for me, you cold blooded murderer! Besides that single character flaw, I still think you're great. I can't say it enough. If you ever need anything, let me know!

Nearing the end of my undergrad, I applied to grad school at Carleton. To Darlene, Caitlyn, Ruth, and Laura; you all made my transition so easy. Any questions I had with regards to well... 
anything, all of you were there. Oh, and Caitlyn, thanks for talking to me pretty much every morning before (or when) you were working! And with the recent additions of Sarah and Roisin, you both helped me in copious amounts, and were always there for me. Thank you so much.

Now, to Ashkan. You accepted me into your team, for which I am forever grateful. You gave me a chance to succeed after my undergrad. You gave me a new topic that you wanted to study. Your office door was (almost) always open for me, just like you said. Oh, and we took a risk submitting my first paper to the New England Journal of Medicine, but it was well worth it in the end. I know that we will always be friends, regardless of where we are.

To my fellow graduate students: Mohsen, Dan, Houman, Katy, Maryam, Taylor, you took a microbiologist and trained him into a yeast geneticist. It was a hard transition, but I learnt many valuable skills. I love you all and if you need anything, let me know! To my first team: Mike, Laura, Mariam, and Amanda, thanks for your help and making me into a better person. Again, if you ever need anything let me know.

Thank you as well to my family for helping me deal with my stress during my years at Carleton. I clearly could not be in the place I am now without all of your patience, guidance, and support.

I guess we are getting close to the end of the page, which means this needs to end soon. This onepage summary does not include all my acknowledgments, but I do remember everything everyone has ever done for me. So thank you very much, don't hesitate to call me for a favour! Now, enjoy the product of my blood, sweat, and tears. 


\section{Table of Contents}

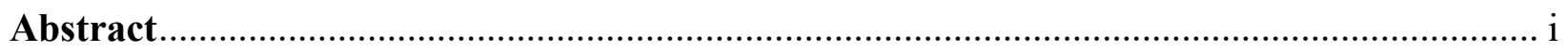

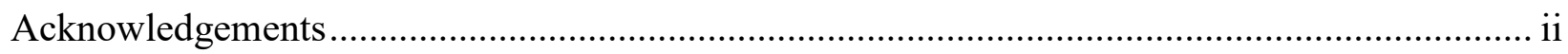

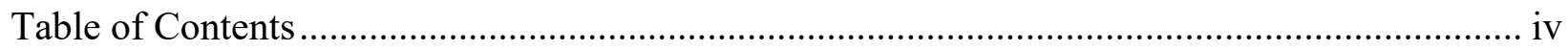

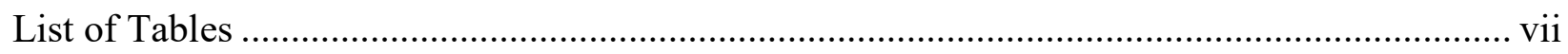

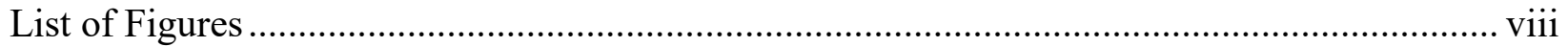

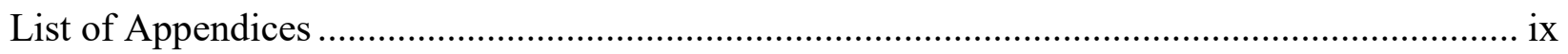

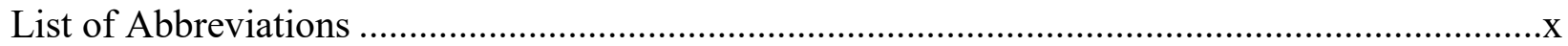

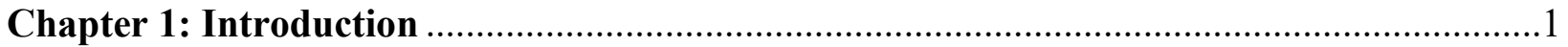

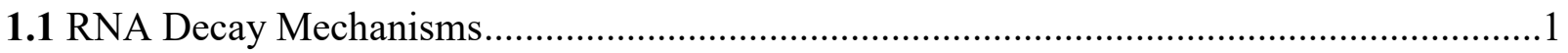

1.1.1 Deadenylation-dependent mRNA decay............................................................2

1.1.2 Deadenylation-independent mRNA decay ………....................................................2

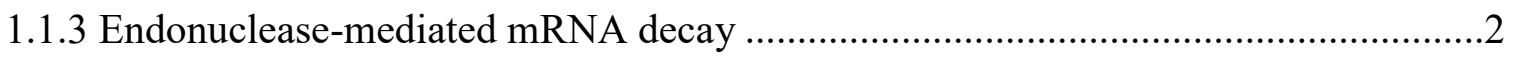

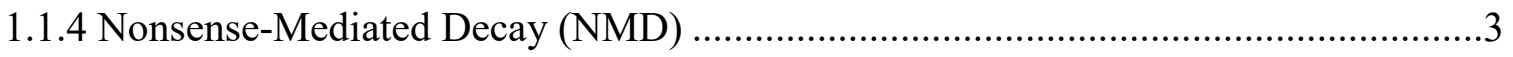

1.1.5 No-Go Decay (NGD) .........................................................................................

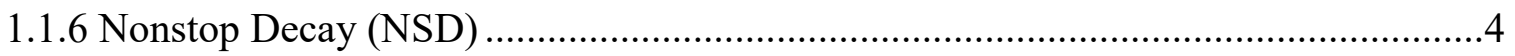

1.1.7 Processing Bodies (P-bodies) ..........................................................................

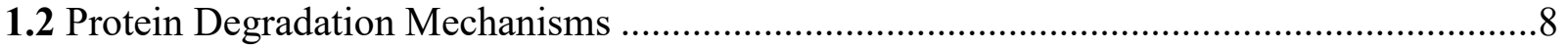

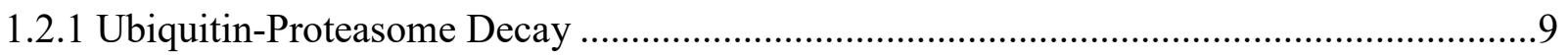

1.2.2 Lysosomal Degradation and Autophagy.............................................................13

1.2.2.1 Macroautophagy ………………........................................................15

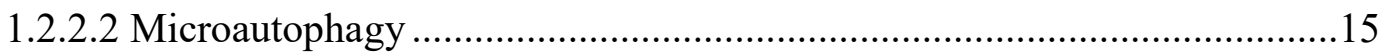

1.2.2.3 Chaperone-mediated Autophagy ……………......................................16

1.2.2.4 Autophagy Related Diseases................................................................16

1.3 Recent Advances in NSD - A NSD Screen Reveals a Link to the Proteome ......................19

1.3.1 Nonstop Mutations in The TYMP Gene Does Not Induce NSD.............................22

1.3.2 Nonstop Protein Degradation Is Mediated by Ltn1 .................................................23

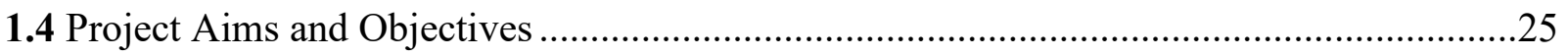


2.1 Plasmid Constructs, S. cerevisiae strains, media, reagents, and drugs ............................27

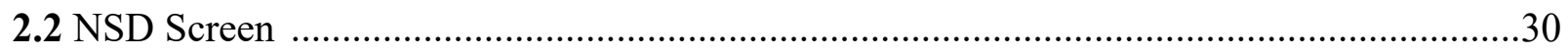



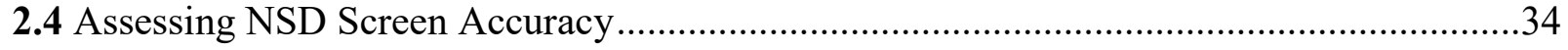

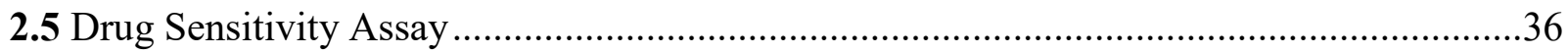

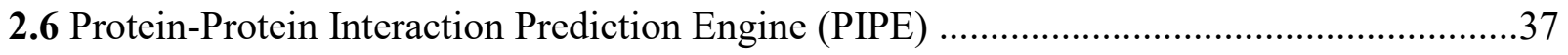

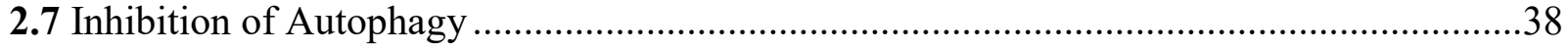

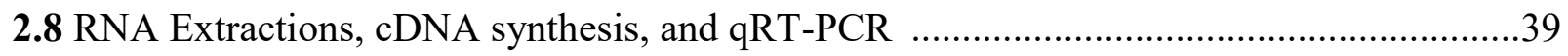

2.9 Protein Extractions, Bradford Assay, and Western Blots ............................................42

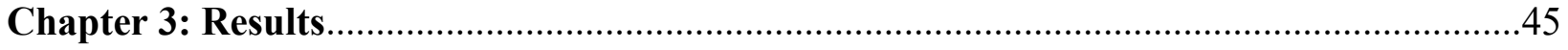

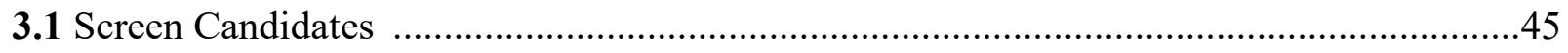

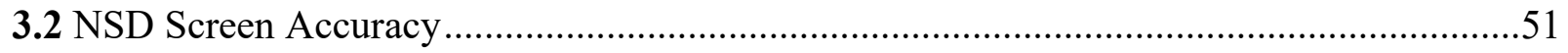

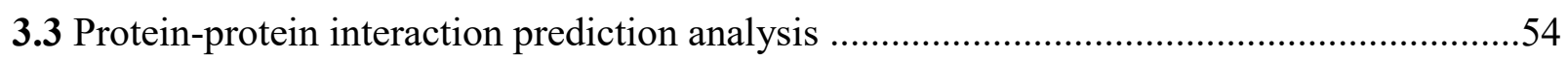

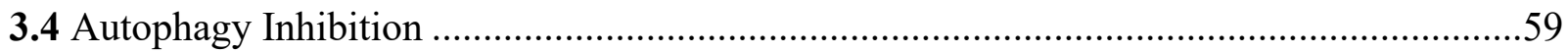

3.5 Nonstop mRNA content analysis for target yeast strains ..........................................65

3.6 Nonstop protein content analysis for target yeast strains .........................................67

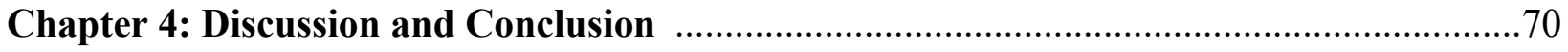

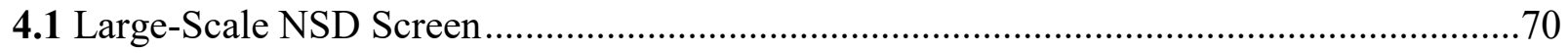

4.1.1 Autophagy Related Genes................................................................................ 71

4.1.2 Pheromone Regulated Proteins ................................................................ 72

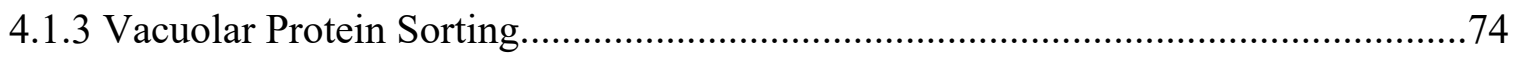

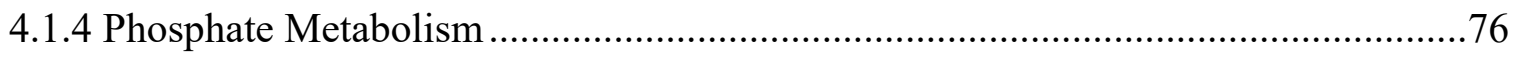

4.1.5 Found in the Mitochondrial Proteome …............................................................79

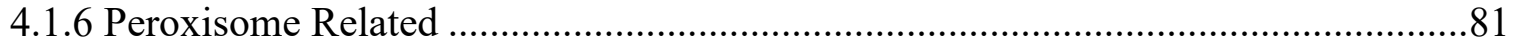

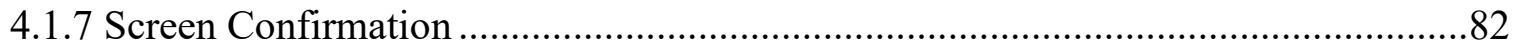

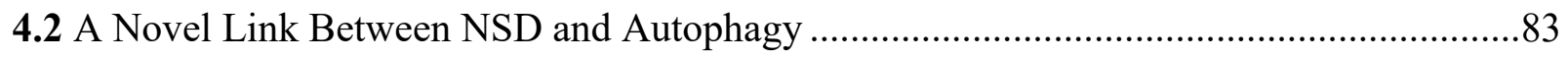

4.2.1 The Addition of Verteporfin does not Influence the Growth of $\operatorname{atg} 12 \Delta$ or $v p s 30 \Delta . .83$

4.2.2 Nonstop mRNA Abundance in Unchanged in the Autophagy Mutant Strains ........85

4.2.3 Nonstop Protein Abundance Seems to Increase in the Autophagy Mutants ............86 
4.3 Future Directions, Experimental Improvements, and Conclusion ................................88

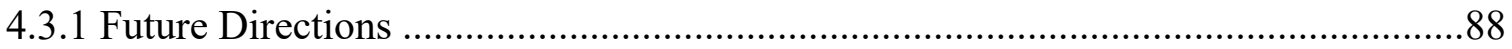

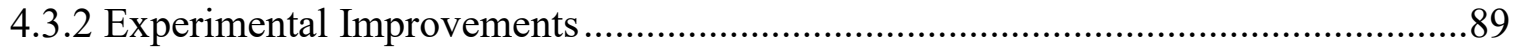

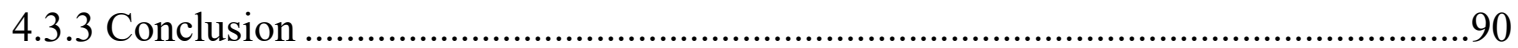

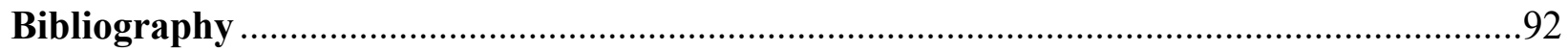




\section{List of Tables}

Table 1: The gene family clusters (family, gene, function) of the NSD gene candidates .....

Table 2: The top 40 gene candidates produced from the NSD screen.......................................53

Table 3: The PIPE output for the predicted interactions with the NSD screen candidates ...........56

Table A1: The 446 gene candidates produced from the NSD screen .....................................104

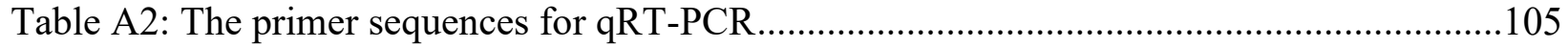




\section{List of Figures}

Figure 1: The mechanism of mRNA NSD in yeast .........................................................6

Figure 2: The Ubiquitin-Proteasome system for aberrant protein degradation ..........................12

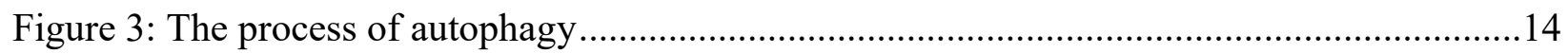

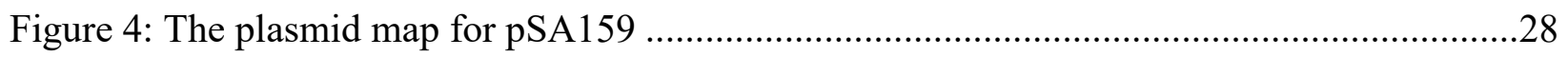

Figure 5: A result plate containing NSD gene candidates .......................................................47

Figure 6: Gene Ontology enrichment analysis for the NSD gene candidates.............................48

Figure 7: The heat map based on large-scale growth curves for 378 NSD gene candidates.........52

Figure 8: Growth sensitivity analysis for the WT, $\operatorname{atg} 12 \Delta, v p s 30 \Delta$, and ski7 $4 \ldots \ldots \ldots \ldots \ldots \ldots \ldots \ldots . . . . . .61$

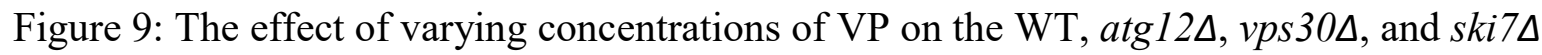
under -HIS $+1 \mathrm{mg} / \mathrm{mL} 3 \mathrm{AT}$ stress conditions.

Figure 10: The relative nonstop his 3 mRNA abundance for the WT, $\operatorname{atg} 12 \Delta, v p s 30 \Delta$, and ski7 $\ldots$....66

Figure 11: The apparent nonstop protein abundance of the WT, $\operatorname{atg} 12 \Delta, v p s 30 \Delta$, and ski7 $\ldots \ldots \ldots \ldots . . .68$

Figure 12: The proposed relationship between NSD and the $P H O$ gene candidates...................78

Figure A1: The standard curve for His 3 primer efficiency................................................106

Figure A2: The standard curve for protein concentrations used in this study .........................107 


\section{List of Appendices}

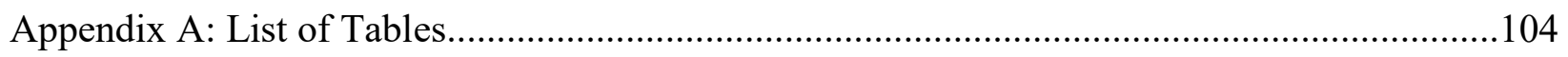

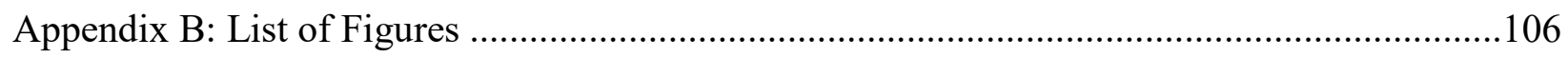

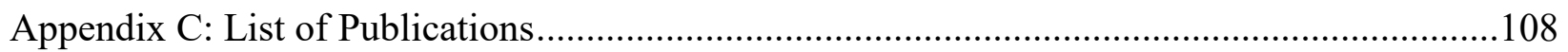




\section{List of Abbreviations}

APS: Autophagosome

ATP: Adenosine Triphosphate

cDNA: complementary DNA

CFTR: Cystic Fibrosis Transmembrane Receptor

CMA: Chaperone-mediated Autophagy

DNA: Deoxyribonucleic acid

EJC: Exon Junction Complex

GFP: Green Fluorescent Protein

GTP: Guanine Triphosphate

HECT: Homologous to the E6-AP COOH Terminus

-HIS: Dropout mix lacking histidine

IP5: inositol 1,3,4,5,6-pentkisphosphate

IP6: inositol 1,2,3,4,5,6-hexakisphosphate

LB: Luria Broth

m7G: 7-methylguanylate cap

MNGIE: Mitochondrial Neurogastrointestinal Encepthalomyopathy

mRNA: messenger RNA

mRNP: messenger ribonucleoprotein

mTOR: Mammalian Target of Rapamycin

NGD: No-go Decay

NMD: Nonsense-mediated Decay

NSD: Nonstop Decay

ONC: Overnight Culture

ORF: Open reading frame

PABP: Poly(A) Binding Protein

PAS: Preautophagosome Structure

PaT: Poly(A) Tail 
P-bodies: Processing bodies

PE: Phosphatidyltheanolamine

PIPE: Protein-Protein Interaction Prediction Engine

PIPE-Score: Scoring system for PIPE

PPI: Protein-Protein Interaction

PTC: Premature termination codon

qRT-PCR: quantitative reverse transcriptase PCR

RNA: Ribonucleic acid

SDL: Synthetic Dosage Lethality

SDS-PAGE: Sodium dodecyl sulfate polyacrylamide gel electrophoresis

SENDA: Static encephalopathy of childhood with neurodegeneration in adulthood

ssDNA: Single stranded DNA

SW-Score: Similarity-Weighted Score

TEM: Transmission Electron Microscopy

TOR: Target of Rapamycin

tRNA: transfer RNA

Ublc: Ubiquitin-like conjugation systems

-URA: Dropout mix lacking uracil

VHL: Von Hippel-Lindau

VP: Verteporfin

YPD: Yeast/Peptone/Dextrose

3AT: 3-Amino-1.2.4-triazole

3'-UTR: 3' untranslated region 


\section{Chapter 1: Introduction}

\subsection{RNA Decay Mechanisms}

Eukaryotic and prokaryotic cells contain quality control mechanisms that ensure cell survival. These mechanisms range from the transcriptome to the proteome. The quality control of mRNA transcripts is essential to cellular homeostasis ${ }^{1}$. If the quality control mechanisms are impaired or are dysfunctional, it is thought that diseases can occur. In theory, mutated mRNA may produce a misfolded protein and depending on the protein, this could be devastating to the cell. If the misfolded proteins were to interact differently with its partners, downstream effects may occur. For example, if a cell cycle checkpoint protein is misfolded (and thereby dysfunctional), it could alter the function of its checkpoint protein complex ${ }^{2}$. Once this occurs, aberrant DNA could be allowed to continue through the cell cycle possibly producing additional misfolded proteins, or other downstream effects. It is therefore extremely important for the cell to have evolved RNA surveillance and degradation mechanisms. In nature, severely altered mRNAs are often recognized and subjected to degradation (mRNA turnover). In general, mRNA can be degraded through three standard decay pathways: the deadenylation-dependent mRNA decay pathway, the deadenylationindependent mRNA decay pathway, and the endonuclease-mediated mRNA decay pathway ${ }^{3}$. These three pathways function to maintain a balance for the relative distribution of natural mRNAs. In addition, the scientific community currently knows of three major degradation pathways for altered mRNA based on the type of damage: nonsense-mediated decay (NMD), nogo decay (NGD), and nonstop decay (NSD) ${ }^{3}$. 


\subsubsection{Deadenylation-dependent mRNA decay}

The deadenylation-dependant pathway will shorten the poly(A) tail (PaT) of transcripts targeted for degradation ${ }^{4}$. Being a reversible step, if the targeted transcripts have been mistakenly targeted readenylation can take place ${ }^{3,4}$. When a transcript is correctly targeted for degradation the cell will begin one of two irreversible degradation processes: decapping or $3^{\prime} \rightarrow 5$ ' decay. The decapping mechanism will remove the 5, 7-methyguanosine cap (m7G cap) induced by the recruitment of the Lsm1-7 complex on the deadenylated 3' untranslated region (UTR). The function of the m7G

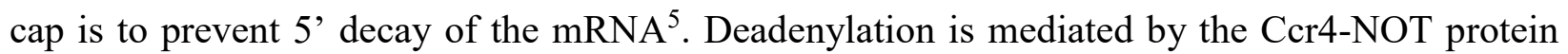
complex, or PARN ${ }^{4}$. Removing of the $\mathrm{m} 7 \mathrm{G}$ cap is achieved by the Dcp1 and Dcp2 protein complex. Once the cap is removed, Xrnl will mediate the $5^{\prime} \rightarrow 3^{\prime}$ decay. In the alternative $3^{\prime} \rightarrow$ 5' decay pathway, the targeted transcript will be degraded from the 3' end (that has been deadenylated) by the exosome complex (comprised of Ski2, Ski3, Ski7, and Ski8 in yeast ${ }^{6}$ ). After degradation, the remaining $\mathrm{m} 7 \mathrm{G}$ cap is degraded by the decapping enzyme Dcp5.

\subsubsection{Deadenylation-independent mRNA decay}

Within the deadenylation-independent pathway, the targeted mRNA is not required to be deadenylated for degradation to proceed. Similar to the final steps of the $5^{\prime} \rightarrow 3^{\prime}$ decay in the dependent pathway, Dcp1 and Dcp2 target the m7G cap. The difference, however, is due to the Edc3-Rps28B protein complex. This complex activates the decapping enzymes to initiate decapping. After the cap is removed, Xrn1 mediates the $5^{\prime} \rightarrow 3^{\prime}$ decay.

\subsubsection{Endonuclease-mediated mRNA decay}

The remaining pathway involved in regulating gene expression through the degradation of mRNA is the endonuclease-mediated mRNA decay pathway ${ }^{3}$. The most efficient pathway, endonucleasemediated decay will employ the use of endonucleases to cut the mRNA. During translation, the ribosome will read through the mRNA, but will be stopped by a secondary structure (commonly a 
stem loop ${ }^{3}$ ). The endonuclease pathway will then cut the mRNA near the site of the secondary structure, generating a new 3' and 5' end. The newly exposed ends will then undergo 3' $\rightarrow$ 5' decay via the exosome, and 5' $\rightarrow$ 3' decay via $\mathrm{Xrn} 1$.

\subsubsection{Nonsense-Mediated Decay (NMD)}

Nonsense-mediated decay (NMD) is triggered by the presence of a premature termination codon (PTC) within the mRNA ${ }^{7}$. A PTC can be introduced via a nonsense mutation. Normal translation of the nonsense transcript will lead to truncated, non-functional and dysfunctional proteins ${ }^{8}$. From the cellular point of view, having a truncated protein may have drastic downstream effects, such as loss of cell cycle control leading to the development of tumours ${ }^{2}$. Therapeutics exist which bypass PTC's, and allow a semi-functional protein to be manufactured ${ }^{8}$. A more likely scenario, however, is that the nonsense transcript will be sent for degradation in a P-body, ${ }^{9,10}$ where the NMD machinery is held. The mechanism for NMD has been partially elucidated ${ }^{3,11}$. First, the PTC is recognised resulting in the recruitment of the exon junction complex (EJC) and the Upf3 protein upstream of the PTC. Next, the aberrant mRNA is exported to the cytoplasm, where Upf2 forms a protein complex with Upf3 and the EJC. The SURF complex (comprised of Smg1, Upf1, eRF3, and eRF1) associates with the translating ribosome. Smg1 will phosphorylate Upf1, which will cause Upf1 to bind to Upf2 thereby linking the EJC to the ribosome. The release factors eRF3 and eRF1 are then dissociated, allowing the binding of Smg7.

\subsubsection{No-Go Decay (NGD)}

First discovered in S. cerevisiae, little is known about the No-go decay (NGD) decay pathway. Current knowledge on this pathway suggests that NGD will detect stalled ribosomes on the aberrant mRNA (possibly due to a secondary structure), and preventing the recruitment of translation factors to the aberrant $\mathrm{mRNA}^{3,12,13}$. It has also been suggested that endonucleases may 
cut near the stall site, thereby releasing the stalled ribosome. The resulting mRNA fragments are then suggested to be degraded by the exosome complex, and Xrn1, in a similar fashion to the endonuclease mRNA decay pathway.

\subsubsection{Nonstop Decay (NSD)}

Nonstop decay (NSD) exists to remove mRNA transcripts that lack stop codons (nonstop mutation $)^{14}$. Nonstop mutations are believed to be random in nature as there appears to be no evolutionary benefit to having this type of mutation. A lesser known surveillance mechanism, research into NSD has largely been minimal as most research has been devoted to understanding NMD (there are about 10 times more studies into NMD than NSD). However, research into NSD has revealed key proteins (such as Ski7 and Dom34) which appear to be essential to the pathway ${ }^{15}$. Nonstop mutations can appear randomly, or may be induced with DNA rearrangement as is the case with nonsense mutations ${ }^{16}$. What is not known, however, is the function of nonstop transcripts. In eukaryotes, previous studies have shown that nonsense mutations can be induced in T-cell receptors to produce antigen receptor variation ${ }^{16,17}$, giving a key function to nonsense mutations. Perhaps nonstop mutations also have a cellular function, but considering that a nonstop transcript would not be an open reading frame (ORF), to date a function has not been proposed for nonstop mutations. Understanding the mechanisms, and the cellular factors involved in NSD has remained a neglected and important area of research.

A general view of all RNA degradation pathways places the accepted NSD degradation pathway performs (in part) at the transcript level ${ }^{3}$. The pathway is conserved across all three domains of $\operatorname{life}^{14}$, and is composed of two parts: a Ski7 dependent $3^{\prime} \rightarrow 5^{\prime}$ decay pathway, and a Ski7 independent $5^{\prime} \rightarrow 3^{\prime}$ decay pathway ${ }^{3,14}$. In the Ski7 dependent pathway, a translating ribosome will first read through the ORF, eventually stalling on the PaT, and displacing the poly(A) binding 
protein (PABP). This tail would not normally be translated as the termination codon will appear before the PaT. In addition, the presence of the tail is to protect the 3' end of the transcript from degradation via exonucleases by binding the $\mathrm{PABP}^{3}$. It is thought that the ribosome will stall on the PaT due to self-complementarity (U pairing with A), forming an internal stem loop structure within the tail ${ }^{18}$. This secondary structure will then stall the translating ribosome. Next, the Ski7 protein is recruited to the stalled ribosome. The signalling mechanism to recruit Ski7 is currently unknown. In contrast, it is thought that the distance between a PTC and the PaT is what activates degradation by NMD. Perhaps a similar mechanism exists for NSD, however it is quite evident that more research into the signalling mechanisms for the activation of NSD are needed.

Once Ski7 is recruited to the ribosome, the C-terminal of the protein will bind to the internal Asite of the stalled ribosome $\mathrm{e}^{3,14}$. Interestingly, the structure of the Ski7 protein is similar to the GTPase domain of the elongation factor-1A and eRF3 proteins ${ }^{3}$. This interaction between Ski7 and the empty A-site will release the stalled ribosome. After the ribosome is released, Ski7 will then recruit the SKI exosome complex. This exosome complex is comprised of Ski2, Ski3, and $\mathrm{Ski}^{6}$. It is this complex which will degrade the aberrant mRNA in a $3^{\prime} \rightarrow 5^{\prime}$ manner. In the Ski7 independent decay pathway, the translating ribosome again will displace PABP. It is this loss of PABP that will stimulate the exoribonuclease Xrn1 (aka Ski1) to degrade the aberrant mRNA in a $5^{\prime} \rightarrow$ 3' fashion. 


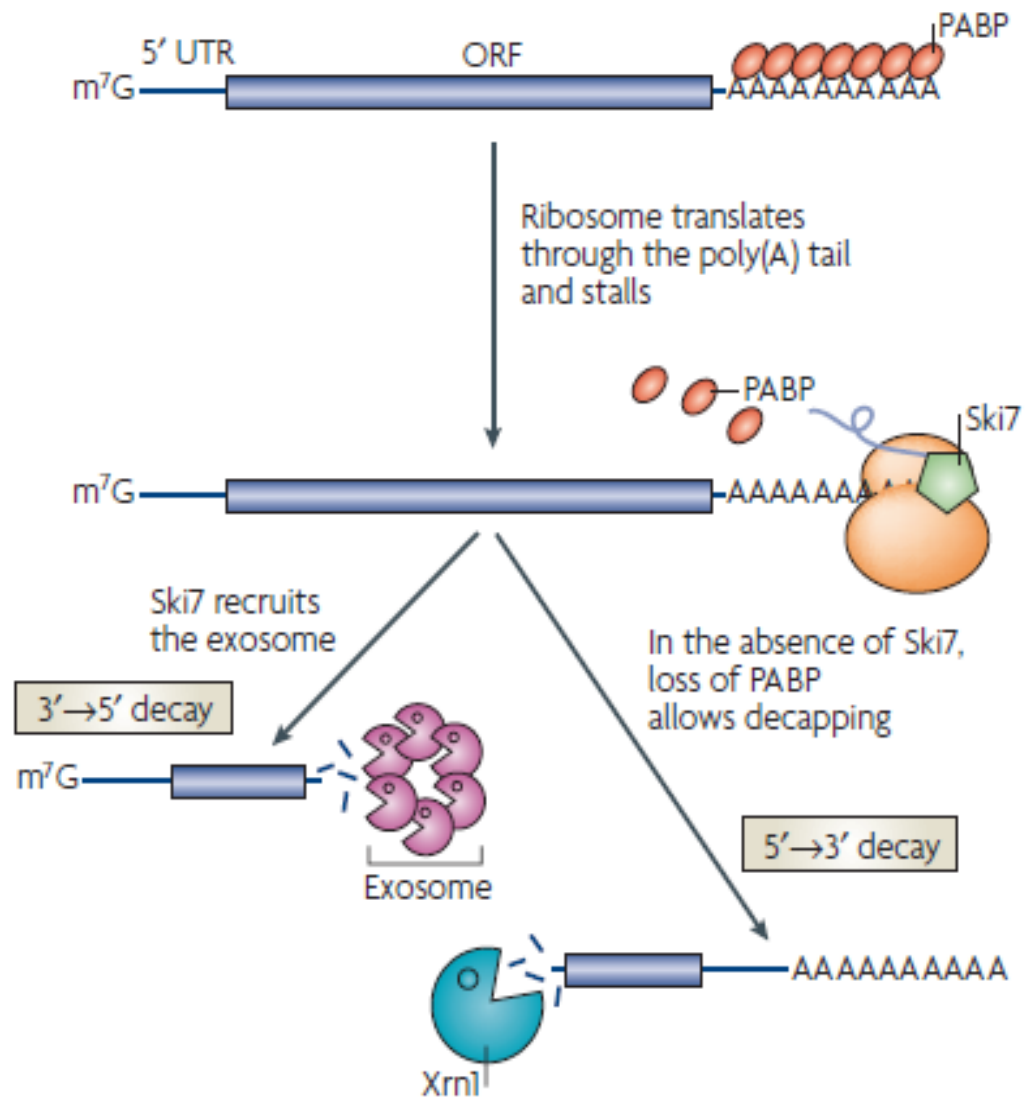

Figure 1: The mechanism of mRNA NSD in yeast. mRNA lacking a stop codon can be degraded 3' $\rightarrow$ 5' by the Ski7 pathway, or 5' $\rightarrow$ 3' via decapping enzymes and Xrn1. The preferential pathway is the Ski7 3' $\rightarrow$ 5' pathway. Adapted from Garneau et al ${ }^{3}$. 


\subsubsection{Processing Bodies (P-bodies)}

A P-body is a specialized stress granule, and is defined as an association of translationally repressed messenger ribonucleoprotein (mRNPs) with the mRNA decay machinery ${ }^{9}$. The function of a P-body is to either degrade aberrant mRNA, or to hold translationally repressed mRNA for future translation ${ }^{9}$. The P-body appears to be conserved across all domains of life, and is comprised by several protein complexes, including the decapping machinery complex (including the Dcp1/Dcp2 enzymes and the decapping activators Dhh1/RCK/p54, and Scd6/Rap55), the Lsm1-7 complex, the $5^{\prime} \rightarrow 3^{\prime}$ exosome, Xrn1, and $\operatorname{Pat}^{9}$. P-bodies will localize to the autophagy pathway to complete the degradation process ${ }^{19}$. 


\subsection{Protein Degradation Mechanisms}

Similar to mRNA turnover, proteins in the cell are in a dynamic state of turnover ${ }^{20}$. Though the importance of protein turnover is well known, the majority of research previously focused on how DNA is transcribed to RNA, with protein research only being initiated over 60 years ago ${ }^{20}$. The general assumption was that proteins would be in a steady state, and only degraded if necessary ${ }^{20}$. Now, the scientific community has elucidated two main mechanisms of protein degradation: the ubiquitin-proteasome system, and the lysosomal system ${ }^{20,21}$. Having a dysfunctional protein turnover mechanism may result in diseases such as cancer and neurodegenerative disorders. Induction of cancer from dysfunctional or misfolded proteins is well elucidated ${ }^{2}$. Briefly, a dysfunctional protein may interfere with the cell cycle either at checkpoints or in DNA synthesis $^{2,22}$. Given that the cell cycle is so tightly regulated, any interruption in the cycle can be very troublesome for the cell.

Several neurodegenerative disorders result from a dysfunctional ubiquitin-proteasome pathway and the lysosomal degradation systems ${ }^{23}$. The build up of aberrant proteins can contribute to the onset of Huntington's disease, Parkinson's disease, and Alzheimer's disease ${ }^{24-26}$. It is this build up that is synonymous with aggregate toxicity ${ }^{27}$. Dysfunctional or impaired protein degradation pathways have been shown to lead to aberrant protein aggregation, and is suggested to be a contributing factor to neurodegenerative disorders ${ }^{27}$. However, why protein aggregates result in toxicity is still unclear. An interesting hypothesis suggested by Currais and colleagues speculates that misfolded protein aggregation may trigger neuronal inflammation, leading to neurodegeneration $^{28}$. This may be a consequential hypothesis as Alzheimer's, Huntington's, and Parkinson's diseases have all been linked to neuroinflammation ${ }^{24-26}$. Nevertheless, it is very apparent that a dysfunctional proteome can lead to serious disorders. 
Impairing protein degradation via the proteasome may in some cases be beneficial. In the case of cystic fibrosis, a nonsense mutation will produce a truncated, dysfunctional cystic fibrosis transmembrane conductance regulator (CFTR) protein ${ }^{29}$. This chloride transporter functions in the human lung, and will transport chloride ions across the mucous membrane ${ }^{30}$. Though not directly fatal, having a dysfunctional CFTR protein is thought to lead to the accumulation of mucous in the lung $^{31}$. Interestingly, it is this mucous that is an ideal growth medium for bacterial pathogens such as Pseudomonas aeruginos ${ }^{32}$. It is therefore evident that losing the function of CFTR can be a serious problem. The cell has been shown to use the ubiquitin proteasome degradation pathway to degrade the truncated CFTR protein ${ }^{33}$. Currently, a therapy exists that blocks the degradation of the truncated CFTR protein by PTC readthrough ${ }^{34}$. The theory behind this treatment is that depending on the location of the nonsense mutation, the truncated protein may partially restore

function ${ }^{35}$. PTC readthrough can be induced by chemical agents that add a single amino acid to the CFTR protein, allowing the ribosome to translate through the $\mathrm{PTC}^{34}$. Compounds such as Ataluren (PTC124) does not induce a PTC readthrough, but rather forces the translating ribosome to in essence "skip" the PTC and produce a functional CFTR protein ${ }^{36}$. Therefore, inhibiting the proteasome does not always lead to severe deficiencies, but can serve a beneficial function.

\subsubsection{Ubiquitin-Proteasome Degradation}

Ubiquitin is a small $(8 \mathrm{kDa})$ molecule that mediates the targeted degradation of proteins, and that is conserved across eukaryotes ${ }^{37}$. Attachment of the ubiquitin molecule to the targeted protein is mediated by three classes of ubiquitin enzymes: the E1 ubiquitin-activating enzyme, the E2 ubiquitin-conjugating enzyme, and the $\mathrm{E} 3$ ubiquitin ligase ${ }^{37}$. Ubiquitin recruits the $\mathrm{E} 1$ dimer to its C-terminal glycine residue through an ATP-driven reaction. The ubiquitin molecule is then transferred from E1 to E2 via a thiol group on E2. The ubiquitin is then transferred to the targeted 
protein through a reaction catalyzed by E3. Ubiquitin selectively binds to free lysine residues on the protein, usually in the N-terminus. Targeting proteins for degradation via ubiquitin will then recruit the proteasome for proteolysis. The E3 ligases can be divided into 2 major sub-categories: the E3 HECT (Homologous to the E6-AP COOH Terminus) domains and the E3 RING finger motifs $^{38,39}$. Ubiquitin is transferred to a conserved cysteine residue within the HECT domain through a thioester bond ${ }^{39}$. This cysteine residue is generally conserved across HECT domain proteins. The first HECT domain described was the E6-AP protein, which functions to target the cellular proteins such as Blk for degradation ${ }^{38}$. Interestingly in the presence of the HPV oncoprotein E6, the E6-AP protein targets $\mathrm{p} 53$ for degradation ${ }^{38}$. Loss of normal function of E6AP can result in Angelman syndrome ${ }^{38}$.

The RING finger domain can be comprised of two conserved residues: the $\mathrm{HC}$ domain and the $\mathrm{H} 2$ domain. The $\mathrm{HC}$ domain is defined by a cysteine residue, where the $\mathrm{H} 2$ domain is defined by a histidine residue ${ }^{39}$. RING can be further sub-categorised into two distinct groups: the single and multisubunit proteins. A single subunit protein contains both the substrate binding site and the RING finger domain in a single molecule, whereas the multisubunit protein contains multiple subunits that make up the overall structure of the molecule ${ }^{39}$.

The $26 \mathrm{~S}$ proteasome is a large enzyme comprised of two smaller subunits: the $20 \mathrm{~S}$ core particle and the 19S regulatory particle ${ }^{39}$. The core particle is comprised of two different polypeptide chains: the $\alpha$ chain, and the $\beta$ chain. These two polypeptide chains are arranged in an $\alpha-\beta-\beta-\alpha$ configuration to complete a single subunit. The proteasome itself is comprised of several of these subunits. Catalysis of the ubiquitinated proteins occurs in the cavity of the $20 \mathrm{~S}$ core particle, access to which is controlled by the $\alpha$ chains. The function of the $\alpha$ chains are thought to mediate the unfolding of the ubiquitinated proteins for their eventual degradation. The regulatory particle 
recognises the polyubiquitinated protein $^{39}$. The cell contains two isoforms of the proteasome: the larger 26S proteasome (which is thought to mediate the degradation of ubiquitinated proteins with 4 or more lysines) and the smaller 20S proteasome. 


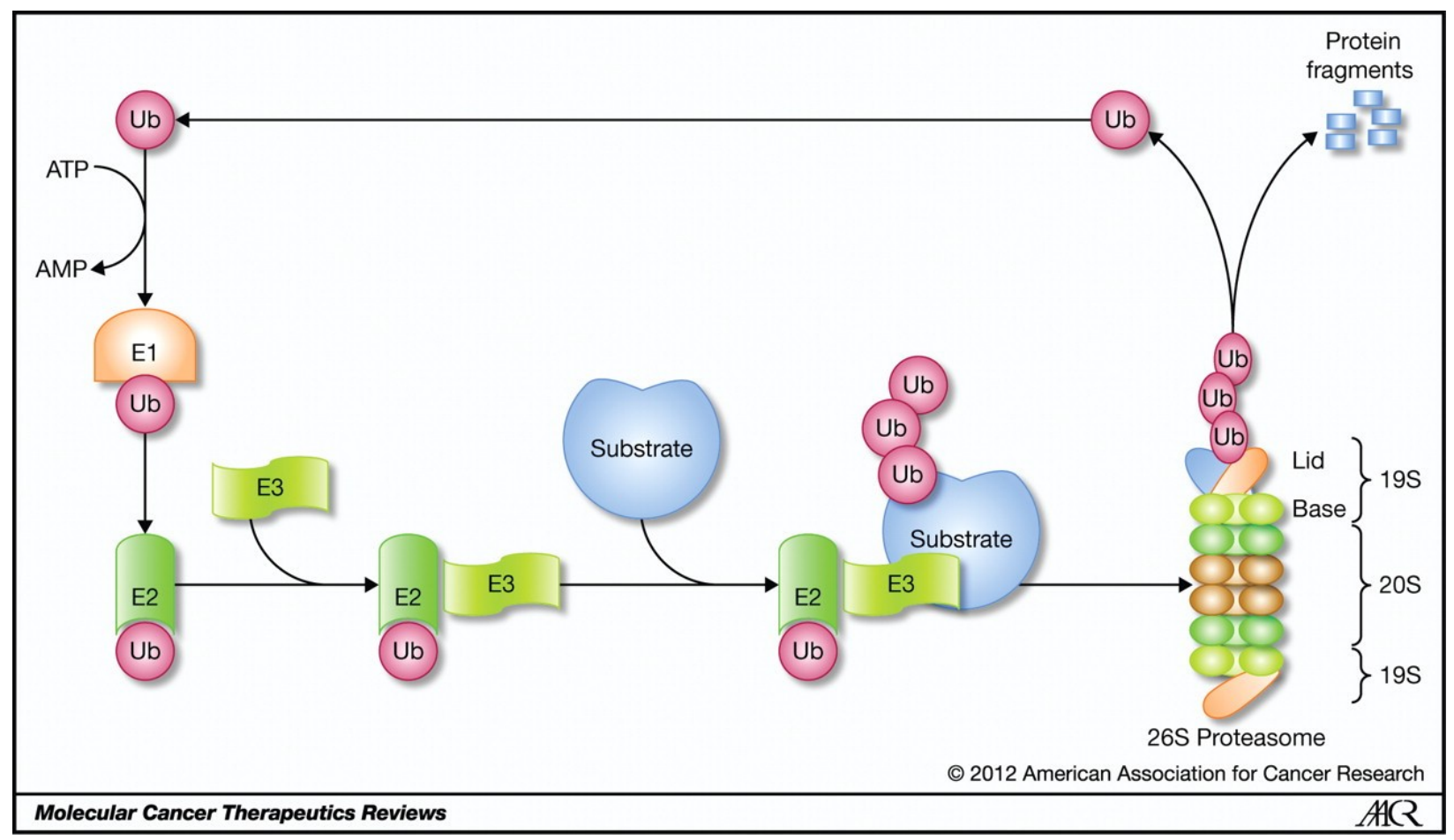

Figure 2: The Ubiquitin-Proteasome system for aberrant protein degradation. The E1 enzyme becomes ligated with ubiquitin, which is then transferred to the E2 enzyme. The E3 enzyme then associates with the E2-Ub complex. The substrate to be degraded is then recruited the E3 complex, where it is ubiquitinated, signalling the substrate to be degraded by the proteasome. Adapted from Rahimi, $2012^{40}$. 


\subsubsection{Autophagy and Lysosomal Degradation}

Autophagy has been shown to be conserved across eukaryotic cells, and functions to maintain cellular homeostasis through the degradation of dysfunctional organelles, misfolded proteins, lipids, nucleic acids, and ribosomes ${ }^{41}$. The autophagy pathway has also been shown to remove infecting bacteria ${ }^{42}$. In general, the autophagy pathway is initiated by a cellular stress including nutrient depletion, cellular infection, etc ${ }^{43}$. Nutrient depletion will inhibit the activity of the Target of Rapamycin (mTOR, TOR in yeast) kinase ${ }^{44}$ mTOR is a conserved kinase across eukaryotes that regulates the growth of the cell by maintaining cellular homeostasis through anabolic reactions such as protein synthesis, and catabolic processes such as autophagy ${ }^{44}$. Under normal cellular conditions, nutrients are thought to interact with the mTOR kinase, which functions to repress the activity of $\operatorname{Atg} 1^{45}$. Under nutrient depletion, the mTOR kinase will not be stimulated, possibly losing its functionality. This will then inhibit the repression of the Atg1 complex, signalling for the induction of autophagy ${ }^{45}$. The autophagy pathway can be divided into three main categories: macroautophagy, microautophagy, and chaperone-mediated autophagy ${ }^{44}$. 


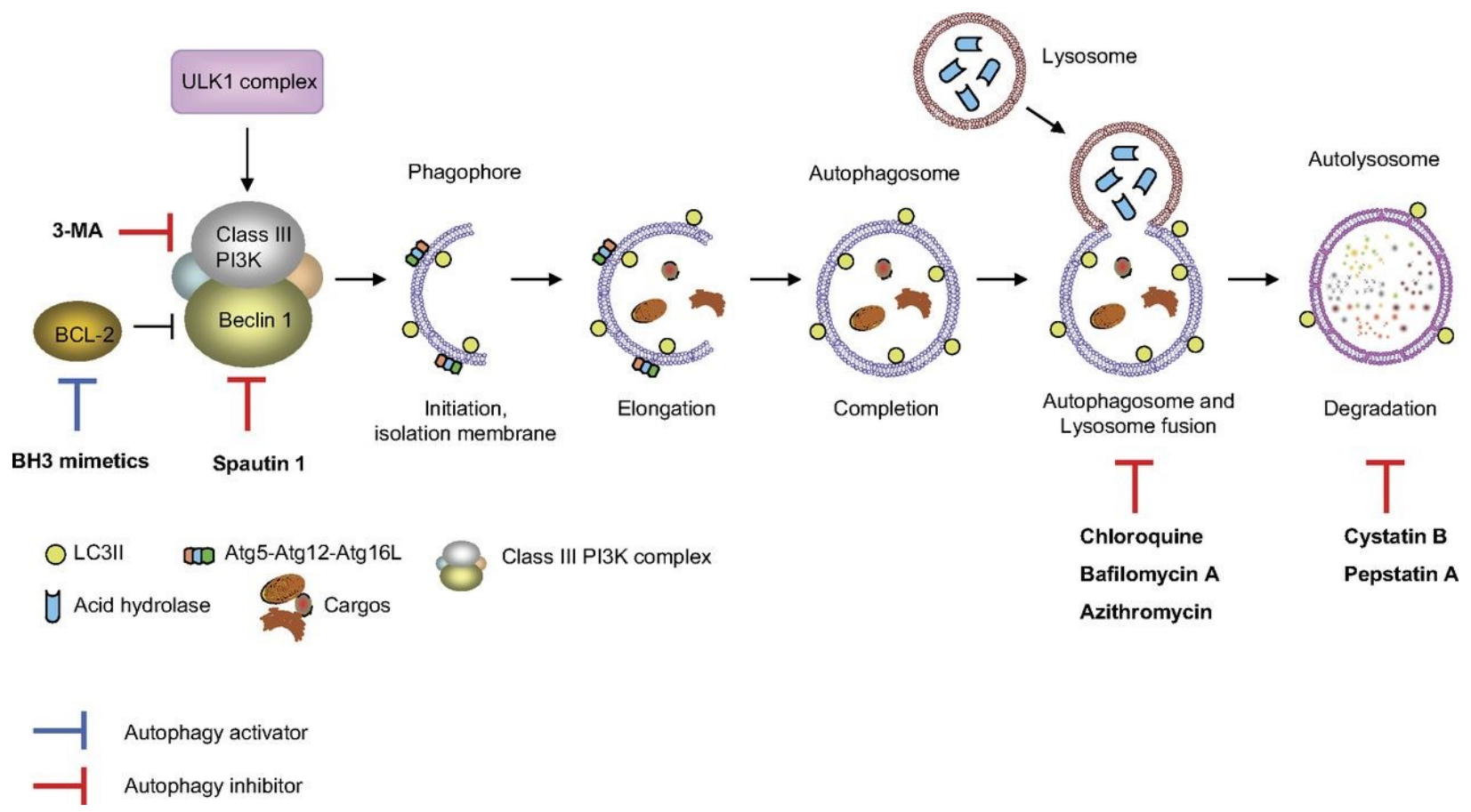

Figure 3: The process of autophagy. After autophagy is activated via cell stress, the phagophore elongates, and beings to form a pre-autophagosome around the cargo. Atg8 and the Atg5 complex close the now mature APS around the cargo, where the APS then fuses with the vacuole, forming an autolysosome. At this point, the APS is exposed to acid hydrolases within the lumen of the vacuole, permitting the degradation of the internalized cargo. Adapted from Nakahira and Choi, $2013^{46}$. 
1.2.2.1 Macroautophagy: During macroautophagy, the transient pre-autophagosomal structure (PAS) produces an isolation membrane that is then formed into an autophagosome (APS). The production of the APS is mediated by two protein conjugation systems: the Atg8 system, and the $\operatorname{Atg} 12$ system $^{47}$. The ubiquitin-like protein Atg8 (LC3 in humans) conjugates with the membrane lipid phosphatidyltheanolamine (PE) to become lipidated ${ }^{47}$. The lipidated form of Atg8 has been shown to be a reliable reporter for autophagy activity ${ }^{48}$. The additional conjugation system, Atg5Atg12, Atg16, also functions to lipidate Atg8 as well as mediate the tethering of the autophagic membrane, forming the $\mathrm{APS}^{47,49}$. The Atg5-Atg12, Atg16 complex first forms by an association between Atg5 and Atg12, forming a dimer. Next, two of these dimers associate with Atg16. This trimeric association is thought to then facilitate membrane tethering, as well as the recruitment of $\operatorname{Atg} 3-\operatorname{Atg} 8$ to $A \operatorname{tg} 12$ to promote the lipidation of $A \operatorname{tg} 8$ via $\mathrm{PE}^{47}$. The tethering function of the Atg12 system will facilitate the fusion of the PAS together, producing the APS. Importantly, the APS will form around any cargo targeted for degradation. Once formed, the APS will then transport the cargo to the vacuolar lysosome for degradation and recycling.

1.2.2.2 Microautophagy: Microautophagy is a nonselective degradation process that is fundamentally different from macroautophagy. Unlike macroautophagy, microautophagy facilitates the direct entry of cargo into the vacuolar lysosome ${ }^{50}$. The first step of macroautophagy and microautophagy are the same: the triggering of the mTOR pathway. Once the induction of microautophagy is stimulated, the vacuolar lysosomal membrane begins to invaginate producing what is referred to as an autophagic tube ${ }^{50}$. The cargo then runs down the autophagic tube to the polar end, where vesicle formation begins. The process of vesicle formation, expansion, and scission are mediated by the ubiquitin-like conjugation (Ublc) systems ${ }^{50,51}$. At this point, the growing vesicle resembles a bud ${ }^{50}$. As the vesicle expands, the bud will need copious amounts of 
lipids. It has been shown that within the bud, there are no detectable level of proteins but in fact a high concentration of lipids, holding with the hypothesis ${ }^{50}$. Once vesicle expansion is complete, vesicular enzymes begin the removal of the vesicle from the autophagic tube. Importantly, these enzymes localize to the lumen of vesicle to complete the curvature of the vesicle ${ }^{50}$. The vesicle is now free of the autophagic tube, and can now undergo degradation within the vacuolar lysosome.

1.2.2.3 Chaperone-mediated autophagy: One of the most selective autophagy pathways, chaperone-mediated autophagy (CMA) specifically functions to transport targeted proteins to the vacuolar lysosome for degradation ${ }^{52}$. Further, the CMA pathway specifically targets a recognition motif within a misfolded protein, allowing for the specific degradation of aberrant proteins ${ }^{52}$. The motif recognition sequence consists of: $\mathrm{X}, \mathrm{Q}, \mathrm{K} / \mathrm{R}, \mathrm{F} / \mathrm{V} / \mathrm{L} / \mathrm{I}, \mathrm{E} / \mathrm{D}, \mathrm{Q}$ where $\mathrm{X}$ is a random aminoacid $^{52}$. This pentapeptide is found in all CMA substrates ${ }^{52}$. Once recognised, the CMA substrate is then bound to a CMA chaperone, and targeted to the surface of the vacuolar lysosome. The CMA substrate then interacts with the lysosome-associated membrane protein type 2A (Lamp2A) on the surface of the vacuolar lysosome, where it then undergoes unfolding to cross the vacuolar lysosomal membrane ${ }^{52}$. Once internalized, degradation of the aberrant protein via proteases can occur.

1.2.2.4 Autophagy related diseases: Given the importance of autophagy to cellular homeostasis, defects in the autophagy pathway can lead to various disorders. In humans, a lysosomal storage disorder is generally defined as a disease caused by any dysfunction within the lysosomes normal function. As autophagy and the vacuolar lysosome are integrated, some have speculated that lysosomal storage disorders could also be autophagy disorders ${ }^{53}$. In fact, some evidence supports that a dysfunctional autophagy pathway can lead to various cancers, various neurological disorders, Crohn's disease, and a number of additional diseases ${ }^{54}$. A review of human diseases and 
defects in the autophagy pathway by Jiang and Mizushima surmise that loss of function mutations in key autophagy genes can lead to these disease phenotypes ${ }^{54}$. The human Beclin1 gene (VPS30/ATG6 in yeast) is essential to APS formation ${ }^{55}$. A loss of function mutation within this gene has been demonstrated to result in breast, ovarian, prostate, and colorectal cancers ${ }^{55}$, presumably due an interruption in the cell cycle. Considering that the onset of cancer is broad, interrupting autophagy and APS formation could lead to dysfunctional organelles not being degraded, misfolded proteins not being recycled, and aberrant mRNA not being removed. These are a few hypotheses associated with the loss of the APS and a dysfunctional autophagy pathway in the onset of cancer.

Lysosomal storage disorders have long been associated with neurological disorders, including Static encephalopathy of childhood with neurodegeneration in adulthood (SENDA) ${ }^{54,56}$. This disorder results in childhood motor and mental retardation, with a sudden onset of dystonia and parkinsonism in their mid 20's ${ }^{54}$. Morphological changes include white matter lesions and iron accumulation in the globus pallidus ${ }^{54}$. Interestingly, whole-exome sequencing of SENDA patients revealed a mutation in the human autophagy related gene WDR45 (homolog of the yeast ATG18 gene). Atg18 functions in autophagosome formation, and is recruited to the autophagosome formation site by binding phosphatidylinositol 3-phosphate. Therefore, loss of Atg18 in humans may lead to PAS accumulation in the cell. Confirming the link between Atg18 and PAS accumulation, Saitsu and colleagues observed that Atg18 expression was reduced in the SEDNA patients. The authors further demonstrated that the reduced expression of Atg18 is directly responsible for the accumulation of the $\mathrm{PAS}^{57}$, resulting in a vacuolar lysosomal disorder.

Crohn's disease is an iliac disorder that is the result of inflammation of the intestinal track, usually from the presence of infectious bacteria ${ }^{58}$. A link between defects in autophagy and Crohn's has 
long been postulated, as the autophagy pathway will degrade invading bacteria in a process referred to as xenophagy ${ }^{58}$. Invading bacteria undergo ubiquitination, to promote their destruction 58. Genome-wide investigations and sequencing has revealed that mutations in the human ATG16L1 gene are found in Crohn's patients ${ }^{58,59}$, which is interesting as Atg16 is a key component of the Atg12 complex (as mentioned in 1.2.2.1). Loss of function of Atg16 has been demonstrated to result in the loss of ATG8p lipidation, and autophagosome formation. Loss of APS formation will likely result in no destruction of invading pathogens, a result demonstrated by Kageyama et al. where they were able to show that the presence of Salmonella within the cytosol will recruit the Ublc systems to promote degradation ${ }^{60}$.

It is clear that loss of a normal functioning autophagy pathway can lead to devastating outcomes for the cell, and can lead to the onset of various disorders and diseases. Given the importance of autophagy no cellular homeostasis, the loss of function can lead to the lack of degradation for misfolded proteins, aberrant mRNA, dysfunctional organelles, and invading bacteria. In particular, the lack of degradation of misfolded proteins can lead to protein accumulation, thereby leading to protein toxicity which has been implicated in a number of serious neurological disorders, and some cancers. Though it is a stress induced system, autophagy is an important cellular pathway, and needs to be further studies for its implication in the onset of human disease. 


\subsection{Recent Advances in NSD - A NSD Screen Reveals a Link to the Proteome}

Until 2007, little was known about the NSD pathway. A study performed by Wilson et al., in 2007

revealed 16 genes that had never been linked to $\mathrm{NSD}^{61}$. The a nonstop His 3 reporter (pAV188)

with a Ura3 selectable marker. The authors first transformed and screened the single gene deletion

with pAV188 for genes involved in NSD. The screen was done on synthetic complete media lacking histidine, and produced 16 candidates. To confirm these candidates, the individual candidates were rescreened on an individual basis on -HIS media. To ensure that the nonstop phenotype is due to the single gene deletion, the authors knocked out the indicated gene in their $\alpha$ strain BY4741 (containing a his3山). This confirmed that the single gene deletions do produce the nonstop phenotype.

The authors also sought to determine what genes affect the half-life of nonstop proteins. Using their pAV184 plasmid - containing a nonstop Protein A mRNA reporter - they transformed pAV184 into their in-house $\alpha$-strain yAV670, and a proteasome defective strain yAV720 (containing a pre94). Importantly, yAV670 contains a his $3 \Delta$. They found that in their proteasome deficient candidates, that the nonstop Protein A is not degraded.

The genomic screen produced 16 gene candidates that may be involved in NSD including the SKI exosome (SKI2, SKI3, SKI7, and SKI8), IPK1, PRE9, UMP1, YMR247C, SSN2, SSN3, MED1, PIK1, HTZ1, SIR3, YGR122W, NUP2, and $Y L R 021 \mathrm{~W}$ ). The functional families produced by their screen include: the SKI exosome complex, RNA polymerase II mediators that interact with the mRNA deadenylase (SSN2, SSN3), mRNA processing (IPK1), a histone H2 variant (HTZ1), gene silencing (SIR3), a subunit of the nuclear pore complex (NUP2), proteasome-mediated protein degradation (PRE9, UMP1, YMR247C (later identified as LTN1)), and two genes with unknown 
functions (YGR122W, and YLR021W (later identified as IRC25)). It is interesting that other than the SKI exosome and $S S N 2 / 3$, that there were not any multiple hits within the same gene family.

From their screen, the authors decided to follow up on the proteasome candidates PRE9, UMP1, and $Y M R 247 C$. Performing qRT-PCR on the nonstop his3 gene revealed a decrease in the nonstop mRNA expression, and resulting in an increase in nonstop Protein A expression. Importantly, performing a protein A stability experiment for the PRE9 deletion demonstrated that relative to an endogenous control (Pgk1), that the nonstop protein A degrades over time, and has a 48-minute half-life compared to the nonstop protein A half-life in the WT which was 16 minutes. This implicates PRE9p in the degradation of nonstop proteins. The PRE9 gene encodes a subunit of the 20S proteasome, and UMP1 encodes a chaperone for the 20S proteasome. Therefore, loss of these two genes may likely result in a dysfunctional proteasome, possibly negating protein degradation. This suggests that nonstop proteins can be degraded via the ubiquitin-proteasome system.

The authors also performed this analysis on their other candidates. The SKI mutants all demonstrated a dramatic increase in nonstop mRNA expression. Interestingly, the ipkl $1 \Delta$ showed a greater increase in expression of the nonstop his 3 gene compared to the ski7L. The IPK1 gene encodes the 1,3,4,5,6-pentakisphosphate 2-kinase, which functions to convert inositol 1,3,4,5,6pentkisphosphate (IP5) to inositol 1,2,3,4,5,6-hexakisphosphate (IP6), which have roles in mRNA processing. IP6 production is a 4-step pathway that includes phospholipase C (PLC1) and Ipk2. Interruption of this pathway via these 2 other genes will result in little or no production of IP6. A sensitivity assay on ipkl 1 , ipk2 2 , and PLC1 demonstrated that only the loss of Ipkl resulted in the nonstop phenotype. This indicates that the effect of the ipkla on NSD is not due to the loss of IP6. Loss of Ipkl in yeast will result in defects in tRNA modification, and will result in the accumulation of IP5, which the authors suggest may inhibit mRNA decay. The remaining 
hypothesis is that IPK1p has two distinct roles: one for IP6 production, and one for NSD. A double deletion of IpkI and Ipk2 results in the lack of a nonstop phenotype, negating the hypothesis of a bifunctionality of Ipkl. These results therefore suggest that the accumulation of IP5 in yeast somehow affects NSD, possibly as a regulatory molecule.

The results from this study have found 16 new genes involved in NSD. From these 16 gene candidates, the authors have reported that nonstop protein turnover may be due to the proteasome, as their 4 proteasome candidates all demonstrated low expression of nonstop mRNA, with a dramatic increase in nonstop protein abundance. These results would later inform work performed by Bengtson and Joazeiro. An unexpected result from this screen was the indication that IP5 may act as a regulatory molecule in NSD. This is an interesting result, and should be further explored as very little is still known about the NSD pathway. 


\subsubsection{Nonstop Mutations in The Human TYMP Gene Does Not Induce NSD}

Several diseases have been previously associated with defects in the NSD pathway including: Diamond-Blackfan anemia ${ }^{62}$, mucopolysaccharidosis $\mathrm{II}^{63}$, and FX-coagulation ${ }^{64}$. Recently, Torres-Torronteras and colleagues described a novel nonstop mutation in the human TMYP gene (encoding the thymidine phosphorylase protein) that does not induce NSD of mutated mRNA in a mitochondrial neurogastrointestinal encepthalomyopathy (MNGIE) patient ${ }^{64}$. The function of the TYMP protein is to catalyze the degradation on thymidine into deoxyuridine ${ }^{64}$. Interestingly, at least 5 separate nonstop mutations have also been associated with MNGIE patients ${ }^{64}$. Investigation into the mRNA expression of the nonstop TYMP gene resulted in discovering that no NSD of the transcript was taking place ${ }^{64}$. In contrast, western blotting revealed that the TYMP nonstop protein was undergoing degradation, or was not very stable. The authors then go on to suggest that the mRNA NSD pathway may be inhibited in the mutant background, suggesting that TYMP may be involved in the induction of NSD, perhaps through a signalling pathway. Interestingly, the 5 other nonstop mutations previously associated with MNGIE all show a reduction in nonstop mRNA, lending evidence to a function for the TYMP protein in the NSD pathway (as the protein is being degraded, with an apparent inhibition of NSD). Future studies could focus on elucidating why the loss of the TYMP protein inhibits NSD. As this protein functions to catabolize thymidine, perhaps it has a function in the SKI exosome. As well, considering that TYMP is a phosphorylase, it may phosphorylate a key NSD protein such as the human SKIV2L (Ski2 in yeast) or WDR61 (Ski8 in yeast). If this is correct, we would expect to see a loss of function of the SKI exosome, thus inhibiting NSD. This is the first case study to demonstrate that lack of induction of NSD may be consequential to human disease. 


\subsubsection{Nonstop Protein Degradation is Mediated by Ltn1}

It is important to note that while the translating ribosome reads through the nonstop transcript, a nonstop polypeptide is being produced. The degradation of nonstop mRNA has been partially elucidated (with some questions remaining), however the degradation of nonstop proteins is not well understood. The genomic screen performed by Wilson et al., 2007demonstrated that several additional genes may be involved in $\mathrm{NSD}^{61}$. The proteins encoded by these genes seem to be involved in the proteasome assembly. The assembly factors Ump1, Irc25, Pre9, and Ltn1 were found to be linked to the efficiency of NSD ${ }^{61}$. A study performed by Bengtson and Joazeiro in 2010 demonstrated that the E3 ubiquitin ligase Ltn1 is involved in the NSD machinery ${ }^{65}$. The E3 ligase was shown to target a polylysine track (up to 12 lysine) which can only be generated by a translated PaT. Interestingly, Bengston also shows that the E3 ligase will also target a polyarginine residue, again to a maximum of 12 arginine ${ }^{65}$. They went on to hypothesize that the E3 ligase Ltn1 contributes to nonstop protein clearance. To confirm this hypothesis, Bengtson used two reporters: a nonstop His3 with no polylysine track (K0) and a nonstop His3 with a 12-lysine track, each followed immediately by a stop codon. They then measured the degradation of these two reporters using a $\operatorname{ltn} 1 \Delta$, a deletion of the Ltn1 RING domain, and a not $4 \Delta$. The purpose of the not $4 \Delta$ is to show how the protein is targeted for degradation by this E3 ligase. In the ltn $1 \Delta$, the degradation of K0 and K12 did not occur (compared to a WT), suggesting that the Ltn1 RING domain targets the polylysine track for degradation. The degradation of $\mathrm{K} 0$ was not effected as this can be considered a normal protein. In the not $4 \Delta, \mathrm{K} 12$ expression was not restored, suggesting the E3 ligase Ltn1 is specific to nonstop proteins. As an important control, Bengston also tested the stability of the von Hippel-Lindau (VHL) protein. This experiment is meant to demonstrate that the misfolding and ubiquitination of VHL does not attract the E3 ligase Ltn1. They found that the deletion of $\ln 1 \Delta$ 
did not affect the expression of the VHL protein, suggesting that Ltn1 targets nonstop proteins only, and does not act in general protein quality control. In addition, Bengtson also tested the nonstop mRNA levels in the ltn1 $\Delta$. There was no effect on mRNA expression in any of the deletion backgrounds. Bengston goes on to suggest that the E3 ligase Ltn1 will target nonstop proteins to the proteome for degradation. Overall, these results suggest that nonstop decay occurs on 2 levels: the mRNA level through the Ski7 dependent and independent pathways, and on the protein level possibly through Ltn1 and the ubiquitin proteasome. 


\subsection{Project Aims and Objective}

Cellular homeostasis is a pivotal, dynamic process that will balance the generation and degradation of mRNA transcript and their encoded proteins within the cell. Maintaining homeostasis requires several pathways within the cell that work together in a tightly regulated process. Interrupting these processes can result in the cell accumulating proteins, possibly making them toxic. The cell has evolved various pathways which span mRNA decay and protein decay. The focus of this study is to discover novel genes involved in the NSD cellular degradation pathway.

To discover novel genes involved in this pathway, we will use a nonstop reporter (pSA159) that will be transformed into the yeast $\alpha$-strain Y6547, which contains a his $3 \Delta$. This strain will then be crossed to the single gene deletion set. A screen using nutrient depletion selection will be used to then find genes that may be involved in NSD. After the candidates have been found, several rounds of verification will be used to filter out any false-positive candidates, and to determine if the remaining candidates are correct. Once the remaining candidates are confirmed, a subset will be used to determine their role in NSD.

Considering that the previous screen performed by Van hoof only produced 16 gene candidates (12 if we remove the SKI family - which is the fundamental protein complex in NSD), we believe that we can improve on their screen. The significance of finding previously undescribed genes involved in NSD can help determine the overall functionality of this pathway. For example, the study performed by Bengston and Joazeiro found a link between NSD and the ubiquitin proteasome in 2010. Considering that various neurological disorders have been linked to the proteasome, this could indicate that nonstop proteins may be involved in the onset of these disorders in that the nonstop proteins could accumulate, possibly causing protein toxicity. If we can find genes involved in other cellular processes that appear to be linked to NSD, this could help 
further elucidate the NSD pathway, and uncover new mechanisms. There is also the chance that we could produce new hypotheses attributing NSD to disease. 


\section{Chapter 2: Materials and Methods}

2.1 Plasmid Constructs and $S$. cerevisiae strains, media, reagents, and drugs

Nonstop mRNA plasmid - pSA159: To uncover new genes involved in NSD of mRNA, we first obtained the nonstop plasmid pSA159 from Bengtson et al., 2010 ${ }^{65}$. This plasmid contains an ampicillin resistance marker, a Ura3 selectable marker, and a GFP-FLAG-his3 (nonstop) fusion marker. The nonstop mutation has not been reported, and the sequence of the plasmid was not available. The pSA159 construct was produced in the Aiba lab at the Department of Molecular Biology at Nagoya University ${ }^{66}$, to which they provide an outline to produce the plasmid in "Translation of aberrant mRNAs lacking a termination codon or with a shortened 3'-UTR is repressed after initiation in yeast" ${ }^{\prime 66}$ which we used to decipher and approximate sequence. Using the now reconstructed sequence, we produced an approximate plasmid map for pSA159 (Figure 4). 


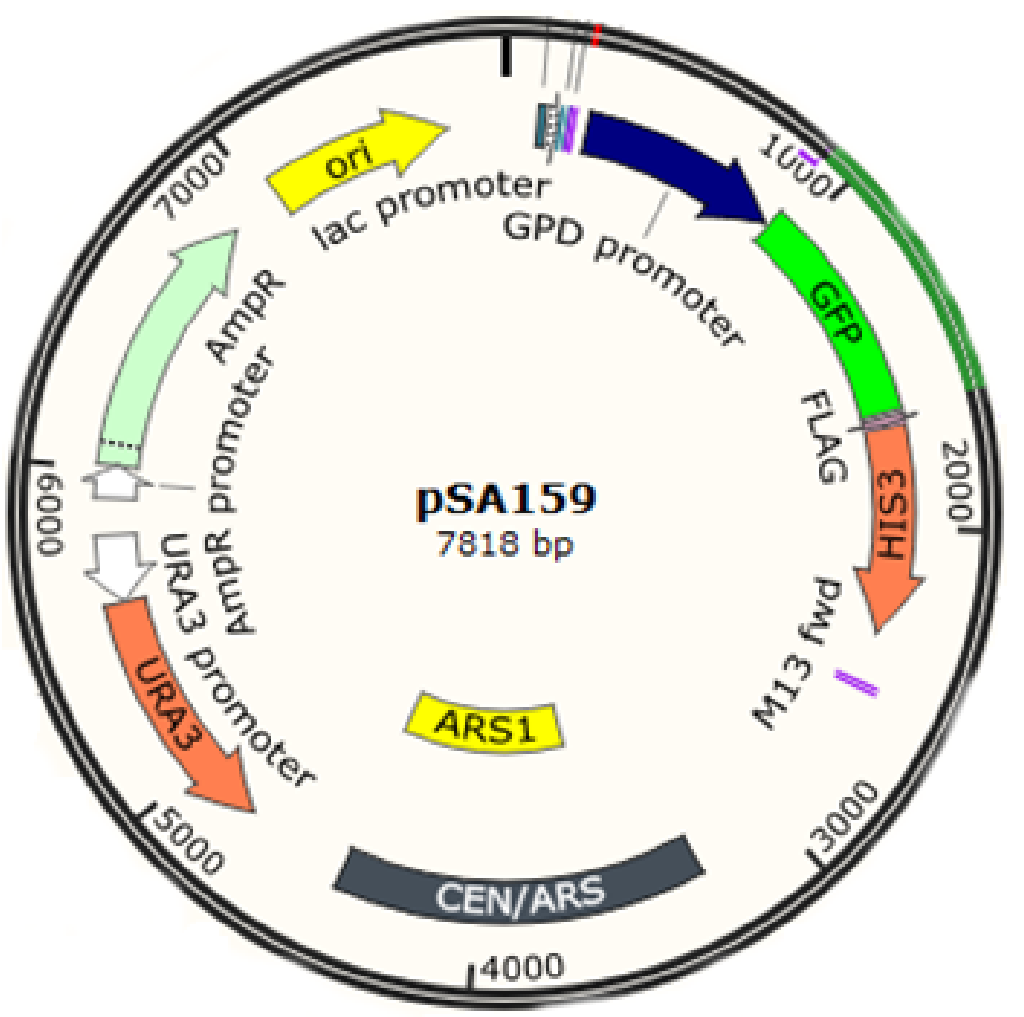

Figure 4: The plasmid map for pSA159. This plasmid contains a GPD promoter, an ampicillin resistance marker, a Ura3 selectable marker, and a GFP-FLAG-his3 (nonstop) fusion translational marker. This plasmid is used in this study to uncover novel genes involved in NSD. 
S. cerevisiae and E. coli strains: We ordered a $S$. cerevisiae a strain from Boone et al at the University of Toronto to carry out the large-scale screen. The $\alpha$ strain (Y6547) contains a deleted His 3 gene, although the deletion may not be complete ${ }^{67}$ ( $90 \%$ deletion of the his 3 gene). In addition, the CAN1 gene is replaced with a MFA1 promoter fused to $L E U 2$. There are also single gene deletions including lyp 1, ura3, leu2, his3, and met15. We used competent E. coli cells (DH5 $\alpha$ ) as they can be transformed easily with plasmids.

Media: Media used includes Yeast Peptone Dextrose (YPD), -URA (dropout mix), -HIS (dropout mix), lysogeny broth (LB) broths and agar. To select for plasmids, we used -URA or -HIS. To produce these dropout mixes, we combined set amounts of all amino acids, excluding the one we wish to select for. In the case of -HIS, all amino acids are combined excluding histidine. In some cases, media is combined with drugs to improve the selection conditions.

Antibiotics and Drugs: 3-Amino-1,2,4-triazole (3AT) is a competitive inhibitor of the His3 gene product imidazoleglycerol-phosphate dehydratase (IGPD) ${ }^{68}$. This enzyme catalyzes the $6^{\text {th }}$ step of the cellular His3 biosynthetic pathway ${ }^{68}$. Verteporfin (VP) is thought to inhibit the formation of autophagosomes by interfering with the phagophore expansion (closing of the double membrane particle), thus negating the formation of autophagosomes ${ }^{69}$. Gentamicin (G418) acts to inhibit the elongation phase, blocking peptide synthesis ${ }^{70}$. Ampicillin binds to transpeptidase, inhibiting bacterial cell wall synthesis ${ }^{71}$. 


\subsection{NSD Screen}

To perform a genome wide investigation of genes not previously reported to be involved in NSD, we decided to first transform the pSA159 plasmid into Y6547 following the standard transformation protocol.

Standard Transformation Protocol: A visible amount of Y6547 cells were inoculated into YPD broth and allowed to incubate at $30^{\circ} \mathrm{C}$ shaking for 24 hours. Then, $2 \mathrm{~mL}$ of the overnight culture was re-inoculated into $40 \mathrm{~mL}$ of YPD broth and allowed to incubate again in the $30^{\circ} \mathrm{C}$ incubator for an additional 4 hours. This re-inoculation provides fresh nutrients for the overnight culture as it is likely that all the nutrients from the ONC were expended. After the 4-hour incubation, the optical density at $600 \mathrm{~nm}\left(\mathrm{OD}_{600}\right)$ was then measured (Ultrospec3000 UV/Visible Spectrophotometer Pharmacia Biotech). For an ideal transformation, an $\mathrm{OD}_{600}$ of $0.8-1.0$ is necessary. The inoculum was then transferred to a Falcon Tube and centrifuged at 5000 Rotations Per Minute (RPM) for 5 minutes to collect the yeast cells. The supernatant was then discarded, and the pellet was then washed with $10 \mathrm{~mL}$ of distilled water $\left(\mathrm{dH}_{2} \mathrm{O}\right)$, and subsequently vortexed to re-suspend the pellet. An additional round of centrifugation with the same time and speed was performed, and the supernatant discarded. Next, $200 \mu \mathrm{L}$ of $0.1 \mathrm{M}$ Lithium Acetate (LiOAc) was added to the pellet, and subsequently vortexed. Then, $50 \mu \mathrm{L}$ of re-suspended cells was transferred to a micro-centrifuge tube. To this volume, $240 \mu \mathrm{L}$ of $50 \%$ Polyethylene glycol (PEG) was added as this keeps the cells intact. After this, $36 \mu \mathrm{L}$ of $1 \mathrm{M} \mathrm{LiOAc}$ was added to make the cell membrane permeable. Then, $10 \mu \mathrm{L}$ of heron sperm DNA (single stranded DNA - ssDNA) was added. The purpose of ssDNA is to provide a decoy for the yeast cell, as any foreign DNA will be degraded. Finally, $5 \mu \mathrm{L}$ of the pSA159 plasmid was added immediately after the ssDNA. The entire volume was then briefly and lightly vortexed and placed into a $30^{\circ} \mathrm{C}$ incubator for 1.5 hours, vortexing 
lightly every 10 minutes. After this incubation period, the cells were then subjected to a heat shock at $42^{\circ} \mathrm{C}$ for 15 minutes in a water bath. The cells were then allowed to relax for 5 minutes, and were then centrifuged briefly ( 10 seconds at maximum speed) to collect the cells into a pellet. The supernatant was discarded, and the pellet was re-suspended in $110 \mu \mathrm{L}$ of $\mathrm{dH}_{2} \mathrm{O}$. This volume was then transferred to a -URA agar plate, due to the Ura3 selection marker in pSA159. The plate was then transferred to a $30^{\circ} \mathrm{C}$ incubator for 3 days to allow for the selection of yeasts that were successfully transformed with pSA159.

After the 3-day incubation, the plates were checked for colony growth. If there were the presence of colonies, one was picked a re-streaked onto -URA plates, to confirm the growth of yeast. Once the colony was confirmed to be yeast (as opposed to E. coli contamination), the now transformed Y6547 with pSA159 (herein referred to as NS $\alpha$ ), was inoculated into -URA liquid and allowed to incubate at $30^{\circ} \mathrm{C}$ shaking for 24 hours. The following day, the inoculum was then plated onto square -URA agar plates and allowed to incubate at $30^{\circ} \mathrm{C}$ overnight. After a 24-hour incubation period, the square -URA agar plates were now thoroughly coated with NS $\alpha$ cells.

Large Scale Transformation Methodology: With the NS $\alpha$ strain now in hand, and on a square URA plate, we used the standard pinning method to transfer colonies. Our deletion set consists over $\sim 5000$ single gene deletions. This deletion set allows us to query which genes are involved in NSD. Our controls for the NSD screen were the 10 genes which have been confirmed to be involved in NSD. These genes include: DOM34, SKI7, SKI2, SKI3, SKI8, HBS1, LTN1, ITT1, ENT5, and NAM7.

The NS $\alpha$ strain was transferred to 14 square YPD agar plates, and the deletion set was then pinned on top of the NS $\alpha$ strain to facilitate mating being $\alpha$ and a. The resulting cells were the incubated twice, once at room temperature for 24 hours, and then at $30^{\circ} \mathrm{C}$ for an additional day. This was 
done to allow the $\alpha$ and a cells to mate. After the incubations, the $M A T a / \alpha$ cells were plated onto -URA + G418 and allowed to incubate at $30^{\circ} \mathrm{C}$ for 2 days to select for diploid cells.

These diploid cells were then transferred to Enriched Sporulation Media (ESM). This selection media will select for the diploid cells, and we facilitate sporulation. The cells were then allowed to incubate at $22^{\circ} \mathrm{C}$ for 9 days. Sporulation cells were then transferred to SDHis/Arg/URA+Canavanine plates for 2 days at $30^{\circ} \mathrm{C}$. This media will select for haploid progeny cells that have been crossed with the pSA159 plasmid.

Next, the MATa progeny cells were transferred to SD/MSG-His/Arg/URA+G418+Canavanine plates to select for Canavanine resistance. The cells were allowed to incubate at $30^{\circ} \mathrm{C}$ for 2 days. Finally, the MATs progeny cells were transferred to -URA $+\mathrm{G} 418$ and incubated for 1 day at $30^{\circ} \mathrm{C}$ to complete the methodology. This media will select for the plasmid, and will negate the growth of contaminants. The plates were stored for up to 1 month before being transferred to new -URA + G418 plates.

NSD Screen: The MATa progeny cells have theoretically now been crossed with the pSA159 plasmid. As we are looking to select for cells that are using the nonstop his 3 in pSA159, we first tried to select for the plasmid using agar lacking histidine (-HIS). This, however, resulted in all colonies being viable and growing. This may be due to the incomplete deletion of his 3 in the Y6547 $\alpha$ strain, as histidine can still theoretically be produced. We then decided to use $3 \mathrm{AT}$ due to its function as a cellular HIS3 biosynthesis inhibitor. Using a concentration gradient, we found that the ideal concentration of $3 \mathrm{AT}$ was $1 \mathrm{mg} / \mathrm{mL}$ for our screen. This concentration was then applied to the entire transformation methodology plate, resulting in 446 gene candidates. A gene candidate is defined in this project as any colony from the methodology that grows on nutrient agar lacking histidine, and in the presence of 3AT. We then moved on to data analysis. 


\subsection{Data Analysis}

We needed to find a way to analyze 446 potential gene candidates for their involvement in NSD. The first step was to first identify the 446 candidates using GeneMania (available at: http://genemania.org/). This online database provides users with the names and molecular functions of yeast genes. Knowing the coordinates of the 446 candidates, we found out the gene names, and their subsequent functions. We then decided to use Panther GO-Slim to reveal the activity of the genes (available at: http://www.pantherdb.org/tools/compareToRefList.jsp). This, provided us with the general processes of the candidate genes. How many families span the 446 gene candidates? Is there a particular family that has never been linked to NSD that has been produced by the screen? These are the questions we set out to answer. This provided several interesting gene families including: Autophagy-Related Genes (ATG), Vacuolar Protein Sorting (VPS) genes, Pheromone Regulated (PRM) genes, and genes Found in Mitochondrial Proteome (FMP) in addition to 17 ribosomal genes (table 1). As well, 6 of the 10 control genes were apart

of the candidate list including: DOM34, SKI7, SKI2, SKI3, SKI8, and LTN1. Interestingly, the DOM34 paralog HBS1 did not appear in our screen. At this point we had the information we needed to start experimental validation of the NSD screen. 


\subsection{Assessing NSD Screen Accuracy}

Growth Curves: To help confirm the accuracy of the screen, we decided to run growth curves on 378 of 446 strains. 100 candidates were excluded as they were dubious open reading frames. First, the 378 single gene deletion strains were manually transferred onto one -URA square plate. Next, using a 96 pin colony transfer apparatus (referred to as a "pinner" from here on), each colony was transferred onto a separate -URA square plate ( 96 colonies per plate, over 4 plates). The respective colonies were then allowed to grow for 2 days at $30^{\circ} \mathrm{C}$.

To start the growth curve, each strain was inoculated from its respective plate into a deep well 96 well plate containing $1 \mathrm{~mL}$ of -URA. The plate was then sealed, and was added to a shaking $30^{\circ} \mathrm{C}$ incubator for 24 hours. The next day, 8 COSTAR 96-well plates were prepared (4 containing $170 \mu \mathrm{L}$ of -URA, and 4 containing -HIS $+1 \mathrm{mg} / \mathrm{mL} 3 \mathrm{AT}$ ). Next, $30 \mu \mathrm{L}$ of the overnight culture was transferred to the -URA wells first, and then the absorbance was taken using a FLUOstar OPTIMA plate reader for 3 time points: 0 hours, 4 hours, and 8 hours. For each time point, the -URA culture was read first, followed immediately by the $-\mathrm{HIS}+3 \mathrm{AT}(30 \mu \mathrm{L}$ added to $170 \mu \mathrm{L}$ of media). The absorbance values were then transferred to an excel sheet for further analysis.

Data Analysis: We needed to quantify the growth of the 378 queried strains relative to the WT. We used two conditions, the control -URA and the experimental -HIS + 3AT. We first normalized the growth values to the -URA values to provide value Y (see below for definition), where value $\mathrm{X}$ is the raw growth value of the sample. Next, these growth values were substituted in to equation 1. This equation will consider the constant values as well as the input raw growth values. The constants are based on a standard curve generated from a correlation between $\mathrm{OD}_{600}$ measurements and cell density (cells $/ \mathrm{mL}$ ). A regression analysis produced a polynomial line of best fit with the equation of the line being equation 1 , with an $\mathrm{R}^{2}$ value of 0.9954 . We used a WT strain to establish 
a baseline growth rate. Solving equation 1 will result in value $\mathrm{Y}$, which is the now normalized growth value. We then took value $\mathrm{Y}$ at each time point ( 0 hour, 4 hour, and 8 hour) and found the fold change to yield value $Z$. This $Z$ value will tell us the concentration of cells being produced over the incubation period.

Equation 1: $\left.\mathrm{Y}=\left(2.2988 *\left(\mathrm{X}^{2}\right)\right)-((\mathrm{X} * 0.6344)+0.2821)\right) *\left(10^{7}\right)$

Where $\mathrm{X}=$ the raw sample growth value (initial value).

Where $\mathrm{Y}=$ the normalized sample growth value.

Equation 2: $\mathrm{Z}=\mathrm{Y}_{(4 \text { hour or } 8 \text { hour })}-\mathrm{Y}_{0 \text { hour }}$

Where $\mathrm{Z}=$ the cells being produced over the incubation period. 


\subsection{Drug Sensitivity Assay}

To assess the sensitivity of $\operatorname{atg} 12 \Delta$ and $v p s 30 \Delta$ to 3 AT, we performed a drug sensitivity assay. This test will test a serial dilution of overnight culture under the same drug concentration. First, the WT,

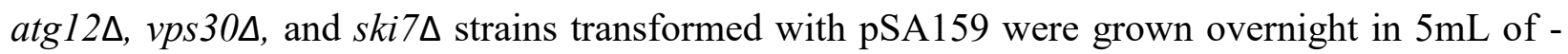
URA. After the 24-hour incubation, $100 \mu \mathrm{L}$ of the overnight culture was added to $900 \mu \mathrm{L}$ of dH2O. We then performed a serial dilution down to $10^{-4}$ cells $/ \mathrm{mL}$. The cells were then transferred to a URA plate (control condition) and -HIS $+1 \mathrm{mg} / \mathrm{mL} 3 \mathrm{AT}$ (experimental condition). After drying, the plates were then transferred to a $30^{\circ} \mathrm{C}$ incubator for at least 2 days. We found that the experimental condition takes 4 days to grow compared to 2 days for the -URA control conditions. Pictures of both conditions can be found in figure 8 . 


\subsection{Protein - Protein Interaction Prediction Engine (PIPE)}

The Protein-Protein Interaction Prediction Engine (PIPE) was initially developed to investigate short co-occurring polypeptide sequences between two proteins to determine their likelihood of interaction $^{72-74}$. This likelihood of interaction is captured by two scores: PIPE-Score and

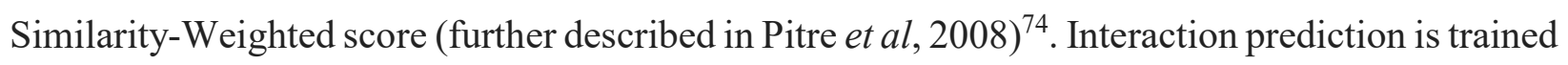
on previously known interactions, which informs the prediction of novel interactions. Given a database of known interactions (confirmed using wet-lab approaches), the residues that mediate the interactions are used to train PIPE. In theory, if two given residues on the query proteins are similar to two known residues on 2 interacting proteins, these residues may mediate an interaction on the two query proteins. Given a user input database, PIPE will predict interactions in the user database. If an interaction is predicted, the likelihood of the interaction is given based on two assigned scores: the PIPE-Score, and the Similarity-Weighted score (SW score). In this study, we utilized PIPE for the candidates produced by the NSD screen. 


\subsection{Inhibition of Autophagy}

To confirm that autophagy has been inhibited in $\operatorname{atg} 12 \Delta$ and $v p s 30 \Delta$, we obtained the autophagy inhibiting drug verteporfin from the Roberge lab at the University of British Columbia. We started

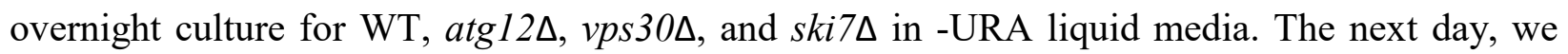
performed a concentration gradient of verteporfin, ranging from $1 \mathrm{nM}$ to $100 \mathrm{nM}$ (concentration range was $0 \mathrm{mM}, 1 \mathrm{mM}, 10 \mathrm{mM}, 50 \mathrm{mM}$, and $100 \mathrm{mM}$ ). Each culture tube contained: respective volume of verteporfin, $1 \mathrm{mg} / \mathrm{mL}$ of $3 \mathrm{AT}, 100 \mu \mathrm{L}$ of overnight culture, and -HIS liquid up to a total volume of $5 \mathrm{~mL}$. The cells were then allowed to incubate at $30^{\circ} \mathrm{C}$ for 24 hours. Importantly, verteporfin is a light sensitive drug so all culture tubes were wrapped in aluminum foil to prevent light from affecting the drug. The next day, $1 \mathrm{~mL}$ of overnight culture was assessed for growth using $\mathrm{OD}_{600}$. Figure 9 illustrates the results for this experiment. 


\subsection{RNA Extractions, cDNA synthesis, and qRT-PCR}

RNA Extractions: All RNA was extracted using the RNA Extraction Procedure from the Bio-Rad

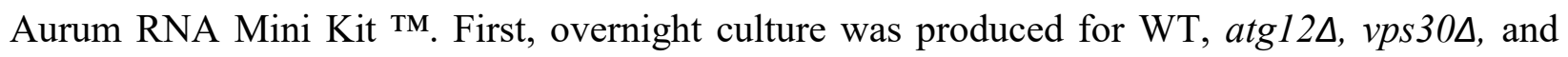
ski7 $\mathrm{in} 5 \mathrm{~mL}$ of -URA. 24 hours later, $1 \mathrm{~mL}$ of the overnight culture was transferred to a $2 \mathrm{~mL}$ centrifuge tube, and was centrifuged a maximum for 1 minute. The resulting supernatant was discarded, and $1 \mathrm{~mL}$ of $50 \mathrm{U}$ (units) zymolase was added to the pellet. After a 10-minute incubation at room temperature, the volume was centrifuged at 5000RPM for 5 minutes. The supernatant was discarded, and $350 \mu \mathrm{L}$ of Lysis solution was added to the pellet, which was subsequently resuspended. Next, and additional $350 \mu \mathrm{L}$ of $70 \%$ ethanol was added, and mixed accordingly. Next, the entire volume was transferred to an RNA binding column in $2 \mathrm{~mL}$ capless tubes. The binding column was then centrifuged at maximum for 30 seconds. The filtrate was then discarded. We then added $700 \mu \mathrm{L}$ of the low stringency wash solution to the RNA binding column, and subsequently centrifuged under the previous conditions. Again, the filtrate was discarded. We then prepared the DNase solution by reconstituting $5 \mu \mathrm{L}$ of DNase I with $75 \mu \mathrm{L}$ of DNase dilution solution, for a total volume of $80 \mu \mathrm{L}$. The entire $80 \mu \mathrm{L}$ volume of DNase solution was then added to the binding column, and allowed to incubate at room temperature for 15 minutes. After this incubation period, the binding column was centrifuged at maximum for 30 seconds, with the filtrate discarded. Next, $700 \mu \mathrm{L}$ of High stringency wash was added to the binding column, and was centrifuged for 30 seconds at maximum. After discarding the filtrate, $700 \mu \mathrm{L}$ of Low stringency wash was added, and centrifuged under the previous conditions. The RNA binding column was then transferred to a sterile RNase free $2 \mathrm{~mL}$ tube. Finally, $50 \mu \mathrm{L}$ of $70^{\circ} \mathrm{C}$ elution solution was added to the column, and was allowed to incubate for 5 minutes. Next, the tube was then centrifuged at maximum for 30 seconds. This last step was repeated twice to increase the concentration of RNA. The purified RNA 
was then subjected to a Nanodrop to assess RNA purity using the DeNovix DS-II Spectrophotometer.

cDNA Synthesis: After purity of the RNA was confirmed, we produced the cDNA using the 5X All-In-One RT MasterMix with AccuRT Genomic DNA Removal Kit ${ }^{\mathrm{TM}}$ from ABM Canada. First, up to $2 \mu \mathrm{g}$ of the purified RNA was added to $2 \mu \mathrm{L}$ of AccuRT Reaction Mix ( $4 \mathrm{X}$ ) to a total volume of $8 \mu \mathrm{L}$. The solution was then allowed to incubate at room temperature for 5 minutes. After this incubation period, $2 \mu \mathrm{L}$ of the AccuRT Reaction Stopper (5X) was added to the solution. The genomic DNA removal is now complete. We then added $4 \mu \mathrm{L}$ of the $5 \mathrm{X}$ All-In-One RT MasterMix, and $6 \mu \mathrm{L}$ of RNase Free Water for a total volume of $20 \mu \mathrm{L}$. The solution was then allowed to incubate at $25^{\circ} \mathrm{C}$ for 10 minutes, followed by 15 minutes at $42^{\circ} \mathrm{C}$. The reaction was then terminated with a 5-minute incubation at $85^{\circ} \mathrm{C}$. The newly generated first strand cDNA was then assessed for purity using the DeNovix DS-II Spectrophotometer. Finally, the cDNA was aliquoted and stored at $-20^{\circ} \mathrm{C}$ for downstream use in qRT-PCR.

qRT-PCR: Once the purity of the cDNA was confirmed, we performed qRT-PCR. Using reaction volumes of $10 \mu \mathrm{L}$, we combined forward and reverse primers (Table A2), sterilized Milli Q water, $1 \mu \mathrm{g}$ of cDNA, and the Bio-Rad SYBR Green ${ }^{\mathrm{TM}}$ reaction mix. Our primers will amplify the forward region of the nonstop his 3 gene from the pSA159 plasmid. Before qRT-PCR was attempted, primer quality was verified using bioinformatics tools, and gel electrophoresis (data not included). After primer quality was confirmed, and we were confident the primers were not contaminated, we moved on to qRT-PCR. All reactions were prepared in a Bio-Rad qPCR microwell plate on ice. Once preparation was complete, the qRT-CR plate was transferred to a CFX Connect Real-Time System using the following conditions: Annealing temperature at $57^{\circ} \mathrm{C}$ for 50 cycles, with a $72^{\circ} \mathrm{C}$ extension temperature. We included a melt curve to determine if primer dimers had occurred. The 
standard curve and the results from the qRT-PCR can be found in figure A1 and figure 10 respectively. 


\subsection{Protein Extractions, Bradford Assay, and Western Blots}

Protein Extractions: The gene candidate cultures were first inoculated into $3 \times 5 \mathrm{~mL}$ of -URA media for 24 hours, or to an $\mathrm{OD}_{600}$ of $\sim 1.0$. The cells were then transferred to a $15 \mathrm{~mL}$ conical tube, and centrifuged at $4^{\circ} \mathrm{C}$ and $3000 \mathrm{RPM}$ for 5 minutes. The now pelleted cells were then washed with $2 \mathrm{~mL}$ of ice-cold sterilized Milli Q water. Once resuspended, the cells were centrifuged again under the previous conditions, discarding the supernatant after complete. The cells were then subjected to a brief exposure to liquid nitrogen to freeze the pellet. The cells were then placed on ice and allowed to thaw. Next $50-100 \mu \mathrm{L}$ of lysis buffer $\left(10 \mu \mathrm{L}\right.$ for every $1 \mathrm{OD}_{600}$ unit) was added to the pellet. The pelleted cells were then subsequently resuspended, and the total volume transferred to an Eppendorf tube. Add an equal volume of $0.5 \mathrm{~mm}$ glass beads and lyse the cells by lightly vortexing for 5 minutes. Centrifuge the resulting mixture at $4^{\circ} \mathrm{C}$ for 10 minutes. The supernatant was then transferred to a fresh Eppendorf tube, and stored at $-20^{\circ} \mathrm{C}$.

Bradford Assay: To determine to concentration of the protein extracts, we performed a BCA assay using the $\mathrm{BCA}^{\mathrm{TM}}$ Protein Assay Kit from Thermo Scientific (Product number: 23225, Lot number: IA109437). Protein standards were produced following the provided procedure. We performed the assay using a 96 well-round bottom plate. Visualization was performed at $562 \mathrm{~nm}$ using a Synergy H1 microplate reader (BioTek) with the final concentrations of crude protein being: $616 \mathrm{mg} / \mathrm{mL}$, $589 \mathrm{mg} / \mathrm{mL}, 699 \mathrm{mg} / \mathrm{mL}$, and $636 \mathrm{mg} / \mathrm{mL}$ for the $\mathrm{WT}$, atg $12 \Delta, v p s 30 \Delta$, and ski7 $\Delta$ respectively. The standard curve for the protein standards can be found in figure A2 in the appendix. The $\mathrm{R}^{2}$ value for the curve is 0.9914 .

Western Blots: Crude protein was measured for protein concentration using a BCA assay. Once the values were known, the appropriate volume of protein was added to an equal volume (1:1) of Lamelli buffer supplemented with $\beta$-mercaptoethanol (5\%). The protein solution was then 
subjected to boiling for 3 minutes, and subsequently centrifuged to collect the sample. We then loaded 50mg of crude protein into each well of an SDS-PAGE gel. We first ran the SDS-PAGE gel at $60 \mathrm{~V}$ for 30 minutes to collect the proteins at the stacking gel. Next, the voltage was increased to $120 \mathrm{~V}$ for 90 minutes, or until the Lamelli buffer bands ran off the gel.

The SDS-PAGE gel was then transferred onto a $0.45 \mu \mathrm{m}$ nitrocellulose membrane (BioRad) and sandwiched between Extra think blot paper (BioRad). Transfer buffer (molarity) was added to the sandwich and directly to both the membrane and the gel. The transfer was completed using a TransBlot SD Semi-Dry Transfer Cell (BioRad), transferring at 23V for 65 minutes.

The membrane was then subjected to blocking using 5\% skim milk (\%w/v) in TBST for 1 hour. Next, the blocking buffer was removed, and the $1^{\circ}$ antibody was added. The concentration of the $1^{\circ}$ is $1: 1000$, whereas the $2^{\circ}$ is $1: 5000$. Two proteins were targeted for expression: GFP (experimental), and Pgk1 (endogenous control). The anti-GFP antibody is conjugated to horseradish peroxidase, so there is no need for a $2^{\circ}$ antibody. The anti-GFP antibody (Santa Cruz) is a mouse monoclonal antibody with a weight of $27 \mathrm{kDa}$, and is available at https://www.scbt.com/scbt/product/gfp-antibody-b-2. The anti-Pgk1 is not conjugated, so a $2^{\circ}$ antibody specific to anti-Pgk1 is required. The anti-Pgk1 antibodies are mouse monoclonal antibodies with a weight of $45 \mathrm{kDa}$. The antibodies localize to the cytoplasm, and have an $\operatorname{IgG}$ isotype. Further antibody information on anti-PGK1 can be found at www.abcam.com/pgk1antibody-22c5d8-ab113687.html. 1X TBST was used for the 5 washing steps, 5 minutes each. After washing, the membrane was subjected to chemiluminescent substrates (Clarity ${ }^{\mathrm{TM}}$ Western ECL Substrates: Peroxide solution and Luminol/Enhancer solution) and immediately visualized using a Fusion Fx visualizer from Vilber Lourmat. Exposure times ranged from 2-6 minutes. After probing with anti-GFP, the membrane was stripped using stripping buffer for 10 minutes. The 
membrane was then extensively washed with $1 \mathrm{X}$ TBST (5-7 washes) to remove any remaining stripping buffer. The results can be found in figure 11 below. 


\section{Chapter 3: Results}

\subsection{Screen Candidates}

The degradation of aberrant mRNA is an important quality control mechanism for the cell. The production of misfolded proteins from aberrant mRNA has the potential to interrupt important cellular processes, as protein interaction networks may be compromised. Depending on which interaction network is disrupted, protein sorting, signal transduction, metabolic pathways, and the cell cycle, among numerous other processes, can suffer. These pathways are integral to cell homeostasis, and if interrupted can interfere with cell survival. Proteins that would normally be degraded are allowed to persist and accumulate in the cell, possibly becoming toxic ${ }^{23}$. It is therefore extremely important to study the mechanisms of cellular homeostasis, including mRNA degradation. Here, we sought to discover novel genes involved in the degradation of nonstop mRNA. In order to accomplish this we utilized the yeast non-essential gene knockout collection. We transformed this collection with a construct carrying a nonstop his 3 mRNA. We reasoned that those mutants that suppress NSD would be allowed to grow under-HIS selective media.

From the approximately 5,000 genes tested, we found 446 consistent gene deletion candidates based on their growth profiles in a positive selection screen. Our screen selected for single gene deletion mutants that can grow under nutrient depletion (-HIS) and in the presence of a histidine biosynthesis inhibitor (3AT). The purpose of 3AT was to ensure that the biosynthesis of histidine from a possible endogenous source is negated. This will increase the dependency of cell growth on the pSA159 plasmid to produce histidine. We first needed to determine the optimal concentration of $3 \mathrm{AT}$ to use. We therefore performed a drug serial deletion assay on NSD related genes $s k i 7 \Delta, d o m 34 \Delta$, and $h b s 1 \Delta$. The concentration gradient ranged from $1 \mathrm{mg} / \mathrm{mL}$ to $20 \mathrm{mg} / \mathrm{mL}$ 3AT. We found that a working concentration for $3 \mathrm{AT}$ was $1 \mathrm{mg} / \mathrm{mL}$. In a large-scale transformation 
approach, single gene deletion mutants were transformed with the pSA159 plasmid, which contains a nonstop his 3 translational marker. Theoretically, any mutants that grow under the selection conditions must be using the nonstop his 3 from pSA159 to produce HIS.

We first aimed to cluster the identified 446 NSD (figure 5) candidates based on GO-term process (figure 6). This resulted in several processes ranging from transcription to protein targeting. Interestingly, $24.62 \%$ of the gene candidates had unknown functions. The processes found using Panther seem to indicate an overall general trend within the candidates in trafficking and sorting. This is very interesting as it may indicate that NSD is more complicated than previously thought.

We then clustered the candidate genes into their respective families (table 1). The candidate genes seem to cluster into 7 main families: autophagy related, pheromone regulated, vacuolar sorting, phosphate metabolism, mitochondrial genes, pexophagy genes, and the superkiller family. With the exception of phosphate metabolism and the mitochondria, these families seem to be related directly to intracellular trafficking. Considering that autophagy is one of the main families produced by the NSD screen, we chose to investigate this potential link. To our knowledge, no one has yet linked NSD to autophagy, making this an interesting and potentially novel link. 


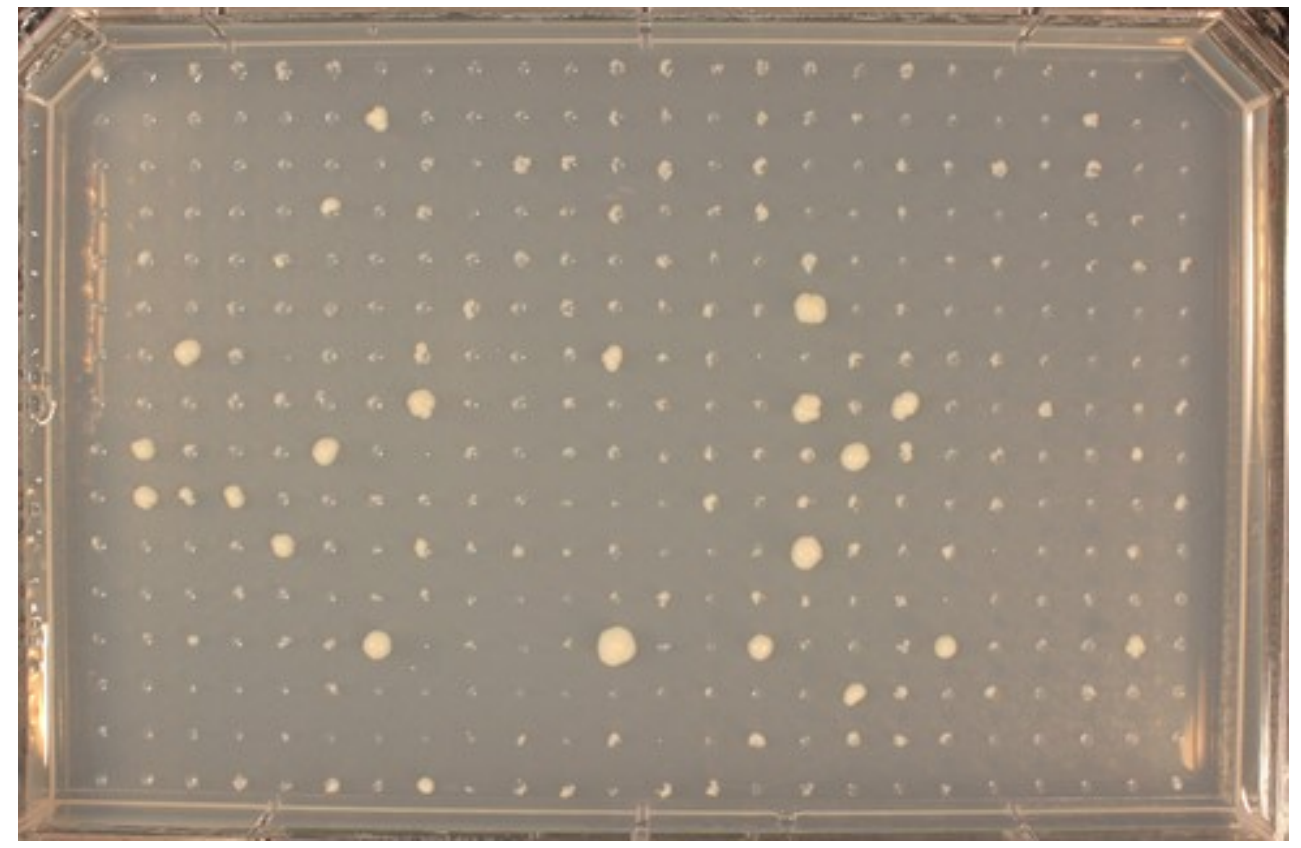

Figure 5: A result plate containing NSD gene candidates. The bigger colonies represent gene candidates, as they can express the NS his3 gene under -HIS+3AT stress conditions. Smaller colonies that show no growth we consider to be non-candidates. 


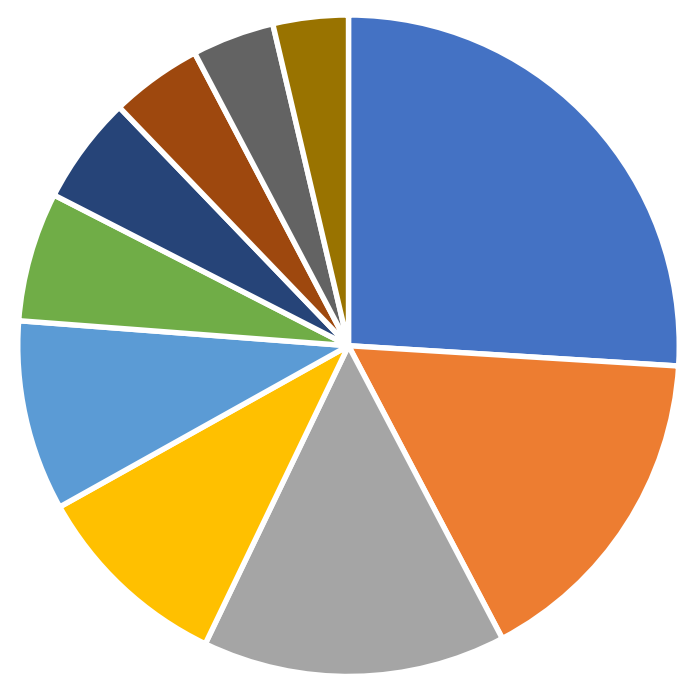

- Unknown Process

- Involved in the Cell Cycle

- Sporualtion

- Mitochondrial Organization
- Organelle Fission and Organization

- Chromatin Organization

- Golgi Transport

Figure 6: Gene Ontology enrichment analysis for the NSD gene candidates. The main category is unknown process (light blue), which accounts for $24.62 \%$ of the gene candidates. The process of transcription (orange) is the next largest category produced from the gene candidates, at $15.47 \%$. Organelle fission and organization (grey) is the next most abundant process which is comprised of $12.9 \%$ of the NSD gene candidates. The cell cycle (yellow) and chemical response (dark blue) both report at $8.5 \%$ and $8.1 \%$ respectively. Chromatin organization (green), sporulation (royal blue), protein targeting (dark red), Golgi transport (dark grey), and mitochondrial organization (gold) are all listed at 5.5\%, 4.6\%,3.9\%, 3.5\%, and 3.2\% respectively. This indicates that the NSD pathway may be involved in various cellular transport processes, and protein biosynthesis. 
Table 1: The gene family clusters (family, gene, function) of the gene candidates

Gene Family
Gene Name

ATG12

ATG13

$A T G 21$
Gene Function
AuTophagy Related

Genes (ATG)
Regulates expression of ATG8p, vesicle formation

\section{Phe $\underline{R} \underline{\text { MONone-Regulated }}$}

Protein (PRM)

\section{PRM1}

PRM4

PRM9
Essential for autophagy, recruits ATG14p to PAS

Essential for autophagosome formation

Involved in membrane fusion during mating

Proposed to be involved in mating

Motif involved in COPII binding

Vacuolar Protein $\underline{\text { Sorting }}$

VPS21

Involved in autophagy and ionic stress tolerance

(VPS)

VPS30

Essential for autophagy

VPS55

Involved in late endosome to vacuole transport

VPS74

Mediates enzyme targeting to the Golgi Apparatus

PHOsphate Metabolism

PHO4

Activates transcription in response to phosphate stress

(PHO)

PHO23

Involved in transcriptional regulation of PHO5p

PHO80

Regulates response to nutrient levels and environment

PHO84

High-affinity organic phosphate transporter

Found in Mitochondrial

FMP14

Involved in assembly of F1F0 peripheral stalk

Proteome

FMP22

Protein of unknown function

(FMP)

FMP25

Required for assembly of respiratory complex III

FMP26

Determining mitochondrial architecture

FMP33

Putative protein of unknown function 
FMP37

FMP49

\section{PEroXisome Related}

(PEX)
PEX17

PEX22

PEX14
Highly conserved subunit of mitochondria pyruvate carrier

Mitochondrial protein of unknown function
Central component of peroxisomal importomer complex

Membrane peroxin of the peroxisomal importomer complex

Putative peroxisomal membrane protein
SuperKIIler

(SKI)
SKI2

SKI3

SKI7

SKI8
Component of SKI exosome, putative helicase

Mediates 3'-5' mRNA decay

GTPase involved in 3' -5' mRNA decay

SKI complex protein mediates 3'-5' mRNA decay 


\subsection{NSD Screen Accuracy}

To assess the accuracy of the NSD screen, we performed large-scale growth curves on a subset (378) of the gene candidates. The growth curves were performed in -URA for the control condition, and $-\mathrm{HIS}+1 \mathrm{mg} / \mathrm{mL} 3 \mathrm{AT}$ as per the conditions of the screen. Growth readings $\left(\mathrm{OD}_{600}\right)$ were taken at 0,4 , and 8 hours. Readings were normalized to -URA, and to the 0 -hour mark. The resulting value gave the growth change over time, relative to the -URA media control. Finally, we normalized the "change" values to a constant for the WT growth. This gave a normalized change value for the 378 gene candidates relative to the WT. Figure 4 illustrates the heat map for this experiment. Red cells denote heavy growth whereas the green cells denote poor growth, relative to the WT respectively.

The results illustrated in figure 7 indicate that $\operatorname{atg} 13 \Delta$ and $y j l 147 c \Delta$ grew the best, whereas $s v s 1 \Delta$ and yil152w $\Delta$ grew the least. The top 10 best candidates are as follows: $\operatorname{atg} 13 \Delta, y j l 147 c \Delta$,

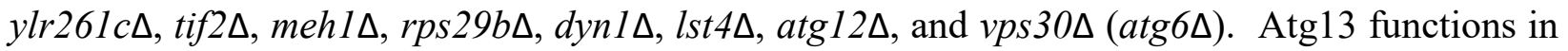
vesicle formation, and is required for autophagy ${ }^{75}$. Importantly, Atg13 also functions in the recruitment of Atg14 to the PAS ${ }^{45}$. Interestingly, YLR261C ORF is also commonly named VPS63. The Vps63 protein is putative, and has a $98 \%$ alignment to the Ypt6, with a deletion in vps63 resulting in defects in protein sorting ${ }^{76}$, and hence possibly involved in autophagy. Therefore, in the top 10 hits for the heat map there are 3 candidates directly involved in and required for autophagy, with a potential autophagy candidate in Vps63. Using a cut-off value of 2 fold (the candidates that grow 2 times more relative to the WT) we identified the top 40 gene candidates produced by the screen (reported in table 2). 


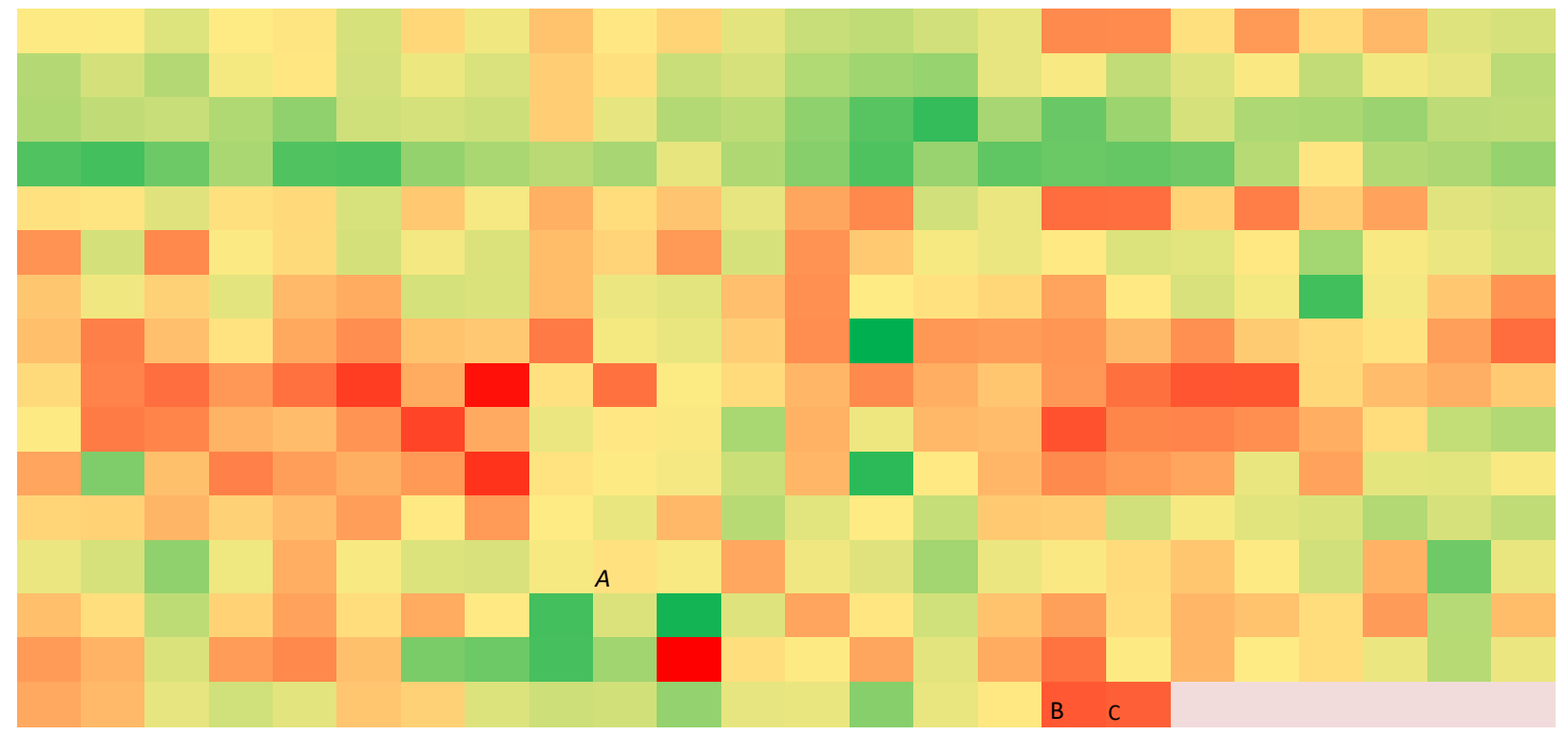

Figure 7: The heat map based on large scale growth curves for 378 NSD gene candidates.

The readings $\left(\mathrm{OD}_{600}\right)$ were taken at 0,4 , and 8 hours. The heat maps colour range denotes heavy growth (red) and poor growth (green) relative to the WT. ski7 $(\mathrm{A}), \operatorname{atg} 12 \Delta(\mathrm{B})$, and $v p s 30 \Delta$ (c) are located at cells 298, 377, and 378 respectively. Light pink denotes an empty cell. 
Table 2: The top 40 gene candidates produced from the NSD screen.

\begin{tabular}{cccc}
\hline ATG13 & YJL147C & YLR261C & TIF2 \\
MEH1 & RPS29B & DYN1 & LST4 \\
ATG12 & VPS30 & LSB1 & HOP1 \\
YJL122W & YGR015C & APE2 & YIL092W \\
YKR021W & UBS1 & MAD2 & YJR124C \\
ERV14 & SPO11 & TOP3 & YJR008W \\
SKI2 & YJR119C & SEC72 & PIB2 \\
PAC1 & YBP2 & FRT2 & GAP1 \\
FUS2 & TOS1 & JJJ2 & RRD1 \\
COX8 & SAP185 & STB5 & YGL109W
\end{tabular}

*Protein Targeting: $\mathrm{P}=0.040117$, Organelle fission and organization: $\mathrm{P}=0.002294$, Cell Cycle: $\mathrm{P}=0.003126$, Cytoskeleton Organization: $\mathrm{P}=0.043819$. 


\subsection{Protein-Protein Interaction Prediction Analysis}

A Protein-protein interaction (PPI) is an association between 2 or more proteins to carry out a specific function. PPIs are required for most physiological and cellular processes to occur. Many examples of PPIs can be found in signal cascade pathways, the ubiquitin proteasome degradation pathway, transcription, cell cycle etc. Local networks of PPIs also exist in form of complexes, and are critical to cellular functions. If, for example, a complex of 4 proteins were to lose an interacting partner, the functionality of the protein complex might be disrupted, and possibly negated. Therefore, studying PPIs is an important area of research as this research can uncover new protein networks, disease aetiology, in addition to novel functions for different proteins.

To study potentially new links between our screen candidates as well as to further expand our candidate list, we decided to investigate the interactions that our candidates make with other proteins in the yeast proteome. To accomplish this, we used our Protein-Protein Interaction Prediction (PIPE) algorithm, which was originally developed to predict novel PPIs in yeast, and to report the predicted site of interaction. The PIPE algorithm is ranked among the top prediction tools, based on specificity ${ }^{77}$. PIPE uses a database of previously characterized interactions to inform its predictions. To predict an interaction, the algorithm uses two 20 amino acid sliding windows across the two query proteins. When PIPE predicts an interaction in the window, the score of the potential interaction is reported. In this case, the PIPE-Score is the likelihood of the interaction occurring. Based on the known interaction database, PIPE will rank this score eventually culminating in the most likely interaction site between the two proteins. This highest ranked site is then reported to the user to inform further experimentation. PIPE also incorporates an additional scoring system: the similarity-weighted (SW) score. This SW score will determine the likelihood of a predicted site of interaction to be true. PIPE will generate a list of potential 
residues, and then over computing time, will report how many times each residue occurs. SW score will then compute this number, and produce the most likely residue, culminating in a visual peak of a 3D graph. It is the 3D peak that is the output of the SW score. Our NSD screen produced 446 potential gene candidates that may be involved in NSD. To help expand our candidate list, we performed PIPE analysis on the respective protein candidates by predicting PPIs for the entire 446 protein candidates. Using PIPE in this study is meant to supplement the NSD screen, and to expand the candidate list for future studies.

Performing PIPE on the entire 446 protein candidates against the entire yeast proteome, we found 62 novel PPIs (table 3). PIPE predicts several interacting partners for the Hta1 candidate. Hta1 is a histone protein that has a function in DNA damage repair ${ }^{78}$. The most likely interacting partner predicted by PIPE is Haal, which is a transcription factor that induces the expression of stress genes $^{79}$. Considering our two autophagy candidates, PIPE predicted a novel interaction between Atg12 and a putative protein Ymr085W (PIPE Score - 0.96063563, SW Score - 119.0369431). This putative protein has been predicted by PIPE to interact with several candidates including: Sam1, Kss1, Atg12, and Yg1081W. As for Vps30, PIPE did not predict any novel interactions. Outside of the two candidates, we found that PIPE also predicted a novel interaction for Ski2 and Ski3. Both SKI proteins are predicted to interaction with the ribosomal protein Rpl4A, which may be of interest as the SKI proteins are key components of the nonstop exosome. 
Table 3: The PIPE output for the predicted interactions with NSD screen candidates

\begin{tabular}{|c|c|c|c|}
\hline Candidate Protein & Predicted Partner & PIPE Score & SW Score \\
\hline Apt1 & Apt2 & 0.992303 & 178.8640832 \\
\hline $\operatorname{Atg} 12$ & Ymr085W & 0.96063563 & 119.0369431 \\
\hline Bim1 & Rpl22B & 0.99271098 & 108.1976699 \\
\hline Bud3 & Tdh2 & 0.9999921 & 87.77332891 \\
\hline Eft1 & Lsp1 & 0.99998491 & 66.16353215 \\
\hline eIF2A & Tif2 & 0.99998292 & 88.66449233 \\
\hline Erv14 & Tdh2 & 0.99989261 & 63.23481086 \\
\hline Gbp2 & Imd4 & 0.99181227 & 62.4760629 \\
\hline Gnp1 & Tdh2 & 0.99998016 & 43.4073284 \\
\hline Gyll & Rpl36A & 0.99992955 & 91.31841637 \\
\hline Hta1 & Kar2 & 0.99994661 & 73.16541865 \\
\hline Hta1 & Vth1 & 0.99997686 & 54.03675748 \\
\hline Hta1 & Tif2 & 0.99990586 & 89.28332706 \\
\hline Hta1 & Eft1 & 0.99995699 & 78.44288648 \\
\hline Hta1 & Imd4 & 0.99786209 & 53.6424253 \\
\hline Htal & Haa1 & 0.99994756 & 106.3031137 \\
\hline Kss 1 & Imd4 & 0.99312321 & 35.90426395 \\
\hline Kss 1 & Ymr085W & 0.97082637 & 64.51238058 \\
\hline Lhp1 & Htal & 0.99986173 & 130.763378 \\
\hline Lhs1 & Pir3 & 0.99998484 & 40.84176865 \\
\hline Lsb3 & Ypl264C & 0.92840229 & 80.83963664 \\
\hline Mep1 & Mep1 & 0.99283508 & 212.8704638 \\
\hline Pam1 & $\operatorname{Tdh} 2$ & 0.99998424 & 65.50925178 \\
\hline Pir3 & Pir3 & 0.96954163 & 24.05590798 \\
\hline Rpl11B & Rpl42A & 0.99970337 & 127.0593993 \\
\hline
\end{tabular}




\begin{tabular}{|c|c|c|c|}
\hline Rpl11B & Rp124B & 0.99981025 & 75.79952562 \\
\hline Rpl11B & $\operatorname{Imd} 4$ & 0.99789205 & 55.09388694 \\
\hline Rpl19A & Rpl24B & 0.99982699 & 73.42430796 \\
\hline Rpl19A & Rpl42A & 0.99972955 & 119.6210277 \\
\hline Rpl19A & Rpl11B & 0.9998482 & 98.68702087 \\
\hline Rpl19A & Rpl36A & 0.99970951 & 177.4856935 \\
\hline Rpl22B & Bre5 & 0.9999217 & 119.8890542 \\
\hline Rpl24B & Rpl36A & 0.99963689 & 143.552106 \\
\hline Rpl24B & Rpl42A & 0.99966193 & 96.31211968 \\
\hline Rpl36A & Bre5 & 0.99990044 & 130.8196436 \\
\hline Rpl36A & Rpl42A & 0.99943238 & 122.1051511 \\
\hline Rpl36A & Rpl33A & 0.99943883 & 104.6383277 \\
\hline Rpl4A & Rpl4A & 0.999966 & 229.4762131 \\
\hline Rpl4A & eIF2A & 0.99998128 & 156.8225178 \\
\hline Rp14A & Rp142A & 0.99986596 & 136.3748869 \\
\hline Rp14A & Ski3 & 0.99999175 & 135.7120161 \\
\hline Rpl4A & Rpl24B & 0.99991425 & 91.40550506 \\
\hline Rp14A & Rpl19A & 0.9999314 & 201.5824901 \\
\hline Rpl4A & Ski2 & 0.9999908 & 142.4126836 \\
\hline Rps11B & $\operatorname{Imd} 4$ & 0.99994218 & 62.08230108 \\
\hline Rps11B & Rpl19A & 0.99982825 & 103.8102619 \\
\hline Rps11B & eIF2A & 0.99995313 & 151.2018606 \\
\hline Rps23A & Rpl24B & 0.99976657 & 81.41631653 \\
\hline Rps29B & Bim1 & 0.99966736 & 174.9447817 \\
\hline Rps9B & Rpl24B & 0.99983289 & 73.69953209 \\
\hline Rub1 & Kar2 & 0.93914807 & 81.26272949 \\
\hline Sam1 & Ymr085W & 0.96745576 & 94.36699818 \\
\hline $\operatorname{Tdh} 2$ & Rts1 & 0.99998268 & 77.41720131 \\
\hline
\end{tabular}




\begin{tabular}{cccc} 
Tdh2 & Irc15 & 0.99997338 & 90.04963392 \\
Tdh2 & Tdh2 & 0.99995917 & 237.8580776 \\
Tif2 & Eft1 & 0.99998707 & 79.19121145 \\
Tsa2 & Bre5 & 0.99995444 & 125.0420198 \\
Ubp13 & Rpl24B & 0.9999596 & 70.99859607 \\
Ycr087C-A & Hta1 & 0.99973583 & 105.2068419 \\
Ygl081W & Ymr085W & 0.96176587 & 113.0516841 \\
Ymr085W & Isr1 & 0.96054525 & 123.8596727 \\
Ymr085W & Bre5 & 0.96948957 & 126.8446458 \\
\hline
\end{tabular}




\subsection{Autophagy Inhibition}

Our NSD screen produced several gene candidates that are involved in autophagy. The autophagy pathway is induced under cellular stress to recycle organelles, proteins, mRNA, and various other cellular compounds to maintain cellular homeostasis. Interrupting autophagy has been demonstrated to result in lysosomal disorders in humans.

From the list of the identified gene candidates we chose two candidates to perform in-depth experimentation: $\operatorname{atg} 12 \Delta$ and $v p s 30 \Delta$. The Atg12 protein is a member of the Ublc system ${ }^{80}$. This system also includes Atg8 as a second member. Notably, our screen did not produce $A T G 8$ as a gene candidate. In the future, it would be of interest to examine the involvement of $A T G 8$ in NSD. The Ublc system functions in APS formation, and is essential to the autophagy pathway. The vps30 candidate is an oncogene in humans (Beclin1). The loss of functionality for VPS30 has been shown to lead to the onset of various cancers in humans. It is for these reasons that $\operatorname{atg} 12 \Delta$ and vps30 were chosen for further study. We first needed to confirm that autophagy is inhibited in $\operatorname{atg} 12 \Delta$ and $v p s 30 \Delta$.

To confirm the observed increase in growth of $\operatorname{atg} 12 \Delta$ and $v p s 30 \Delta$ under selection conditions from our large-scale screen, we plated a serial dilution series of our two potential autophagy candidates onto selective media (-URA control, and the -HIS $+1 \mathrm{mg} / \mathrm{mL} 3 \mathrm{AT}$ stress condition). The results from this spot test analysis can be found in figure 5. All cells grow equally on the control -URA plates indicating that the same number of cells are plated. Importantly, the stress conditions demonstrate that the WT cannot appear to grow, whereas $\operatorname{atg} 12 \Delta, v p s 30 \Delta$, and ski7 $\Delta$ all have some growth. Both vps30 $\Delta$ and ski7 $\Delta$ appear to have comparable growth, whereas atg $12 \Delta$ appears to

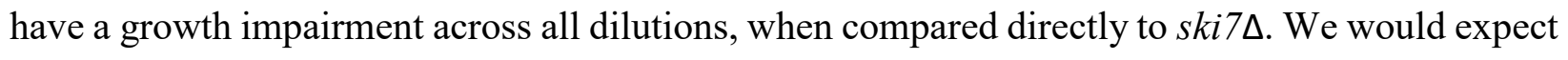
the lack of growth under -HIS + 3AT selection conditions because the WT should have all 
degradation pathways intact. Therefore, all nonstop mRNA and proteins should be degraded, leaving no source of His 3 or histidine for the cells to use for growth. This observation from our spot test analysis confirms that our selected gene deletions appear to give the cells the ability to grow under $-\mathrm{HIS}+3 \mathrm{AT}$ and hence might influence NSD. 


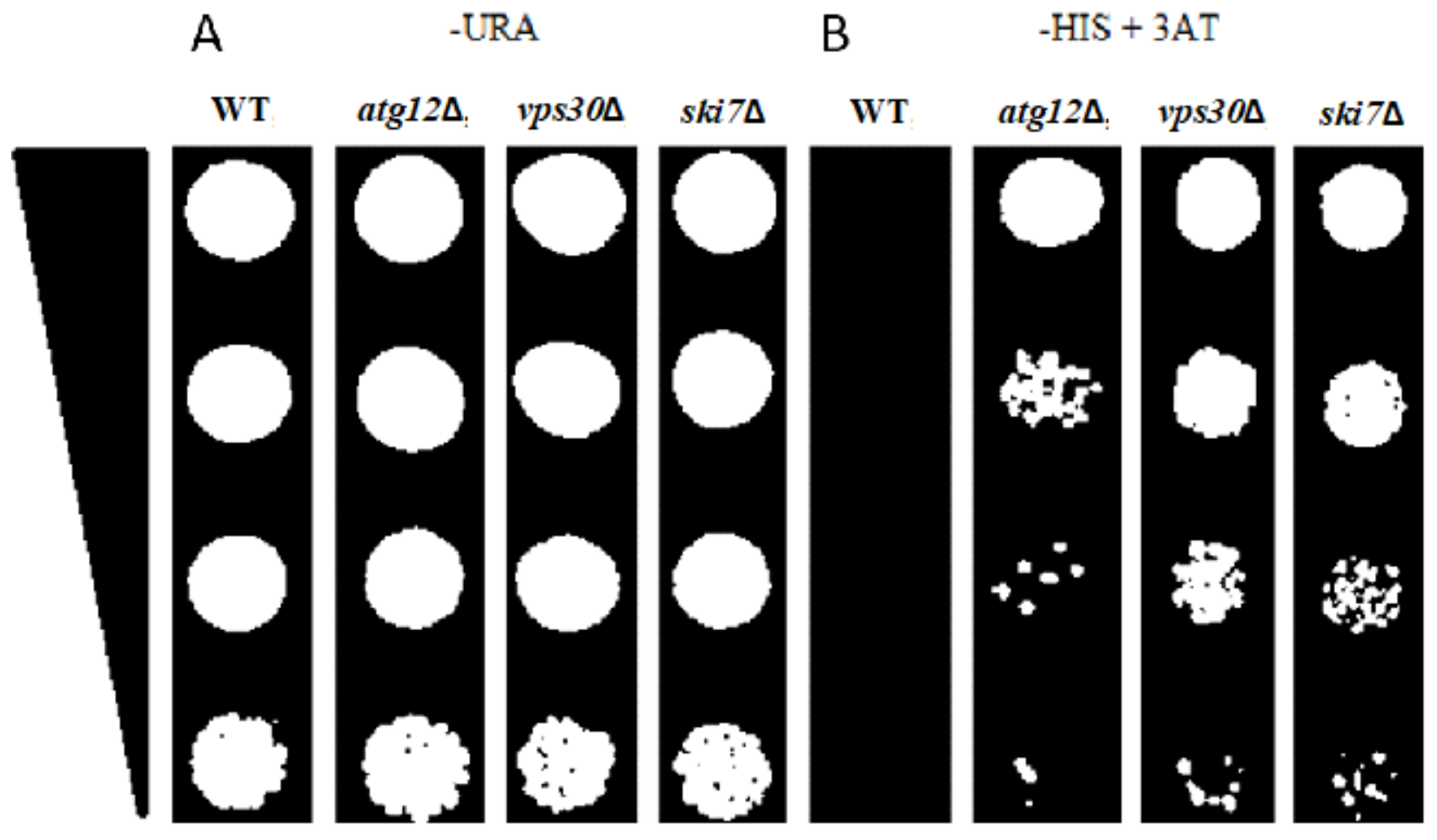

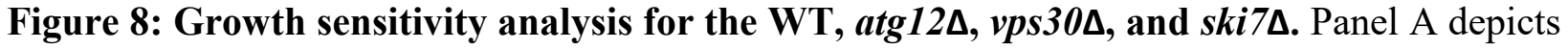
the 4 samples growing on media lacking uracil as a control. Panel B depicts the 4 samples growing on media lacking histidine, and in the presence of $1 \mathrm{mg} / \mathrm{mL} 3 \mathrm{AT}$. Each sample has been through a serial dilution, starting at $10^{-1}$ cells, and finishing at $10^{-4}$ cells. 
To confirm that autophagy is inhibited in $\operatorname{atg} 12 \Delta$ and $v p s 30 \Delta$, we used the autophagy inhibitor verteporfin $^{69}$. We hypothesize that we would not see any effect of VP on growth in the autophagy mutants, as autophagy is presumably already inhibited. We first sought to find the ideal concentration of VP to use in our experiments. Ranging from $1 \mathrm{mM}$ to $100 \mathrm{mM}$ (the exact concentration range is $0 \mathrm{nM}, 1 \mathrm{nM}, 10 \mathrm{nM}, 50 \mathrm{nM}, 100 \mathrm{nM}$ ), we found a convincing dose-response relationship to the concentration of VP and the growth of the WT. In our WT strain, we presume that all cellular machinery is functioning properly. Therefore, the application of VP to the WT in various concentrations should affect the growth of the WT. We found that as the concentration of VP increases, so does the growth of the WT. We then applied the same VP concentration range to

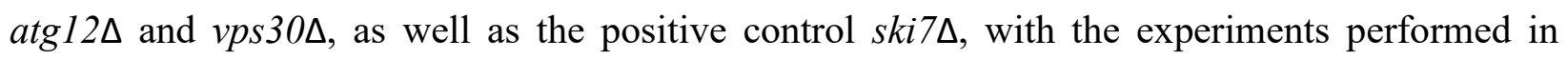
triplicate. The results from the autophagy inhibition can be found in figure 6. As predicted, there appears to be no influence of VP on the growth of $\operatorname{atg} 12 \Delta$ and $v p s 30 \Delta$. Interestingly, this appears to be the same trend with our control ski7ه which was unexpected as we would expect the

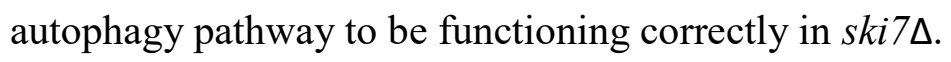



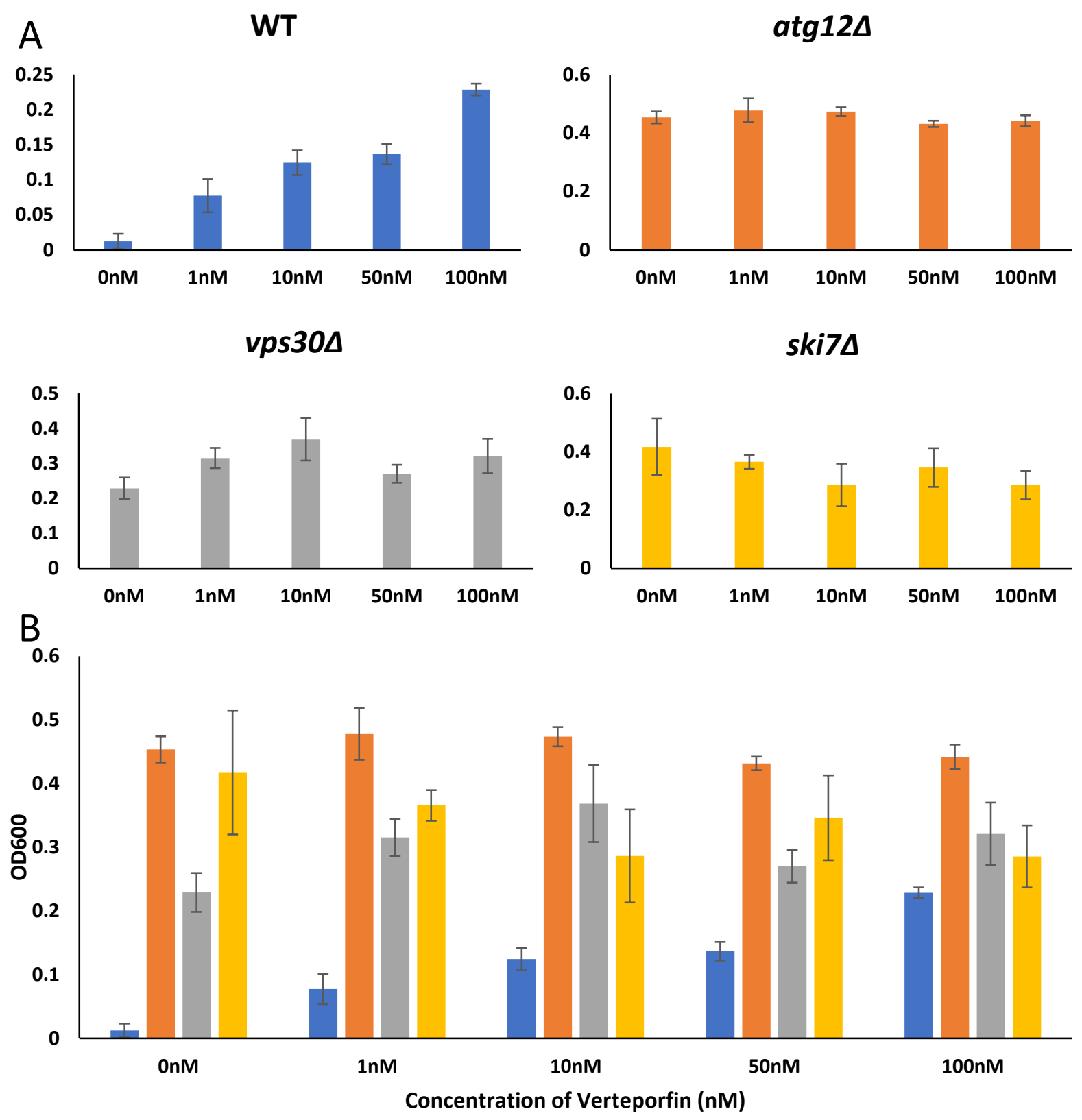

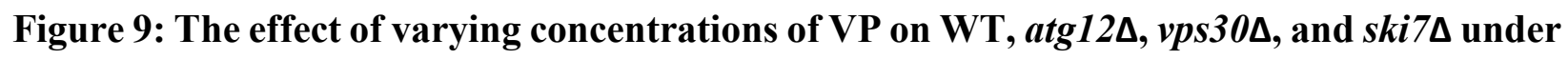
-HIS + 1mg/mL 3AT stress conditions. There appears to be a dose-response relationship in the WT. The greater the concentration of VP, the greater the growth. We used the same concentration

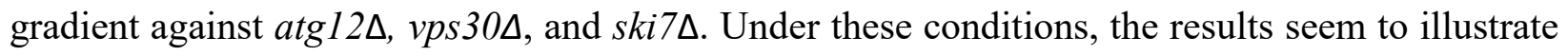
that VP does not influence the growth of the autophagy mutants and the positive control. We 
interpret this as confirming that autophagy is indeed inhibited in $\operatorname{atg} 12 \Delta$ and $v p s 30 \Delta$. If these were not autophagy mutants, then they would likely demonstrate the same dose-response relationship seen in the WT. To see the relationship between all the samples, panel B is the combined sample graphs. All errors are calculated using the standard error of the population. 


\subsection{Nonstop mRNA content analysis for target yeast strains}

The turnover of mRNA is essential to the viability of the cell. Under certain conditions, the cell may be required to upregulate the expression of a given gene, thus producing an increased amount of mRNA and protein. As well, when the mRNA is no longer needed, the cell will degrade it. Similarly the presence of a defective mRNA needs to be regulated. If defective mRNAs were to be translated, it is likely that a defective protein could be produced. Having a defective protein in the cell is not only energy deficient but also could result in cellular dysfunction. Monitoring mRNA quality, production and abundance is therefore an important area of research.

Based on the results from our screen, and confirming autophagy inhibition in $\operatorname{atg} 12 \Delta$ and $v p s 30 \Delta$, we decided to study the NS-his3 mRNA abundance in all mutant and the WT strains. For this we used qRT-PCR analysis. The results from this experiment can be found in figure 10 . We investigated relative expression of the mRNA rather than absolute abundance. All values are relative to the WT. Holding with the overall theory of NSD, the ski7 deletion appears to result in a vast accumulation of NS-his3 mRNA (32.73 units). Interestingly both $\operatorname{atg} 12 \Delta$ and vps30 appear to have a decreased amount of NS-his 3 mRNA ( 0.27 and 0.52 units respectively) relative to the WT. PGK1 was used as a reference mRNA. The standard curve for qRT-PCR can be found in the appendix (Figure A1). 


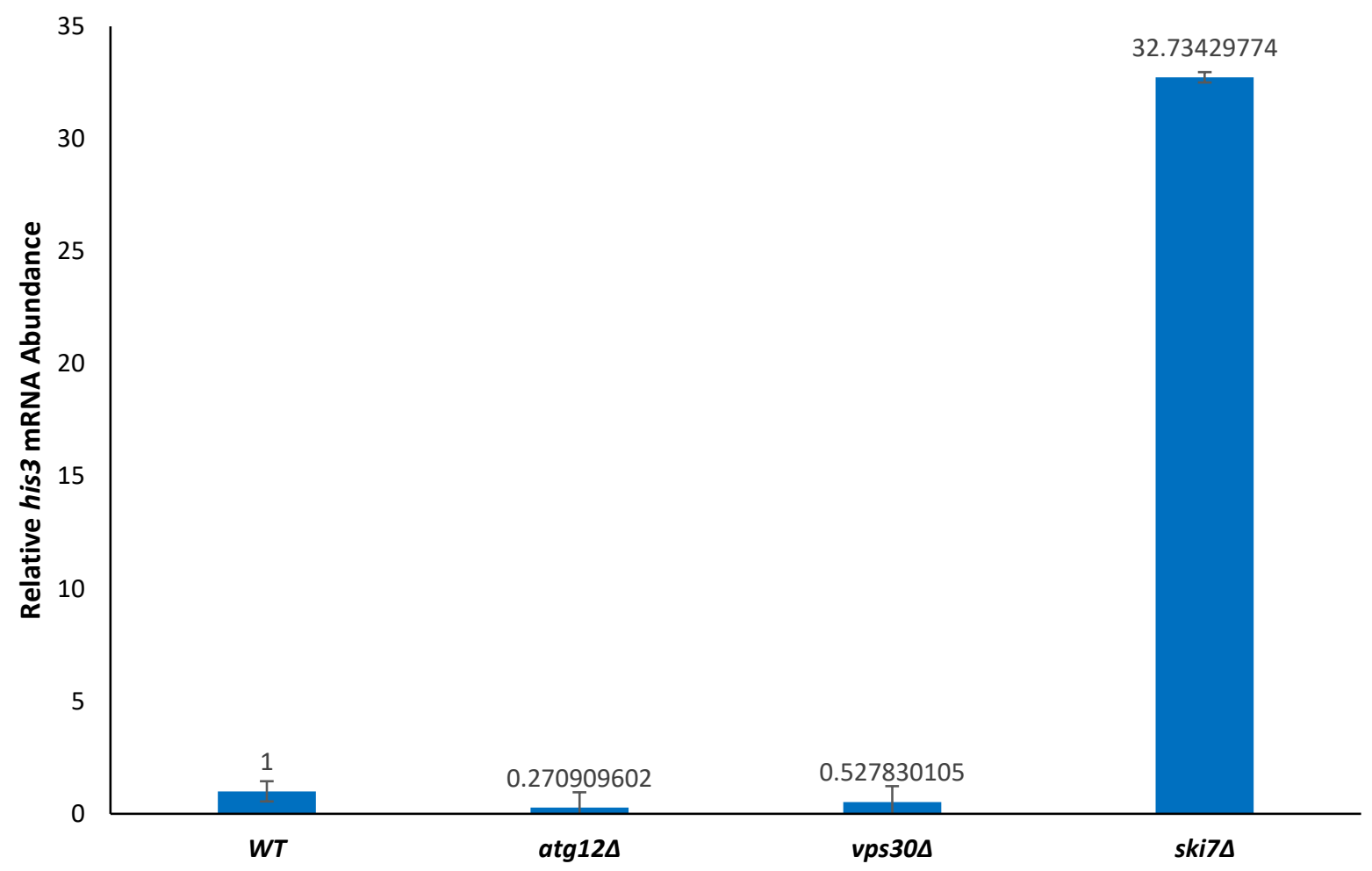

Figure 10: The relative nonstop his3 mRNA abundance for WT, atg12 Using the WT as a baseline, our results seem to indicate a reduced abundance of nonstop mRNA in both the atg 12 and vps30 deletions. Considering that the SKI7 NSD pathway is supposedly intact in the autophagy mutants, this result indicates that the nonstop mRNA is still being degraded, possibly through the SKI7 pathway. Our results illustrate a 32 -fold increase in nonstop mRNA in the ski7 deletion. The error was calculated using the normalized standard error of the population. 


\subsection{Nonstop protein content analysis for target yeast strains}

Proteins carry out the majority of cellular functions. Therefore, the cell evolved processes to regulate the expression of these proteins, which are in a dynamic state of flux. Focussing on their degradation, the cell has two main proteolytic pathways: the ubiquitin proteasome, and lysosomal degradation. The proteasome is comprised of several protein subunits, all of which function to degrade targeted proteins. The target molecule of this system is a small protein referred to as ubiquitin. This molecule recognizes long polylysine tracks on misfolded or otherwise aberrant proteins. Once targeted for degradation, the ubiquitinated protein is then trafficked to the proteasome for degradation. The additional degradation system is through the lysosome. Aberrant proteins have been shown to localize to the APS, which will then fuse to the lysosome. Within the lysosome are various proteolytic enzymes that will complete the degradation of the targeted proteins. What is not known is how proteins are differentiated between the proteasome and the lysosome, marking an important area to study.

Considering that our qRT-PCR results indicate that there is low abundance of nonstop mRNA in the autophagy mutants relative to the WT, we hypothesized that we may see an increase in the abundance of nonstop His 3 proteins. The fusion product of the pSA159 plasmid contains a GFPFLAG fusion tag fused to the nonstop his 3 . We therefore probed for GFP. The abundance of GFP to His3 should be 1:1. It should be noted that we cannot anticipate the effect of the polylysine track on the folding of the nonstop His 3 protein. The results from the western blots can be found in figure 8. Relative to the WT, there appears to be an increase in the abundance of GFP in the atg12 and ski $7 \Delta$ mutants. Interestingly, the vps $30 \Delta$ mutant appears to have a similar abundance of protein relative to the WT. 


\section{GFP Control \\ WT $\operatorname{atg} 12 \Delta p s 30 \Delta$ ski7s}

Anti-GFP

$\sim 27 \mathrm{kDa} \rightarrow$

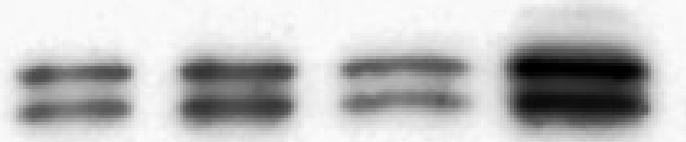

$\leftarrow \sim 28 \mathrm{kDa}$

Anti-Pgk1

$\leftarrow \sim 45 \mathrm{kDa}$

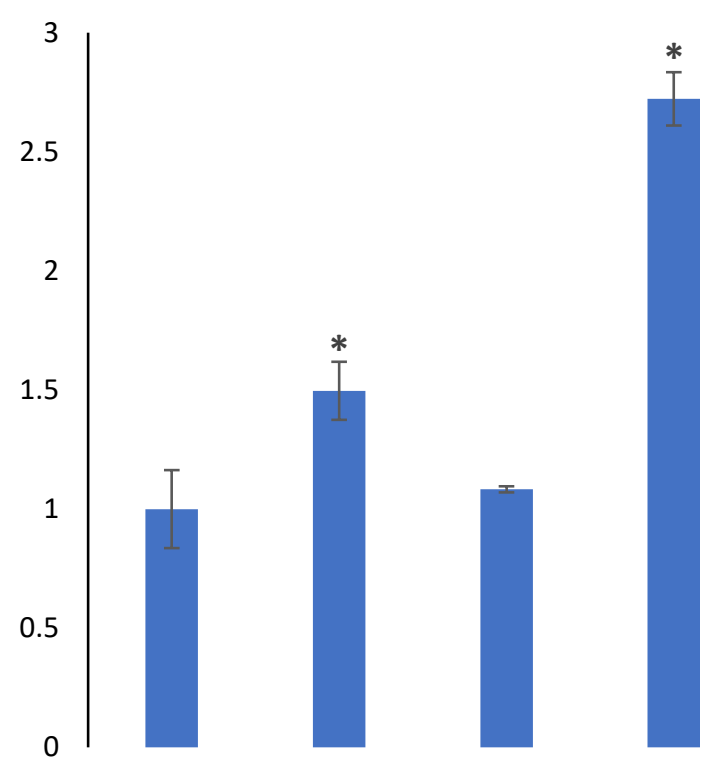

Figure 11: The apparent nonstop protein abundance of the WT, atg12

We used anti-GFP to probe for the fusion product of the pSA159 plasmid, and anti-Pgk1 as an endogenous control. Relative to the WT, there appears to be an increase in nonstop protein in the atg12 and ski7 deletions. These results suggest that in the atg 12 deletion, that nonstop proteins may be accumulating, as well as in the ski7 deletion. Interestingly, we see a similar amount of protein 
in the vps30 deletion relative to the WT. This suggests that nonstop proteins may still be degraded in vps30 deletions, signifying that the functionality of Vps30 may be a trafficking protein. Further studies should be performed to further uncover the link between nonstop protein accumulation and autophagy. Significant difference is denote with an asterisk (*). Errors were calculated using the standard error of the population. 


\section{Chapter 4: Discussion and Conclusion}

\subsection{Large-Scale NSD Screen}

In 2002, Pamela Frischmeyer and collages discovered a novel RNA degradation pathway, which they named nonstop decay ${ }^{81}$. They speculated that mRNA lacking stop codons was fundamentally different from NMD, and the other RNA decay pathways, and should be considered as its own pathway. Later that year, Ambro van Hoof discovered that the SKI7 gene seems to be involved in the mRNA NSD pathway, as its deletion would result in an increased abundance of nonstop $\mathrm{mRNA}^{81}$.

In 2007, van Hoof performed a genome wide screen in yeast to identify new genes involved in NSD, of which they found 16 gene candidates ${ }^{61}$. Later in 2010, Bengston and Joazeiro discovered that nonstop proteins localized to the ubiquitin proteasome system for degradation using candidates produced by van Hoofs screen ${ }^{65}$.

Here, we performed a genome wide screen in yeast using the pSA159 plasmid (obtained from Bengston and Joazeiro), which contains a nonstop his 3 translational marker. We then preformed our own screen using pSA159 to find new genes involved in NSD. In this way, we looked for gene that when deleted the cells where capable of growing in a -HIS media, supposedly as a result of failed NSD. Our screen produced 446 gene candidates that may be involved in the NSD pathway. To ensure the accuracy of the screen, we replicated the results in triplicate to confirm that the results are accurate, \pm 20 colonies. The gene candidates themselves seem to occur in several processes. We decided to only consider a cluster of genes to be a family if 3 or more genes within that family occur in our screen. When we restrict our gene candidates to this definition of a family, our screen produced 7 major gene families. These families include Autophagy Related Genes (ATG), Pheromone-Regulated Protein (PRM), Vacuolar Protein Sorting (VPS), Phosphate 
Metabolism (PHO), genes Found in Mitochondrial Proteome (FMP), and pexophagy (PEX) genes. As well, the screen also produced all known components of the yeast SKI exosome which includes SKI2, SKI3, SKI7, and SKI8 lending evidence to the accuracy of our screen. Further, we also observed the LTNI gene in our screen, which is an important as pSA159 was used in the Bengston study which identified the LTNI gene as a key player in nonstop protein degradation.

\subsubsection{Autophagy Related Genes:}

The ATG gene family produced from the screen include: ATG12, ATG13, and ATG21. As mentioned previously, the Atg12 is a component of the ublc system comprised of both the Atg8 and Atg12 systems ${ }^{80}$. In short, Atg12 mediates the lipidation of Atg8 which in turn will complete the production of an APS from the PAS ${ }^{80}$. The $A T G 13$ gene has been shown to activate the Atg1 protein under nutrient depletion, activating the autophagy pathway ${ }^{75}$. It is also required for vesicle formation and the recruitment of Atg14 to the $\mathrm{PAS}^{75}$. Lastly, $A T G 21$ is required for vesicle formation, as well as localization of the Atg8 $\operatorname{protein}^{82}$. It is well known that autophagy is a degradative process, and that aberrant mRNA and proteins localize to the APS for degradation and recycling ${ }^{19}$. Autophagy has already been linked to $\mathrm{NMD}^{16}$. It is therefore intriguing that this process seems to occur in our screen. The potential link between NSD and autophagy is further expanded in section 4.2 below. 


\subsubsection{Pheromone Regulated Proteins:}

The Pheromone Regulated Proteins (PRM) are proteins that are heavily involved in cell wall synthesis, mating, intracellular trafficking, and sporulation ${ }^{83}$. In our screen, we produced 3 Prm gene candidates: PRM1, PRM4, and PRM9. These three genes all have been reported to have a function in mating and trafficking, but mainly in sporulation. The link between RNA decay and sporulation is less clear. Sporulation in yeast is synonymous to gamete production in humans, in that the parental DNA is being passed on to the F1 generation. To understand the potential relationship between NSD and sporulation, we should consider the evolutionary point of view.

The evolution and integrity of a species is dependent on the environment. The basic principle of evolution considers that for a species to survive, the offspring must be able to adapt to a novel environment. If the offspring cannot survive, the parental genome is not allowed to pass through subsequent generations. However, if the offspring can survive, it must contain a beneficial mutation that allows the offspring to adapt to the environment. Now that the offspring is allowed to survive, it can pass on its genotype to the new generation in a process that continues until the entire species contains that single beneficial mutation.

The process of NSD will remove mutated mRNA and misfolded proteins. If this process is interrupted, then the offspring may express mutated mRNA into misfolded nonstop proteins, which may impact the functionality of the cell. This may in turn not allow the offspring to survive its environment.

A study performed by Bodi et al in 2010 indicated that bulk mRNA during sporulation is methylated $^{84}$. The process of methylation will silence the expression of the mRNA, thereby not 
allowing the corresponding proteins to be produced. Many genes have yet to be identified in this process.

If the methylation process is interrupted during sporulation, genes that should not be expressed normally will become expressed, which could lead to interference in the tightly regulated sporulation process. Given the importance of regulating sporulation, and that bulk mRNAs are silenced during the process, there may be an evolutionary explanation to the potential link between NSD and sporulation that is suggested by our screen. The cell will need to silence all mRNA transcripts that do not directly related or function in the sporulation process, including nonstop transcripts. It is therefore possible that at the evolutionary level, the cell will silence the nonstop mRNA to maintain genome integrity to ensure the survival of the offspring. When the prm 1, prm 4 , and prm 9 deletions are transformed with pSA159, they display the nonstop phenotype indicating that the nonstop his 3 gene on the plasmid is being expressed. This may indicate that the Prm genes are involved in the degradation of the nonstop his3, its silencing, or possibly cell trafficking.

An additional hypothesis is that $P R M 1, P R M 4$, and $P R M 9$ are all involved, in some capacity, in cellular trafficking. The intracellular trafficking of proteins is integral to the cell function. If a protein is misplaced, or is dysfunctional, the cell will suffer. Considering the functions of the PRM candidates, which includes membrane fusion and COPII binding ${ }^{85,86}$, it is likely that these proteins are involved in trafficking. If the intracellular trafficking is impaired, degradation of the nonstop protein may also be affected. Specifically, it might be possible that our 3 Prm gene candidates produce proteins that are involved in aberrant protein trafficking. Further studies are needed to determine the link between the Prm candidates and NSD, which may be one of the suggested hypotheses here. 


\subsubsection{Vacuolar Protein Sorting:}

The trafficking of proteins to their destinations is essential for the protein to carry out its function. The cell has developed trafficking procedures that ensure the targeted protein will carry out its correct function. If at the destination the protein is dysfunctional, the cell will suffer accordingly. It is therefore extremely important for the protein to undergo post-translation modification through the endoplasmic reticulum and the Golgi apparatus. After translation has occurred at the rough ER, the nascent protein is tagged with a localization signal, which will re-localize the protein to the Golgi apparatus - the sorting centre of the cell. It is here that the protein will be modified, and eventually shipped to its destination. If there are misfolded proteins, they are targeted for degradation, and shipped to the proteasome or the vacuolar lysosome for degradation. The Golgi apparatus itself is comprised of several distinct areas: the cis entry face, the cisternae, and the trans exit face. Proteins will enter through the cis face in COPII coated clathrin vesicles, which promote anterograde transport from the ER to the Golgi. After the initial protein sorting, the proteins will be sent to their destinations.

In the case of nonstop proteins, the appearance of $V p s$ in our screen genes is rather intriguing. VPS proteins all have a similar function in that they will aid in the transport of proteins from the Golgi to the vacuolar lysosome in yeast. Our screen found several Vps gene candidates: VPS21,VPS30, VPS55, and VPS74. The VPS21 candidate has a paralog YPT53 (Yeast Protein Two), both of which function in protein transport ${ }^{87}$. Whatsmore, VPS21 is involved (but not required for) autophagy Interestingly, the VPS30 gene candidate is essential for autophagy. Additional aliases for VPS30 include $A T G 6$ which is an ortholog of the human oncogene BECN (Beclin 1) ${ }^{88}$. VPS30 itself is required for protein sorting and is required for the degradation of misfolded proteins. Lesser is known about the VPS55 gene candidate. What is known is that the corresponding protein is 
involved in endosomal trafficking to the vacuole ${ }^{89}$. Interestingly, VPS55 is a homolog of the human obesity gene $O B-R G R P^{89}$. The final Vps gene candidate produced by our screen is VPS74. The resulting protein is involved in intra-Golgi trafficking, and is an ortholog of the human GOLPH3/GPP34/GMx33 gene ${ }^{90}$.

The potential relationship between VPS proteins and NSD may be straightforward. It is possible that the degradation of nonstop transcripts may not directly influence the level of corresponding nonstop proteins, as the nonstop polypeptide may be more stable under a given condition (for example when they are less likely to be degraded). The nonstop protein may therefore be translated at the rough ER, and subsequently transported to the Golgi apparatus for sorting. However, the Golgi should recognise the misfolded nonstop protein (as the addition of a polylysine track will presumably affect the folding of the protein), and send it for degradation. The VPS proteins may then theoretically transfer the nonstop protein to the vacuolar lysosome for recycling. Our screen demonstrates that when the cell loses one of these four genes, that the nonstop his 3 can be expressed, possibly at the protein level. If this is the case, this may implicate the Golgi apparatus and the vacuolar lysosome in the degradation of nonstop proteins, a result that has yet to be reported to this point. 


\subsubsection{Phosphate Metabolism:}

The importance of phosphate to the cell to carry out is activity is obvious. In the absence of phosphate, the cell will not be able to carry out basic functions such as generating ATP. In addition, many signalling pathways that depend on the addition of ATP will no longer function (or be dysfunctional), rending various signal cascades ineffective. Further, the cell will not be able to grow, or undergo replication. In a phosphate-deficient environment, the cell will need to restrict multiple processes in order to survive.

Our NSD screen revealed four gene candidates involved in phosphate metabolism: $\mathrm{PHO} 4, \mathrm{PHO} 3$, PHO80, and $\mathrm{PHO} 84$. The $\mathrm{PHO} 4$ gene candidate functions under phosphate limitation to activate genes involved in phosphate limitation response ${ }^{91}$. $\mathrm{PHO} 33$ is a transcriptional regulator of the PHO5 gene, which functions in the hydrolysis of extracellular nucleotides ${ }^{92}$. The $P H O 80$ is a cyclin that mediates the functionality of the cyclin-dependent kinase Pho85 ${ }^{93}$. The Pho85 functions to regulate cell cycle progression as well as in the regulation of the phosphorylation of $\mathrm{PHO}^{91}$. PHO80 is also heavily involved in the response to phosphate and nutrient limitation due to changing environmental conditions. Lastly, $\mathrm{PHO} 4$ is a metal transporter that is regulated by Pho $4^{94}$. It has been reported that loss of $\mathrm{PHO} 44$ has resulted in the accumulation of heavy metals ${ }^{94}$.

The link between NSD and phosphate metabolism is not initially clear. The 4 gene candidates all display the nonstop phenotype in that they express the nonstop his 3 gene, indicating that it is not being degraded on either the transcript or protein level. To gain insight into this process, let us look at the gene candidate $\mathrm{PHO} 3$. Loss of pho23 may result in dysregulation of the PHO5 gene potentially impacting the functionality of Pho5. We know that Pho5 functions in nucleotide hydrolysis, presumably to generate a source of phosphate under phosphate limitation. Considering that the PHO23 candidate displays the nonstop phenotype, this could indicate that Pho5 may 
degrade nonstop proteins under phosphate limitation. Pho5 is regulated by Pho4, one of our phosphate metabolism candidates. Considering the entirety of the 4 candidates produced by the screen, there appears to be a common link: Pho5.

The possibility of a signal cascade between Pho gene candidates may lead to the degradation of nonstop RNA under nutrient limitation. We know that the function of Pho80 is to activate the Pho85, and that Pho85 activates $\mathrm{PHO}$. Both $\mathrm{PHO} 4$ and $\mathrm{PHO} 3$ are transcriptional regulators of the Pho5, which has been reported to extract phosphate from extracellular nucleotides. With this apparent cascade between the NSD candidates (Figure 9), I suggest that Pho5 is a novel nonstop transcript degrading protein. It is clear that further testing is needed to fully understand the relationship between NSD and the phosphate metabolism gene candidates. 


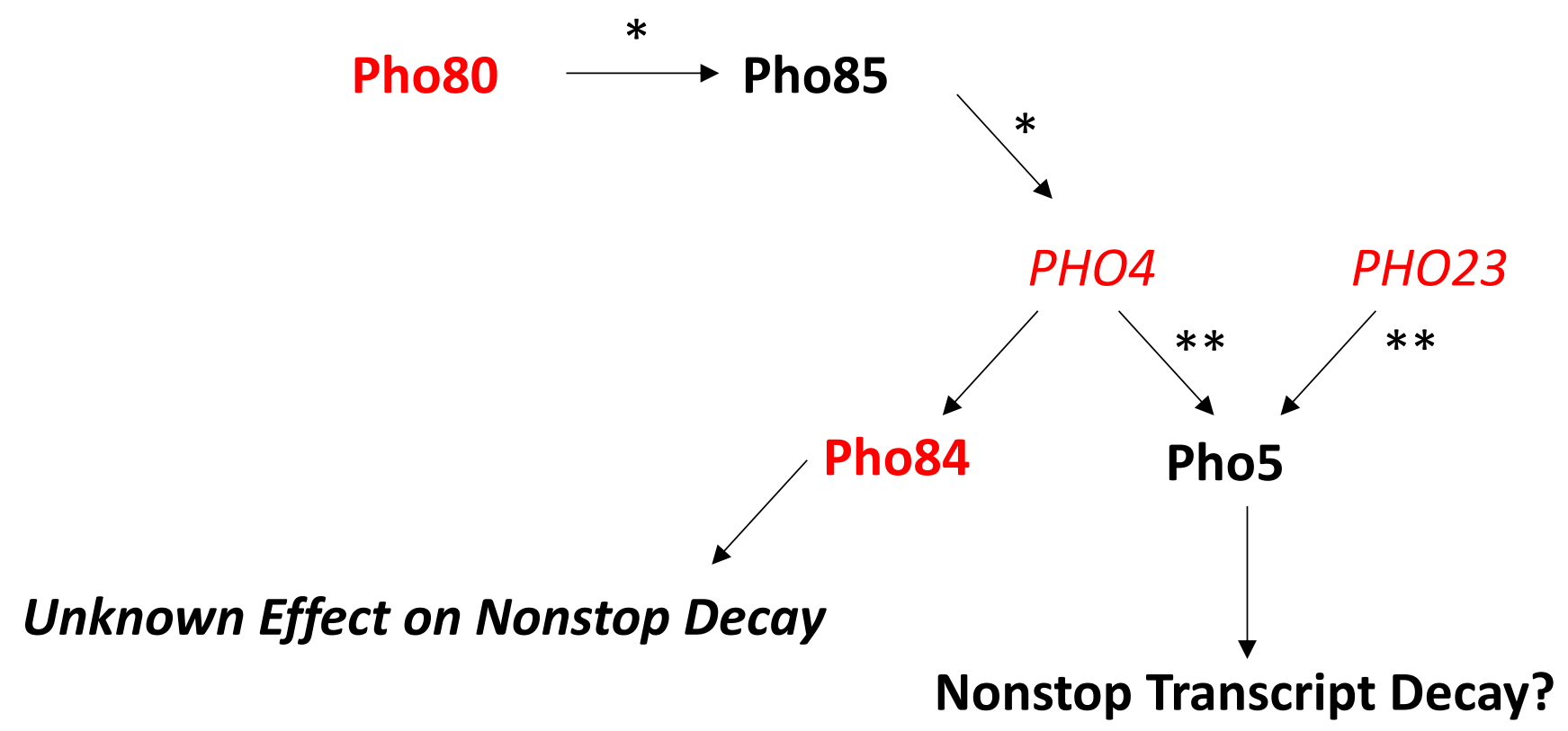

Figure 12: The proposed relationship between NSD and the $P H O$ gene candidates. Red indicates NSD screen candidates. *indicates activation, and **indicates regulation. Loss of the gene candidates may impact the functionality of Pho5, possibly leading to inhibition of mRNA NSD. 


\subsubsection{Found in the Mitochondrial Proteome:}

The production of energy in the form of ATP is the responsibility of the mitochondria. ATP in generated through a series of ion pumps and chaperons that move electrons across the mitochondrial electron transport chain (ETC), eventually culminating in the production of ATP via cellular respiration. The Krebs cycle is the main source of these electrons, which is the process of breaking down the biochemical pyruvate into various isoforms. As it acts as the main energy transducer for the cell, having a dysfunctional mitochondrion can result in various disorders, such as $\mathrm{MNGIE}^{64}$ (described in section 1.3).

Our NSD screen produced seven gene candidates whose products are thought to function within the mitochondrial proteome: FMP14, FMP22, FMP25, FMP26, FMP33, FMP37, and FMP49. The gene candidates FMP22, FMP33, and FMP49 all have unknown functions, and are putative proteins that localize to the mitochondria. Our candidate FMP14 is a component of the F1F0 ATP synthase stalk protein in the ETC, and it has been noted that the loss of this gene results in defects in cellular respiration and energy generation ${ }^{95}$. The product of the FMP25 (BCA1) gene functions in the assembly of the cytochrome bc1 complex ${ }^{96}$. The FMP26 candidate functions in the inner membrane architecture of the mitochondria, and its organization ${ }^{97}$. Finally, the FMP37 candidate is a conserved pyruvate carrier for the mitochondria, and deletions of this gene as associated with the human disorder lactic acidosis ${ }^{98}$.

The 4 mitochondrial candidates that have a known function all seem to participate in ATP production or the ETC. Defects or loss of these gene candidates can affect cellular respiration, which by itself may be an initial hypothesis to relate NSD to the mitochondria. If the mitochondria cannot produce energy for the cell, the cell may shut down all nonessential systems to conserve energy output. This may include NSD, as this pathway may take a lot of energy to degrade both 
aberrant mRNA and proteins. Under energy limitation, it is possible that the cell could shut down this NSD system, thus conserving energy. This would lead to the production of nonstop proteins, thus producing the nonstop phenotype that we see in our screen. It would be interesting to determine the functions of FMP22, FMP33, and FMP37 to see if the gene products function in cellular respiration as well. 


\subsubsection{Peroxisome Related:}

The peroxisome is an endosome that localizes to the vacuolar lysosome for the degradation of peroxide. The peroxide chemical itself can be toxic to the cell, including the induction of the oxidative stress response ${ }^{99}$. This stress response system can go on to affect many other cellular systems, including protein folding and targeting systems through the ER. This, in turn, may affect protein trafficking throughout the cell.

The NSD screen produced three pexophagy genes; PEX14, PEX17, and PEX22. Our PEX14 gene candidate produces its protein product which is a central component of the peroxisome importer complex ${ }^{100}$, and PEX17 is a membrane protein within the importer complex ${ }^{101}$. The PEX22 gene candidate produces a putative peroxisome membrane protein.

A key question is how do defects in peroxide degradation affect NSD? The answer may lie in the oxidative stress response. First, the pexophagy gene deletions from our screen may result in the accumulation of peroxide in the cell. The presence of peroxide can lead to the induction of the oxidative stress response, affecting multiple cellular systems. This in turn will affect protein sorting and trafficking through the ER and the Golgi apparatus. We know that nonstop mRNA will be translated into a nonstop protein. The degradation of the nonstop protein can be carried out through the ubiquitin proteasome, which requires the targeted protein to be sorted. As the sorting and general movement of proteins can require chaperone proteins, it is possible that the oxidative stress response (and the accumulation of peroxide) could lead to chaperone misfolding, possibly affecting cellular trafficking ${ }^{102}$. We speculate here that this is exactly the case with regards to our nonstop protein: the accumulation of peroxide will induce the oxidative stress response, which will negatively affect protein sorting and trafficking of the nonstop protein to the degradation system. 
This will lead to the nonstop protein not being degraded, and can culminate in the accumulation of the nonstop protein, thus generating the nonstop phenotype.

\subsubsection{Screen Confirmation:}

To further test the accuracy of our screen, we selected 378 gene candidates from the screen, and performed growth curves on them to study their growth in liquid media (figure 4). The heat map generated in this way is in essence a confidence map, and will indicate any false positives which are depicted by the colour green. In this way we generated a 40 high confidence gene candidates as reported in table 3 . Consistent with our entire gene candidate list, these top 40 gene candidates seem to be involved in autophagy, trafficking, sporulation, and indirect protein degradation. Of interest the list of top 10 gene candidates identified here includes 5 genes with known influence on autophagy, namely ATG13, MEH1, LST4, ATG12, and VPS30. 


\subsection{A Novel Link Between NSD and Autophagy}

The degradation of the nonstop transcript may occur in a cellular endosome known as an APS similar to nonsense transcripts ${ }^{16}$. In the absence of NMD (which in mammals has been shown to be inhibited in tumor environments, or in the depletion of nutrients ${ }^{16}$ ), nonsense protein may be produced. Once identified, the nonsense protein will then be transported to the APS, which contains proteases. After the protein is degraded, all the nutrients will be recycled in the cell for other functions, making the APS the "recycling centre" of the eukaryotic cell. It is possible, though not supported, that nonstop proteins may also be sent to the APS for degradation. As well, it has been recently demonstrated that stress granules, including P-bodies, are cleared by the APS, indicating that NSD may be interlinked with the APS on both the protein and transcript levels.

\subsubsection{The Addition of Verteporfin does not Influence the Growth of atg $12 \Delta$ or vps $30 \Delta$ : Considering}

that the deletion set used in this thesis could contain additional unintended mutations additional experiments connecting autophagy to NSD are needed. As mentioned previously, the drug verteporfin (VP) is thought to inhibit autophagosome biosynthesis via inhibition of the Atg $14^{103}$, resulting in no formation of autophagosomes in human cells. To this end, we hypothesized that the addition of VP to the autophagy mutants will not have additional affect on their phenotype as they are both hitting the same target. Under standard laboratory condition, the WT strain should contain all degradation machinery, resulting in the degradation of the products of the nonstop his 3 gene. With the addition of VP, autophagy should be inhibited in the WT. This should therefore result in the ability of the WT to use the nonstop his 3 gene, and in fact use its product under stress conditions to survive. As the concentration of VP increases, the inhibition of autophagy appears to increase. We did not find a plateau concentration (the maximum concentration of VP to completely inhibit autophagy), but the dose-response relationship is clearly illustrated (Figure 6). Our hypothesis that 
the addition of VP to our autophagy mutants should not impact their growth also appears to be sound. Across the varying concentrations of VP, the growth of both $\operatorname{atg} 12 \Delta$ and $v p s 30 \Delta$ does not appear to change with the addition of VP. We interpret this as autophagy being inhibited in atg $12 \Delta$ and $v p s 30 \Delta$. Interestingly, we see the same trend in our ski7 $\Delta$ positive control. The addition of VP does not influence the growth of ski7ム. Considering our results with the WT and autophagy mutants, this may indicate some functionality of ski $7 \Delta$ in autophagy. Now that we have confirmed that autophagy is inhibited in $\operatorname{atg} 12 \Delta$ and $v p s 30 \Delta$, we investigated the abundance of nonstop mRNA in different yeast strains. 
4.2.2 Nonstop mRNA Abundance is Unchanged for Autophagy Mutant Strains: If degradation of nonstop mRNA was the target of our autophagy mutant strains, then it would be expected that the content of nonstop his 3 mRNA is increased in autophagy mutants. Figure 7 illustrates our qRT-

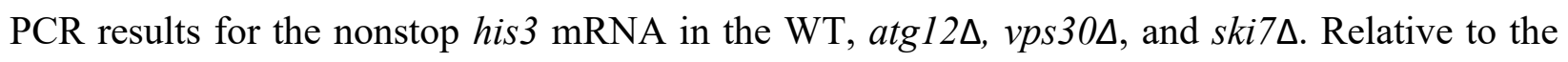
WT, it is very clear that there is a decrease in nonstop mRNA for the autophagy mutants. Our positive control, ski7 $\Delta$ demonstrates a 32 -fold increase in the nonstop mRNA. Considering that the Ski7 is integral to the NSD mRNA decay pathway, this result makes sense. Reduction of nonstop mRNA for autophagy mutants indicates that the target of autophagy doesn't seem to be at the mRNA level.

It is thought that the NSD of mRNA occurs in the cytosol ${ }^{14}$, possibly within P-bodies ${ }^{104}$. The degradation machinery would therefore still be intact in the autophagy mutants, as the Ski7 and exosome are still present. This would allow for degradation to occur. We however originally hypothesized that the abundance of nonstop mRNA would dramatically increase, as we thought that the aberrant mRNA would localize to the autophagosome for degradation. In addition, we thought that autophagy would have some impact on the degradation of the nonstop mRNA because P-bodies do localize to the autophagy pathway for degradation. These points made us believe that we might observe an increase in nonstop mRNA abundance, as if we inhibit APS formation, Pbodies would not be able to degrade the mRNA. It is however very clear to us now that this is not the case, and that the NSD mRNA decay pathway seems intact and functional in the autophagy mutants. If we have interpreted our qRT-PCR results correctly, and there is in fact a lower abundance of nonstop mRNA in the autophagy mutants, then a remaining possibility for mutant strains is that there might be an increase in nonstop protein abundance for the mutants. We therefore decided to investigate nonstop protein abundance through Western Blotting. 
4.2.3 Nonstop Protein Abundance Seems to be Increased in the Autophagy Mutants: The localization of misfolded or otherwise aberrant proteins to the autophagy pathway has been well elucidated, and is generally an accepted form of protein degradation. The targeting of nonstop proteins to the autophagy pathway will allow for the proteolysis and eventual nutrient recycling, allowing for the cell to generate new, intact proteins. Therefore, inhibiting the autophagy pathway may result in the increased abundance of aberrant proteins.

We hypothesize that our nonstop proteins may be localizing to the autophagosome for degradation. Considering that aberrant proteins localize to the autophagy pathway for degradation, we investigated the abundance of nonstop His3 protein within our mutant cells (figure 8). Relative to the WT, we do in fact see an increase in nonstop protein abundance in $\operatorname{atg} 12 \Delta$ and $\operatorname{ski} 7 \Delta$. Interestingly, the vps $30 \Delta$ seems to be of similar abundance to the WT. Our results for Atg12 support the hypothesis that nonstop proteins may localize to the autophagy pathway for degradation. Our result for nonstop protein abundance in $v p s 30 \Delta$ seems to indicate that the nonstop protein is not more abundant than in WT. Considering that $v p s 30 \Delta$ is integral to the autophagy pathway ${ }^{88}$, it is likely that the nonstop protein in vps304 is might be degraded by an independent manner. The study performed by Bengston and Joazeiro indicated that nonstop proteins can localize to the ubiquitin proteasome system for degradation. This may be what is occurring in vps304. Perhaps the cellular conditions produced by the vps30 deletion inhibit the trafficking of targeted proteins to the autophagy pathway, or in other words "block the road". In this case, it is possible that nonstop proteins cannot localize to the autophagy pathway, and instead saturate the ubiquitin-proteasome system, eventually resulting in their degradation. To test this hypothesis, one could use the ubiquitin-proteasome inhibitor MG-132. If our hypothesis is correct, then the addition of this inhibitor should result in the increase of nonstop protein abundance, as there would 


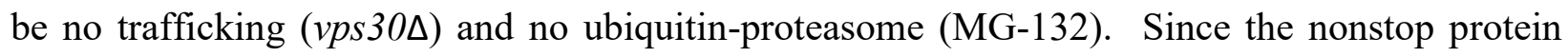
levels for vps304 and WT seems to be the same, it would be of interest to examine the functionality of the proteins. It is possible that a post-translational modification might be responsible for increased activity of the nonstop protein under different physiological conditions. Alternatively, it might be possible that the nonstop proteins in WT may not be accessible where as those in vps304 are accessible and hence fully functional. Regardless, additional experiments are needed to make an informed conclusion.

Our results indicate a double banding pattern across our western membrane at 28 and $27 \mathrm{kDa}$ respectively. This raises the obvious question as to why? The study performed by Bengston and Joazeiro indicated the same banding patterns on their membranes. To understand why we see this pattern, we first should consider what the antibody is targeting on pSA159. The pSA159 nonstop plasmid contains a GFP-FLAG-NShis3 tag, producing the respective polypeptide. Each component weighs approximately $27 \mathrm{kDa}, 1 \mathrm{kDa}$, and $23 \mathrm{kDA}$ respectively. So, the bottom band in the double banding pattern seems to be the cleaved GFP. But what is the $28 \mathrm{kDa}$ band? Within yeast is an enterokinase cleaving enzyme. Upon review of the polypeptide produced from the pSA159 plasmid, we found a single cleavage site at aminoacid 251, between the FLAG and nonstop his3. The enterokinase would then cut at this site, producing two products: GFP-FLAG, and the nonstop his3. The GFP-FLAG weight will be approximately $28 \mathrm{kDa}$ (exact weight is 28.23kDa). This GFP-FLAG cleavage product can therefore account for the top band in the double banding pattern. This also indicates that the nonstop His 3 is cleaved, and should appear at $23 \mathrm{kDA}$. Here we used anti-GFP antibody, so this can explain why we do not see the nonstop His3. 


\subsection{Future Directions, Experimental Improvements, and Conclusion.}

4.3.1 Future Directions: Our screen produced 446 potential gene candidates for NSD in yeast. From these 446 candidates, we found several families that appear to occur in our screen including autophagy, pheromone regulated proteins, vacuolar sorting proteins, phosphate metabolism, the mitochondrial proteome, pexophagy, and the superkiller families. Each one of these families may be the subject of follow-up study for future students. They also highlight the complex network associated with NSD. We have proposed several hypotheses here that may serve as an explanation to how these families relate to NSD. In particular, we were very interested in pursing autophagy, as no one has yet linked NSD to autophagy.

Two cellular trafficking pathways, the Prm and Vps pathways, appear to have some function within the NSD pathway. The intracellular trafficking of proteins, stress granules, and organelles to their prescribed destinations are carried out through these pathways. It is therefore possible that the inhibition or dysfunctionality of these pathways may somehow affect the shipment of aberrant nonstop proteins and P-bodies to the ubiquitin-proteasome and the autophagy pathway.

Our screen results also indicate a link between phosphate metabolism and NSD. Upon review of the functionality of these Pho candidates, there appears to be some preliminary evidence implicating the Pho5 in NSD. The Pho5, under nutrient limitation, will cleave phosphate from extracellular nucleotides, thus providing the cell with energy. Considering the function of Pho5, it is possible that this protein may be a novel NSD mRNA decay factor. Of course, more research is needed to determine this possibility.

The mitochondria is a very important organelle to the cell, as it is the source of the majority of cellular energy. Inhibiting the function of the mitochondria may result in energy limitation, which 
would then require the cell to "turn off" all non-essential systems to conserve energy, which may include NSD.

Lastly, pexophagy is a process that will degrade peroxide. We hypothesize that the accumulation of peroxide will lead to the induction of the oxidative stress response. This will then affect the protein sorting and trafficking throughout the cell. We speculate that this may affect nonstop protein degradation, as the inhibition of trafficking for the nonstop protein could result in the nonstop protein not being degraded, resulting in the nonstop phenotype.

Our results for autophagy indicate that there may be a link to NSD and autophagy, possibly through protein degradation. Our working hypothesis is that nonstop proteins may localize to the autophagy pathway under nutrient stress for degradation, perhaps in combination with the ubiquitin proteasome system. If correct, this would open a new area of research in NSD, as no one has ever linked these two pathways.

4.3.2 Experimental Improvements: To further confirm the accuracy of our gene candidates, it is suggested that all candidates be transformed with additional nonstop plasmids (such as pIT799, pAV184, pTAP NS). In addition, this assay should also be carried out for the initial NSD screen, to confirm that our results are consistent. If our hypothesis is correct, these nonstop plasmids should result in the same phenotype as our pSA159 plasmid. For the autophagy western blots, it might be prudent to use the ubiquitin proteasome inhibition MG-132 to determine if there is an interplay between the degradation of nonstop proteins through autophagy and the ubiquitin proteasome. As well, performing TEM on the autophagy mutants can provide additional confirmation that autophagy is inhibited in these mutants. It is also important to reconstruct the mutant strains to examine if the same phenotype can be observed. In addition reintroduction of 
the deleted gene back into the genome and investigating the reversal of the observed phenotype is highly recommended.

4.3.3 Conclusion: Here, we have performed a genomic screen of the yeast S. cerevisiae to uncover novel genes involved in NSD. A previous screen revealed 16 gene candidates that appear to be involved in NSD, all of which centre around the ubiquitin proteasome. Our screen produced 446 gene candidates, which encompass several cellular processes including autophagy, cell trafficking, metabolism, and cellular respiration. We investigated a potential link between NSD and autophagy, which resulted in an apparent link between these two systems. We hypothesize that nonstop proteins can localize to the autophagy pathway for degradation, possibly in combination with the ubiquitin proteasome. Further testing is needed to confirm the link.

This thesis provides a fundamental starting point for further investigations into NSD. Before this project, the state of the NSD field was limited. Research has suggested that nonstop mRNA is preferentially degraded by the SKI7 NSD pathway, permitting $3^{\prime} \rightarrow 5$ ' decay. As well, the field has also demonstrated that nonstop proteins can localize to the proteasome for degradation. The screen performed by Van hoof also described 16 genes involved in NSD. Our screen has indicated that NSD is considerably more vast than previously thought, encompassing several families and processes including intracellular trafficking, the mitochondria, and metabolic pathways. From a personal point of view, I have learnt about the intricacies of mRNA and protein decay, the proteasome, autophagy, intracellular trafficking, and much more. This project has also given me a new appreciation for the various pathways that are essential to normal cellular function. In particular, the autophagy pathway is fascinating. Before this thesis, I knew very little of this pathway, besides its name and some basic knowledge. Now, I have learnt how autophagy works, and why it is required. This lead me to learning about the TOR pathway, the lysosome, even 
intracellular degradation of bacteria. Whatsmore, I knew very little about the proteasome, and even ubiquitin. I had forgotten that ubiquitin will preferentially bind to polylysine tracks - a hallmark of nonstop proteins. The first paper that I read on NSD was the paper by Bengston and Joazeiro. To be honest, I had no idea what was happening in that paper. Now, reading this paper again and other like it, I completely understand what is happening, and this is due to the knowledge I have gained over the course of this project. Today, this project has indicated that the field of NSD potentially contains many moving parts. Each gene candidate provided here can become a novel hypothesis for the NSD pathway. In particular, this study produced several gene families that are of interest, and require further study to confirm their link to NSD. 


\section{Bibliography}

1. Huang, L. et al. RNA Homeostasis Governed by Cell Type-Specific and Branched Feedback Loops Acting on NMD. Mol. Cell 43, 950-961 (2011).

2. Hanahan, D. \& Weinberg, R. A. Hallmarks of cancer: The next generation. Cell 144, 646674 (2011).

3. Garneau, N. L., Wilusz, J. \& Wilusz, C. J. The highways and byways of mRNA decay. Nat. Rev. Mol. Cell Biol. 8, 113-126 (2007).

4. Chen, C. Y. A. \& Shyu, A. Bin. Mechanisms of deadenylation-dependent decay. Wiley Interdiscip. Rev. RNA 2, 167-183 (2011).

5. Furuichi, Y. Discovery of m(7)G-cap in eukaryotic mRNAs. Proc. Jpn. Acad. Ser. B. Phys. Biol. Sci. 91, 394-409 (2015).

6. Halbach, F., Reichelt, P., Rode, M. \& Conti, E. The yeast ski complex: Crystal structure and rna channeling to the exosome complex. Cell 154, 814-826 (2013).

7. Lykke-Andersen, S. \& Jensen, T. H. Nonsense-mediated mRNA decay: an intricate machinery that shapes transcriptomes. Nat. Rev. Mol. Cell Biol. 16, 665-677 (2015).

8. Bordeira-Carriço, R., Pêgo, A. P., Santos, M. \& Oliveira, C. Cancer syndromes and therapy by stop-codon readthrough. Trends Mol. Med. 18, 667-678 (2012).

9. Parker, R. \& Sheth, U. P Bodies and the Control of mRNA Translation and Degradation. Mol. Cell 25, 635-646 (2007).

10. Teixeira, D. \& Parker, R. Analysis of P-Body Assembly in Saccharomyces cerevisiae. Mol. Biol. Cell 18, 2274-2287 (2007). 
11. Chang, Y.-F. F., Imam, J. S. \& Wilkinson, M. F. The nonsense-mediated decay RNA surveillance pathway. Annu. Rev. Biochem. 76, 51-74 (2007).

12. Inada, T. Quality control systems for aberrant mRNAs induced by aberrant translation elongation and termination. Biochim. Biophys. Acta - Gene Regul. Mech. 1829, 634-642 (2013).

13. Harigaya, Y. \& Parker, R. No-go decay: A quality control mechanism for RNA in translation. Wiley Interdiscip. Rev. RNA 1, 132-141 (2010).

14. Klauer, A. A. \& van Hoof, A. Degradation of mRNAs that lack a stop codon: A decade of nonstop progress. Wiley Interdiscip. Rev. RNA 3, 649-660 (2012).

15. Hoof, A. Van, Frischmeyer, P. A., Dietz, H. C. \& Parker, R. Exosome-Mediated Recognition and Degradation of mRNAs Lacking a Termination Codon. Science (80-. ). 295, 2262-2264 (2002).

16. Wengrod, J. et al. Inhibition of nonsense-mediated RNA decay activates autophagy. Mol. Cell. Biol. 33, 2128-35 (2013).

17. Weischenfeldt, J. et al. NMD is essential for hematopoietic stem and progenitor cells and for eliminating by-products of programmed DNA rearrangements. Genes Dev. 22, 13811396 (2008).

18. Moqtaderi, Z., Geisberg, J. V \& Struhl, K. Secondary structures involving the poly(A) tail and other 3' sequences are major determinants of mRNA isoform stability in yeast. Microb. cell 1, 137-139 (2014).

19. Buchan, J. R., Kolaitis, R. M., Taylor, J. P. \& Parker, R. Eukaryotic stress granules are 
cleared by autophagy and Cdc48/VCP function. Cell 153, 1461-1474 (2013).

20. Ciechanover, A. Intracellular protein degradation: From a vague idea through the lysosome and the ubiquitin-proteasome system and onto human diseases and drug targeting. Cell Death Differ. 1178-1190 (2005). doi:10.1016/j.bmc.2013.01.056

21. Lilienbaum, A. Relationship between the proteasomal system and autophagy. Int. J. Biochem. Mol. Biol. 4, 1-26 (2013).

22. Hanahan, D. \& Weinberg, R. A. The Hallmarks of Cancer Review. Cell 100, 57-70 (2000).

23. Rubinsztein, D. C. The roles of intracellular protein-degradation pathways in neurodegeneration. Nature 443, 780-786 (2006).

24. Rocha, N. P., Reis, H. J., Vanden Berghe, P. \& Cirillo, C. Depression and cognitive impairment in Parkinson's disease: A role for inflammation and immunomodulation? Neuroimmunomodulation 21, 88-94 (2014).

25. Crotti, A. et al. The choreography of neuroinflammation in Huntington's disease. Trends Immunol. 36, 364-73 (2015).

26. Wyss-Coray, T. \& Rogers, J. Inflammation in Alzheimer disease-A brief review of the basic science and clinical literature. Cold Spring Harb. Perspect. Med. 2, 1-23 (2012).

27. Chaudhuri, T. K. \& Paul, S. Protein-misfolding diseases and chaperone-based therapeutic approaches. FEBS J. 273, 1331-1349 (2006).

28. Currais, A., Fischer, W., Maher, P. \& Schubert, D. Intraneuronal protein aggregation as a trigger for inflammation and neurodegeneration in the aging brain. FASEB J. 31, 5-10 (2017). 
29. Linde, L. et al. Nonsense-mediated mRNA decay affects nonsense transcript levels and governs response of cystic fibrosis patients to gentamicin. J. Clin. Invest. 117, 683-692 (2007).

30. Sheppard, D. N. \& Welsh, M. J. Structure and function of the CFTR chloride channel. Physiol. Rev. 79, S23-S45 (1999).

31. Moreau-Marquis, S., Stanton, B. A. B. \& O’Toole, G. G. A. Pseudomonas aeruginosa biofilm formation in the cystic fibrosis airway. Pulm. Pharmacol. ... 21, 595-599 (2008).

32. Mahenthiralingam, E. Emerging cystic fibrosis pathogens and the microbiome. Paediatr. Respir. Rev. 15, 13-5 (2014).

33. Ward, C. L., Omura, S. \& Kopito, R. R. Degradation of CFTR by the ubiquitin-proteasome pathway. Cell 83, 121-127 (1995).

34. Keeling, K. ., Xue, X., Gunn, G. \& Bedwell, D. M. Therapeutics Based on Stop Codon Readthrough. Аnпu. Rev. Genomics Hum. Genet. 15, 371-394 (2014).

35. Belcher, C. . \& Vij, N. Protein Processing and Inflammatory Signaling in Cystic Fibrosis: Challenges and Therapeutic Strategies. Curr. Mol. Med. 10, 82-94 (2010).

36. Brodlie, M., Haq, I. J., Roberts, K. \& Elborn, J. S. Targeted therapies to improve CFTR function in cystic fibrosis. Genome Med. 7, 101 (2015).

37. Sadowski, M. \& Sarcevic, B. Mechanisms of mono- and poly-ubiquitination: Ubiquitination specificity depends on compatibility between the E2 catalytic core and amino acid residues proximal to the lysine. Cell Div. 5, 19 (2010).

38. El Hokayem, J. \& Nawaz, Z. E6AP in the brain: one protein, dual function, multiple 
diseases. Mol. Neurobiol. 49, 827-39 (2014).

39. Glickman, M. H. \& Ciechanover, A. The Ubiquitin-Proteasome Proteolytic Pathway: Destruction for the Sake of Construction. Physiol. Rev. 82, 373-428 (2002).

40. Rahimi, N. The Ubiquitin-Proteasome System Meets Angiogenesis. Mol. Cancer Ther. 11, 538-549 (2012).

41. Yang, Z. \& Klionsky, D. J. An Overview of the Molecular Mechanism of Autophagy. Curr. Top. Microbiol. Immunol. 335, 1-32 (2009).

42. Bauckman, K. A., Owusu-Boaitey, N. \& Mysorekar, I. U. Selective autophagy: Xenophagy. Methods 75, 120-127 (2015).

43. Reggiori, F. \& Klionsky, D. J. Autophagic processes in yeast: Mechanism, machinery and regulation. Genetics 194, 341-361 (2013).

44. Jung, C. H., Ro, S. H., Cao, J., Otto, N. M. \& Kim, D. H. MTOR regulation of autophagy. FEBS Lett. 584, 1287-1295 (2010).

45. Chang, Y.-Y. \& Neufeld, T. P. An Atg1/Atg13 Complex with Multiple Roles in TORmediated Autophagy Regulation. Mol. Biol. Cell 20, 2004-2014 (2009).

46. Nakahira, K. \& Choi, A. M. K. Autophagy : a potential therapeutic target in lung diseases. Am. J. Physiol. Lung Cell. Mol. Physiol. 93-107 (2013). doi:10.1152/ajplung.00072.2013

47. Walczak, M. \& Martens, S. Dissecting the role of the Atg12-Atg5-Atg16 complex during autophagosome formation. Autophagy 9, 424-425 (2013).

48. Nair, U., Thumm, M., Klionsky, D. J. \& Krick, R. GFP-Atg8 protease protection as a tool to monitor autophagosome biogenesis. Autophagy 7, 1546-1550 (2011). 
49. Kuma, A., Mizushima, N., Ishihara, N. \& Ohsumi, Y. Formation of the 350-kDa Apg12Apg5/Apg16 multimeric complex, mediated by Apg16 oligomerization, is essential for autophagy in yeast. J. Biol. Chem. 277, 18619-18625 (2002).

50. Li, W., Li, J. \& Bao, J. Microautophagy: lesser-known self-eating. Cell. Mol. Life Sci. 69, $1125-1136(2012)$.

51. Geng, J. \& Klionsky, D. J. The Atg8 and Atg12 ubiquitin-like conjugation systems in macroautophagy. 'Protein Modifications: Beyond the Usual Suspects' Review Series. EMBO Rep. 9, 859-864 (2008).

52. Cuervo, A. M. \& Wong, E. Chaperone-mediated autophagy: roles in disease and aging. Cell Res. 24, 92-104 (2014).

53. Lieberman, A. P. et al. Autophagy in lysosomal storage disorders. Autophagy 8, 719-730 (2012).

54. Jiang, P. \& Mizushima, N. Autophagy and human diseases. Nat. Publ. Gr. 24, 69-79 (2013).

55. Rohatgi, R. A. et al. Beclin 1 regulated growth factor receptor signaling in breast cancer. Oncogene 34, 5352-5362 (2015).

56. Kuo, S.-Y. et al. Small-molecule enhancers of autophagy modulate cellular disease phenotypes suggested by human genetics. Proc. Natl. Acad. Sci. 112, E4281-E4287 (2015).

57. Saitsu, H. et al. De novo mutations in the autophagy gene WDR45 cause static encephalopathy of childhood with neurodegeneration in adulthood. Nat. Genet. 45, 445449 (2013).

58. Henderson, P. \& Stevens, C. The Role of Autophagy in Crohn's Disease. Cells 1, 492-519 
(2012).

59. Huang, J. \& Brumell, J. H. Bacteria-autophagy interplay: a battle for survival. Nat. Rev. Microbiol. 12, 101-14 (2014).

60. Kageyama, S. et al. The LC3 recruitment mechanism is separate from Atg9L1-dependent membrane formation in the autophagic response against Salmonella. Mol. Biol. Cell 22, 2290-2300 (2011).

61. Wilson, M. A., Meaux, S. \& Hoof, A. Van. A Genomic Screen in Yeast Reveals Novel Aspects of Nonstop mRNA Metabolism. Genetics 784, 773-784 (2007).

62. Chatr-Aryamontri, A. et al. Nonsense-mediated and nonstop decay of ribosomal protein S19 mRNA in Diamond-Blackfan anemia. Hum. Mutat. 24, 526-533 (2004).

63. Lualdi, S. et al. Identification of nine new IDS alleles in mucopolysaccharidosis II. Quantitative evaluation by real-time RT-PCR of mRNAs sensitive to nonsense-mediated and nonstop decay mechanisms. Biochim. Biophys. Acta - Mol. Basis Dis. 1762, 478-484 (2006).

64. Torres-Torronteras, J. et al. A Novel Nonstop Mutation in TYMP does not Induce Nonstop mRNA Decay in a MNGIE Patient with Severe Neuropathy. Hum. Mutat. 2061-2068 (2011). doi:10.1002/humu.21447

65. Bengtson, M. H. \& Joazeiro, C. A. P. Role of a ribosome-associated E3 ubiquitin ligase in protein quality control. Nature $467,470-473$ (2010).

66. Inada, T. \& Aiba, H. Translation of aberrant mRNAs lacking a termination codon or with a shortened 3' -UTR. EMBO J. 24, 1584-1595 (2005). 
67. Hin Yan Tong, A. \& Boone, C. High-Throughput Strain Construction and Systematic Synthetic Lethal Screening in Saccharomyces cerevisiae. Methods in Molecular Biology 36, (2007).

68. Kanazawa, S., Driscoll, M. \& Struhl, K. ATR1, a Saccharomyces cerevisiae gene encoding a transmembrane protein required for aminotriazole resistance. Mol. Cell. Biol. 8, 664-673 (1988).

69. Donohue, E. et al. Inhibition of autophagosome formation by the benzoporphyrin derivative verteporfin. J. Biol. Chem. 286, 7290-7300 (2011).

70. Eustice, D. C. \& Wilhelm, J. M. Mechanisms of action of aminoglycoside antibiotics in eucaryotic protein synthesis. Antimicrob. Agents Chemother. 26, 53-60 (1984).

71. Nguyen-Disteche, M. et al. Sensitirity to Ampicillin and Cephalothin of Enzymes Involved in Wall Peptide Crosslinking in Escherichia coli K12, Strain 44. Eur. J. Biochem. 41, 457463 (1974).

72. Pitre, S. et al. PIPE: a protein-protein interaction prediction engine based on the reoccurring short polypeptide sequences between known interacting protein pairs. $B M C$ Bioinformatics 7, 365 (2006).

73. Pitre, S. et al. Short Co-occurring Polypeptide Regions Can Predict Global Protein Interaction Maps. Sci. Rep. 2, 1-10 (2012).

74. Pitre, S. et al. Global investigation of protein-protein interactions in yeast Saccharomyces cerevisiae using re-occurring short polypeptide sequences. Nucleic Acids Res. 36, 42864294 (2008). 
75. Popelka, H. \& Klionsky, D. J. The molecular mechanism of Atg13 function in autophagy induction: What is hidden behind the data? behind the data? Autophagy 13, 449-451 (2017).

76. Bonangelino, C. J., Chavez, E. M. \& Bonifacino, J. S. Genomic Screen for Vacuolar Protein Sorting Genes in Saccharpmyces cerevisiae. Mol. Biol. Cell 13, 2486-2501 (2002).

77. Park, Y. Critical assessment of sequence-based protein-protein interaction prediction methods that do not require homologous protein sequences. BMC Bioinformatics 10, 419 (2009).

78. Choe, J., Kolodrubetz, D. \& Grunstein, M. The two yeast histone H2A genes encode similar protein subtypes. PNAS 79, 1484-1487 (1982).

79. Swinnen, S. et al. Improvement of yeast tolerance to acetic acid through Haal transcription factor engineering: towards the underlying mechanisms. Microb. Cell Fact. 16, 1-15 (2017).

80. Bedford, L., Lowe, J., Dick, L. R., Mayer, R. J. \& Brownell, J. E. Ubiquitin-like protein conjugation and the ubiquitin-proteasome system as drug targets. Nat. Rev. Drug Discov. 10, 29-46 (2011).

81. van Hoof, A., Frischmeyer, P. A., Dietz, H. C. \& Parker, R. Exosome-mediated recognition and degradation of mRNAs lacking a termination codon. Science (80-. ). 295, 2262-4 (2002).

82. Strømhaug, P. E., Reggiori, F., Guan, J., Wang, C. \& Klionsky, D. J. Atg21 Is a Phosphoinositide Binding Protein Required for Efficient Lipidation and Localization of 
Atg8 during Uptake of Aminopeptidase I by Selective Autophagy. Mol. Biol. Cell 15, 35533566 (2004).

83. Bardwell, L. A walk-through of the yeast mating pheromone response pathway. Peptides 26, 339-350 (2005).

84. Bodi, Z., Button, J. D., Grierson, D. \& Fray, R. G. Yeast targets for mRNA methylation. Nucleic Acids Res. 38, 5327-5335 (2010).

85. Aguilar, P. S., Engel, A. \& Walter, P. The Plasma Membrane Proteins Prm1 and Fig1 Ascertain Fidelity of Membrane Fusion during Yeast Mating. Mol. Biol. Cell 18, 547-556 (2007).

86. Sandmann, T. et al. Suppression of Coatomer Mutants by a New Protein Family with COPI and COPII Binding Motifs in Saccharomyces cerevisiae. Mol. Biol. Cell 14, 3097-3113 (2003).

87. Singer-Kruger, B. et al. Role of Three Rab5-like GTPases, Ypt51p, Ypt52p, and Ypt53p, in the Endocytic and Vacuolar Protein Sorting Pathways of Yeast. J. Cell Biol. 125, 283298 (1994).

88. Cao, Y. \& Klionsky, D. J. Physiological functions of Atg6/Beclin 1: a unique autophagyrelated protein. Cell Res. 17, 839-849 (2007).

89. Belgareh-Touze, N., Avaro, S., Rouille, Y., Hoflack, B. \& Haguenauer-Tsapis, R. Yeast Vps55p, a Functional Homolog of Human Obesity Receptor Gene-related Protein , Is Involved in Late Endosome to Vacuole Trafficking. Mol. Biol. Cell 13, 1694-1708 (2002).

90. Wood, C. S. et al. PtdIns4P Recognition by Vps74/GOLPH3 links PtdIns 4-kinase signaling 
to retrograde Golgi trafficking. J. Cell Biol. 187, 967-975 (2009).

91. Ogawa, N. \& Oshima, Y. Functional Domains of a Positive Regulatory Protein, PHO4, for Transcriptional Control of the Phosphatase Regulon in Saccharomyces cerevisiae. Mol. Cell. Biol. 10, 2224-2236 (1990).

92. Lau, W. W., Schneider, K. R. \& Shea, E. K. O. A Genetic Study of Signaling Processes for Repression of PHO5 Transcription in Saccharomyces cerevisiae. Genetics 150, 1349-1359 (1998).

93. Huang, K. et al. Structure of the Pho85-Pho80 CDK-cyclin Complex of the Phosphateresponsive Signal Transduction Pathway. Mol. Cell 28, 614-623 (2008).

94. Bun-ya, M., Nishimura, M., Harashima, S. \& Oshima, Y. The PH084 Gene of Saccharomyces cerevisiae Encodes an Inorganic Phosphate Transporter. Mol. Cell. Biol. 11, 3229-3238 (1991).

95. Lytovchenko, O. et al. The INA complex facilitates assembly of the peripheral stalk of the mitochondrial F 1 F o -ATP synthase. EMBO J. 33, 1624-1638 (2014).

96. Mathieu, L., Marsy, S., Saint-georges, Y., Jacq, C. \& Dujardin, G. A transcriptome screen in yeast identifies a novel assembly factor for the mitochondrial complex III. Mitochondrion 11, 391-396 (2011).

97. Harner, M. E. et al. Aim24 and MICOS modulate respiratory function, tafazzin-related cardiolipin modification and mitochondrial architecture. Elife 1-23 (2014). doi:10.7554/eLife.01684

98. Kawahata, M., Masaki, K., Fujii, T. \& Iefuji, H. Yeast genes involved in response to lactic 
acid and acetic acid : acidic conditions caused by the organic acids in Saccharomyces cerevisiae cultures induce expression of intracellular metal metabolism genes regulated by Aft1p. FEMS 6, 924-936 (2006).

99. Schrader, M. \& Fahimi, H. D. Peroxisomes and oxidative stress. Biochem. Biophys. ACTA 1763, 1755-1766 (2006).

100. Brocard, C., Lametschwandtner, G., Koudelka, R. \& Hartig, A. Pex $14 p$ is a member of the protein linkage map of Pex5p. EMBO J. 16, 5491-5500 (1997).

101. Huhse, B. et al. Pex17p of Saccharomyces cerevisiae Is a Novel Peroxin and Component of the Peroxisomal Protein Translocation Machinery. J. Cell Biol. 140, 49-60 (1998).

102. Cao, S. S. \& Kaufman, R. J. Endoplasmic Reticulum Stress and Oxidative Stress in Cell Fate Decision and Human Disease. Antioxidants Redox Signal. 21, 396-413 (2014).

103. Donohue, E. et al. The autophagy inhibitor verteporfin moderately enhances the antitumor activity of gemcitabine in a pancreatic ductal adenocarcinoma model. J. Cancer 4, 585-96 (2013).

104. Simpson, C. E., Lui, J., Kershaw, C. J., Sims, P. F. G. \& Ashe, M. P. mRNA localization to P-bodies in yeast is bi-phasic with many mRNAs captured in a late Bfrlp-dependent wave. J. Cell Sci. 127, 1254-62 (2014).

105. Chambers, A., Tsang, J. S., Stanway, C., Kingsman, A. J. \& Kingsman, S. M. Transcriptional control of the Saccharomyces cerevisiae PGK gene by RAP1. Mol. Cell. Biol. 9, 5516-5524 (1989). 


\section{Appendix A - List of Tables}

Table A1: The 446 gene candidates produced from the NSD screen.

\begin{tabular}{|c|c|c|c|c|c|c|c|c|c|}
\hline GAL10 & GAL7 & TCM62 & $A P D 1$ & ARA1 & $R P L 4 A$ & FRT2 & DTR1 & CNE1 & CNE1 \\
\hline PEX22 & RPS9B & SLM4 & YRM114 & $R P L 23 A$ & RXT2 & YAR040C & YAR037W & PRM9 & GRS1 \\
\hline PCS60 & YBR220C & ATG12 & IML3 & SDS24 & $\mathrm{MDH} 3$ & STE5 & YCR087C-A & YDLO96C & YCR079W \\
\hline YCL042W & $Y D L 119 C$ & CHA1 & YPT10 & YBR259W & YDL129W & $V C X 1$ & SAT4 & YCLO75W & YDL157C \\
\hline$Y D L 144 C$ & CTP1 & POL4 & LHP1 & $V G X 2$ & $Y D L 162 C$ & YCLO01W-A & MAL33 & BRE1 & INH1 \\
\hline PCL9 & $R P S 29 B$ & AIR2 & YCL012W & GBP2 & GIC2 & ATC1 & YDL187W & $A S P 1$ & RTN1 \\
\hline YPL203C & TRM8 & HTA1 & $R A D 9$ & YDR112W & ALT2 & $\mathrm{HO}$ & YDL218W & SPO71 & VPS74 \\
\hline PAM1 & LYS4 & TRM1 & $B C S 1$ & $E K I 1$ & SWI5 & $R \cup B 1$ & SOK1 & DIT1 & DON1 \\
\hline$C C C 2$ & $S S D 1$ & RTT103 & YDR287W & HSP42 & YER156C & GIP2 & YER051W & $S N X 41$ & PCL6 \\
\hline RAD4 & TSA2 & $S R I 1$ & PPN1 & GTT3 & APT2 & PAU2 & MET6 & $I Z H 1$ & YFLO34W \\
\hline YER108C & $R P L 22 B$ & GNP1 & ALR2 & FIR1 & УРТЗ1 & BIM1 & YER140W & YFL051W & YOR541C \\
\hline ACA1 & HVG1 & FMP49 & SK18 & MIG2 & POX1 & KSS1 & YGL081W & FMP37 & YGLO79W \\
\hline$Y B P 2$ & $S P R 3$ & YGRO54W & KIP3 & $\mathrm{PHO} 4$ & YGL109W & YFR026C & $\angle S B 3$ & PES4 & RPL11B \\
\hline SLXY & YGL230C & SNT2 & BNA6 & SAP155 & YFR039C & SNF4 & YFR039C & YFR038W & YFR035C \\
\hline ZIP2 & $T P C 1$ & YGL007W & YGL138C & MEP1 & YGL260W & YGR117C & PIB2 & YGL157W & PEX14 \\
\hline YGR017W & YGR137W & $\angle S B 1$ & YGR015C & $R P L 24 B$ & ERV14 & DST1 & STB5 & KRE11 & GTR2 \\
\hline LRP1 & FMP22 & NMD2 & XKS1 & $\mathrm{CRH} 1$ & $B \cup B 1$ & UBR1 & YHLOOSC & STE2O & WSC4 \\
\hline SPO11 & MNT3 & YHROO9C & SPG1 & WSS1 & AGE2 & YHR14OW & YIL042C & SPS100 & $D A P 2$ \\
\hline SPO16 & SCW4 & SAP185 & NUC1 & $B C K 1$ & YJL206C-A & YAP5 & HOP1 & MET28 & NIT2 \\
\hline YJR008W & YJL122W & YILO92W & TIF2 & YPS6 & YJL147C & QDR1 & YJL163C & NTA1 & נJנ2 \\
\hline FMP33 & MAD2 & FMP26 & YJR079W & BIT61 & $R R D 1$ & YIL152W & YJR096W & YJL193W & SWE1 \\
\hline VTH1 & DYN1 & LST4 & TPO5 & LHS1 & STB6 & YJR111C & $Y M R 1$ & PTK1 & YJR124C \\
\hline YJR119C & STC1 & $Y K L 206 C$ & HIR3 & TOF2 & MEH1 & MET14 & KTI12 & HAP4 & YKL107W \\
\hline YJR149W & YKR021W & cox17 & $S D H 1$ & $R G T 1$ & GAP1 & YLLO29W & TPO1 & PIR3 & APE2 \\
\hline YLR326W & $H R D 3$ & TOP3 & YLR345W & YLR338W & YLR125W & YLR016C & GAT3 & YLR261C & YLR257W \\
\hline YLR143W & YLR278W & CTF3 & CSR 1 & YLR042C & SEC72 & $S K 12$ & $\operatorname{cox} 8$ & YLR064W & SAM1 \\
\hline$C D A 1$ & SIC1 & FMP25 & RPL37A & YMR148W & YMR147W & TOS1 & IMD4 & $S P C 2$ & $C D C 73$ \\
\hline YMR166C & DAK1 & SMA2 & YMR085W & YMR073W & мотз & CAC2 & $T S L 1$ & YMLO96W & YLR445W \\
\hline RAD10 & $A P P 2$ & SGS1 & YMRO99C & ZDS2 & RPL36A & MSC1 & PHO84 & $Y M L 122 C$ & GAS3 \\
\hline RPS18B & RIM11 & FUS2 & $Q R 18$ & FMS1 & YMR252C & HOR7 & LTN1 & PCL1 & $R P L 42 A$ \\
\hline WSC2 & PRM1 & YMR262W & SRFG & MON2 & RIM21 & MSB3 & YMR279C & $Y M R 278 W$ & ZDS1 \\
\hline GCR1 & $S L Z 1$ & STB1 & YNL195C & YNL193W & YMR295C & GOT1 & PEX17 & PFA3 & KRE1 \\
\hline YNL321W & YNL320W & FKS3 & CIT1 & DOM34 & PHO23 & CSE2 & YORO93C & YOL163W & VPS21 \\
\hline YORO88W & YNRO21W & YNRO2OC & RTS1 & MSO1 & MOR1 & GPD2 & STI1 & YORO21C & YOL083W \\
\hline MNT4 & HOL1 & BRE5 & CYC2 & HMS1 & EFT1 & $I Z H 2$ & IZH4 & PHO8O & YOR164C \\
\hline YORO5OC & YOR044W & INO4 & ALG8 & LCB4 & YNG1 & $Y R M 1$ & RPS28A & YOR166C & YOLO29C \\
\hline$R R / 2$ & SKI7 & REV3 & LEE1 & SVS1 & YPL162C & PTP2 & YPLO71C & TCO89 & $P P Q 1$ \\
\hline KIN4 & TYE7 & YOR228C & YOR338W & $O D C 2$ & SSU1 & ELP3 & PDE2 & HAP5 & PUS7 \\
\hline HES1 & YOR235W & YPL105C & ATG21 & FMP14 & YPL199C & YOR $271 C$ & $V P H 1$ & PAC1 & GPB1 \\
\hline$S C P 1$ & MEI5 & YPL225W & VPS30 & $L S P 1$ & YOR283W & FRE5 & CAF2O & МUM3 & NCE4 \\
\hline YOR296W & VTC3 & YPL017C & YPL014W & YPLOOGC & PRM4 & GYP5 & TIF4632 & BLM3 & $A C M 1$ \\
\hline DIP5 & YPL264C & ISR1 & PAN2 & YGR273C & MSS18 & HAA1 & ICL2 & $A X L 1$ & FKH1 \\
\hline YDR026C & YAL046C & YPR027C & YPR147C & VPS55 & HST2 & YPR045C & YPR044C & $R P L 43 A$ & SRO7 \\
\hline ТРОЗ & NTO1 & $S M P 2$ & $A S I 1$ & MRPL10 & HPA2 & SKI3 & ATG13 & GDB1 & $A M D 2$ \\
\hline UBS1 & IML2 & SOD2 & ARR1 & YPR196W & ASR1 & --- & --- & --- & --- \\
\hline
\end{tabular}


Table A2: The primer sequences for qRT-PCR

\begin{tabular}{ll}
\hline Primer Name & Primer Sequence $\left(\mathbf{5}^{\prime} \rightarrow \mathbf{3}^{\prime} \mathbf{)}\right.$ \\
\hline HIS3 Forward & ATGACAGAGCAGAAAGCCCTAGTAAAGCGTATTACA \\
HIS3 Reverse & TTCTCCCTTGCAAACCAAGTTCGACAAC \\
PGK1 Forward & CAGACCATTCTTGGCCATCT* \\
PGK1 Reverse & CGAAGATGGAGTCACCGATT* \\
\hline *Designed by Chambers et al.,1989 105 &
\end{tabular}

*Designed by Chambers et al., $1989^{105}$. 


\section{Appendix B - List of Figures}

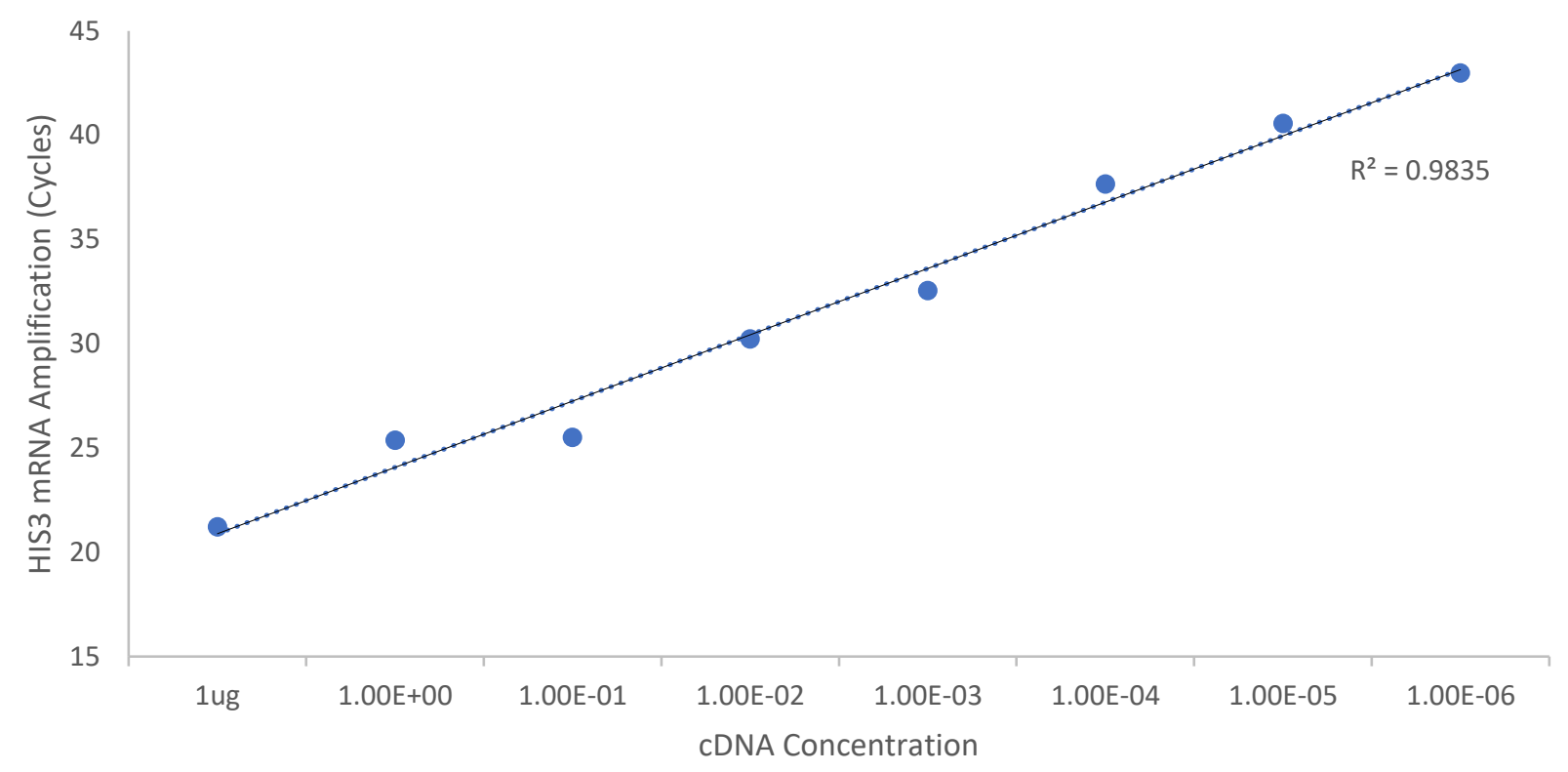

Figure A1: The standard curve for His3 primer efficiency. 


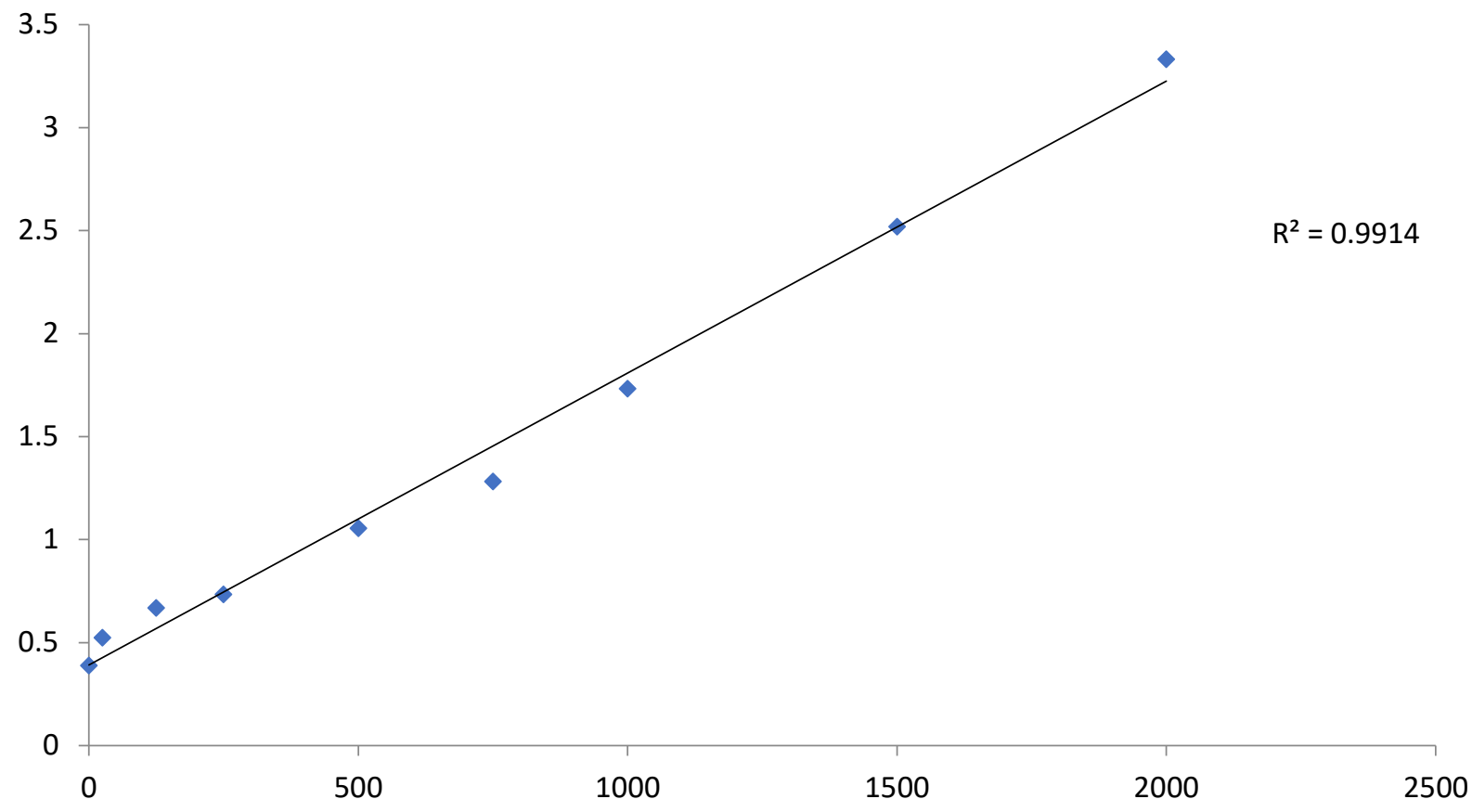

Figure A2: The standard curve for protein concentrations used in this study. The $\mathrm{R}^{2}$ value is 0.9914, which is the slope of the trendline for the protein standards. 


\section{Appendix C - List of Publications}

1: Kazmirchuk, T., Dick, K., Burnside, DJ., Barnes, B., Moteshareie, H., Hajikarimlou, M., Hooshyar, M., Omidi, K., Ahmed, D., Low, A., Lettl, C., Schoenrock, A., Pitre, S., Samanfar, B., Babu, M., Cassol, E., Wong, A., Dehne, F., Green, James R., Golshani, A. Designing Anti-Zika Virus Peptides Derived from Predicted Human-Zika Virus Protein-Protein Interactions. BioRxiv.

2: Omidi, K., Jessulat, M., Hooshyar, M., Burnside, DJ., Schoenrock, A., Kazmirchuk, T., Hajikarimlou, M., Daniel, M., Moteshareie, H., Ramotar, D., Dehne, F., Samanfar, B., Babu, M., Golshani, A. Uncharacterized ORF HUR1 influences the efficiency of non-homologous endjoining repair in Saccharomyces cerevisiae. Gene. 2017. Under Review.

3: Samanfar, B., Shostak, K., Moteshareie, H., Hajikarimlou, M., Shaikho, S., Omidi, K., Hooshyar, M., Burnside, D., Galvan Marquez, I., Kazmirchuk, T., Naing, T., Ludovico, P., YorkLyon, A., Szereszewski, K., Leung, C., Yixin Jin, J., Megarane, R., Smith, M.L., Babu, M., Holcik, M., Golshani, A. The Sensitivity of the yeast, Saccharomyces cerevisiae, to Acetic Acid is Influenced by DOM34 and RPL36A. BMC Molecular Biology. BMMI-D-17-00049. Under Review. 